Portland State University

PDXScholar

$1-1-2011$

\title{
Assessment for Improvement in Higher Education: Faculty Perception of and Participation in Program Assessment
}

Serap Emil

Portland State University

Follow this and additional works at: https://pdxscholar.library.pdx.edu/open_access_etds Let us know how access to this document benefits you.

\section{Recommended Citation}

Emil, Serap, "Assessment for Improvement in Higher Education: Faculty Perception of and Participation in Program Assessment" (2011). Dissertations and Theses. Paper 605.

https://doi.org/10.15760/etd.605

This Dissertation is brought to you for free and open access. It has been accepted for inclusion in Dissertations and Theses by an authorized administrator of PDXScholar. Please contact us if we can make this document more accessible: pdxscholar@pdx.edu. 


\title{
Assessment for Improvement in Higher Education: Faculty Perception of and Participation in Program Assessment
}

\section{by}

\section{Serap Emil}

\begin{abstract}
A dissertation submitted in partial fulfillment of the requirements for the degree of
\end{abstract}

\author{
Doctor of Education \\ in \\ Educational Leadership: Curriculum and Instruction
}

\author{
Dissertation Committee: \\ Christine Cress, Chair \\ Gayle Thieman \\ Liza Finkel \\ Steve Isaacson \\ Yves Labissiere
}

\author{
Portland State University \\ (C)2011
}




\begin{abstract}
Driven by issues of accountability, the assessment movement in higher education has gained significant momentum in recent years. However, successful implementation of assessment processes varies radically across institutions and organizational units. A key issue is faculty engagement. This qualitative case study explored factors that impact faculty participation in a professional school assessment initiative. Findings indicate that factors related to individual faculty characteristics (e.g., career preparation, knowledge, beliefs, and attitudes) and institutional characteristics (e.g., leadership, resources, reward structures, work environment, and technology) influence faculty members engagement in assessment activities. To support faculty adoption of and participation in assessment efforts, leaders need to provide a clear vision, professional expectations, and appropriate resource support to connect assessment efforts to organizational enhancement and effective student learning. Moreover, goal congruence between faculty and educational organization will create an environment, where faculty members can leverage their existing values, transfer their past experiences in regard to assessment. In turn, faculty can utilize engagement in assessment activities as a form of inquiry that leads to teaching and program improvement. Combined, a culture of assessment can be created that is integral rather than additive to teaching, learning, and scholarship.
\end{abstract}




\section{DEDICATION}

\section{To}

My breast cancer survivor mom, Nebahat Emil.

Canim Anneme. 


\section{ACKNOWLEDGEMENTS}

I would like to extend my very special gratitude to my advisor Dr. Christine Cress for guiding me throughout this challenging and complex task and for her constant encouragement and motivation. She inspired me with her professional excellence and guidance through finishing my dissertation.

My special appreciation goes to Dr. Dannelle D. Stevens who broadened my horizon and made this journey possible that has changed and will change my life forever. She was a great mentor who has shared her professional and personal knowledge on academia. She sometimes held my hand and showed me the ways to be a successful academician and taught me how to survive in this academic world.

I also would like to give special thanks to Dr. Steve Isaacson, who I worked with as a graduate assistant and learned from tremendously about program assessment. Also special thanks to Dr. Gayle Thieman, Dr. Yves Labissiere and Dr. Liza Finkel for their continuous support, feedback, guidance, and encouragement. Without their support and encouragement, I would not have finished my dissertation. I also would like to give special acknowledgement to my research participants who were very resourceful, open and flexible in sharing their experiences and insights.

Furthermore, I would like to acknowledge special individuals in my life: Cheryl Ramette as my mentor, my best friend, and supporter from the very beginning of this 
journey; Osman Göktuğ Tanrıkulu, Başak \& Cem Gökçora,Tülin \& İhsan Buğdaypınar as my Portland family; Dr. Carol Mack, Dr. Berrin Erdoğan, Dr. Birol Yeşilada, Dr. Heather Burns, Deborah Miller Allen, Dr. Leslie Munson, Dr. Emek Köse, Dr. Gözde Baç Yıldırım, Dr. Onur Yıldırım, Aylin Kosovaeri Şahin, Çiçek Uma, Dr. Miki Yamashita, Mara Hoogerhuis, Irene Lee, Dr. Soros, Colleen Barretta, Soraya Steele, Giselle Kerth, Jason Holcomb, Chris Cartwright, Zafreen Jaffery, who fully supported, encouraged and inspired me in my doctoral study and the dissertation process; Dr. Randy Hitz, Dr. Christine Chaille, Pat Scott, Julie Thompson, Stefanie Randol, Pati Sluys, the members of the Assessment Task Force and all the other members of the Graduate School of Education. I would also like to thank to my colleagues at Rubicon International for their understanding throughout the process.

Finally, I am most thankful to my beloved parents, Nebahat and Ünal Emil, for their unconditional love, care and support and thanks to my dearest brother Barış Emil, my nephew, Ali Mert Emil and my precious sister Sibel Emil for their existence in my life that gave me the courage and motivation to carry on. 


\section{TABLE OF CONTENTS}

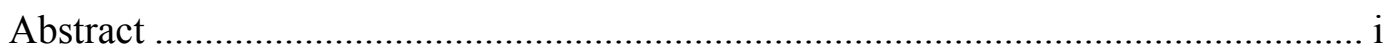

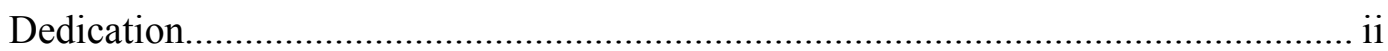

Acknowledgements .......................................................................................... iii

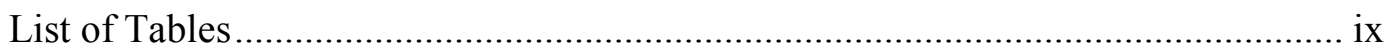

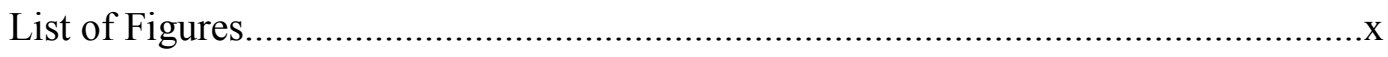

Preface

Chapter I Background and Overview ………………..............................................

History of Higher Education in Reference to Assessment.................................2

Higher Education as an Organization ...........................................................

Faculty Roles and Program Assessment ............................................................6

Changes in Teaching and Learning ................................................................

Teacher-Centered versus Student-Centered Learning

Paradigm Changes in Assessment ..............................................................10

Changing Student Demographics ……………………………………......12

Purpose, Significance and Research Question .................................................13

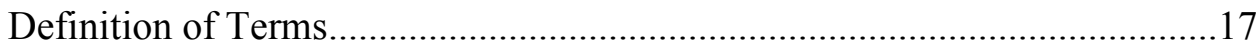

Chapter II Theoretical Framework …………………….......................................18

Theories on Faculty Work …………………………………....................18

Faculty Behavior and Productivity

Self-Knowledge

Social Knowledge 
The Relationship between Self- and Social Knowledge and Faculty Behavior

Framework for Essential Elements

Summary

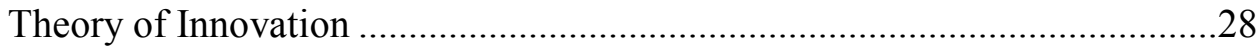

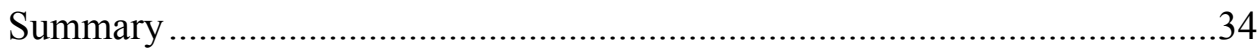

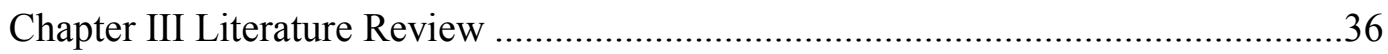

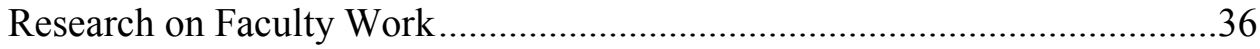

Research on Faculty Involvement in Assessment / Program Improvement ...39

Chapter IV Research Methodology .....................................................................44

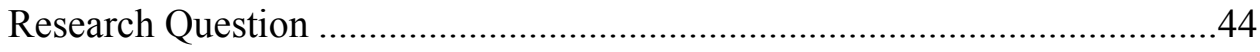

Rationale for Qualitative Methodology ....................................................44

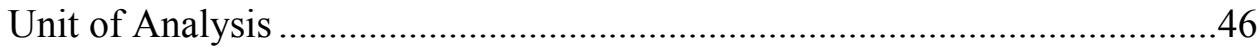

The Role of the Researcher ....................................................................4

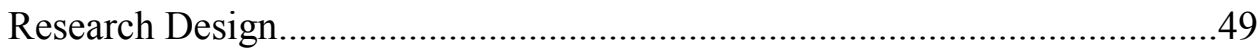

Sampling Strategy

Research Population

Sampling Size

Research Site

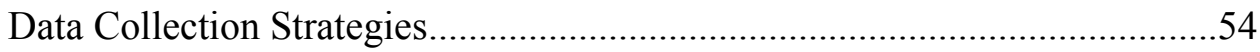

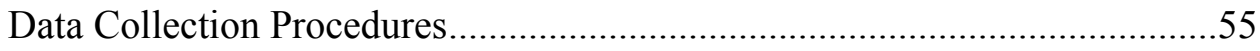

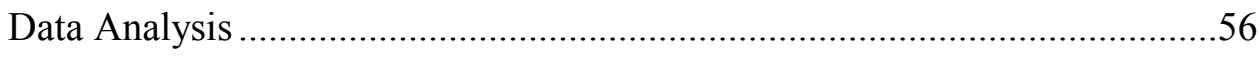

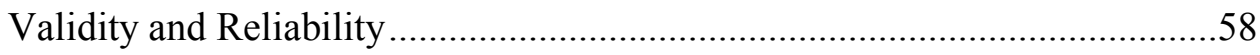

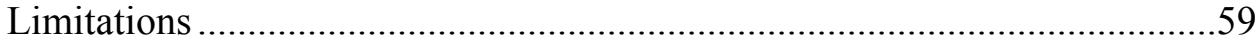




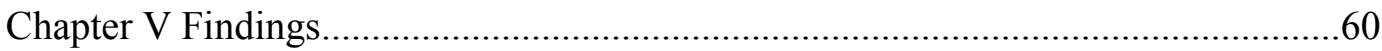

Overall Research Question ........................................................................65

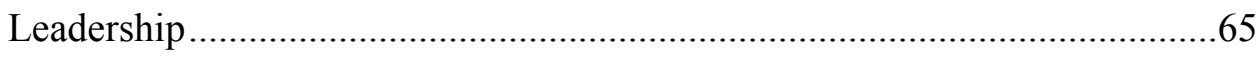

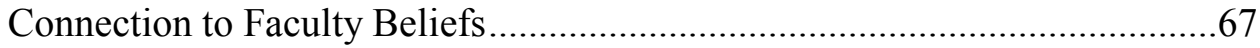

Systematic and Ongoing Assessment .................................................... 71

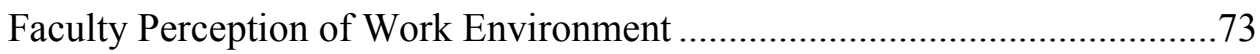

The Use of Resources ........................................................................ 75

Individual Faculty Characteristics.................................... 81

Institutional Characteristics........................................94

Outcomes........................................................ 99

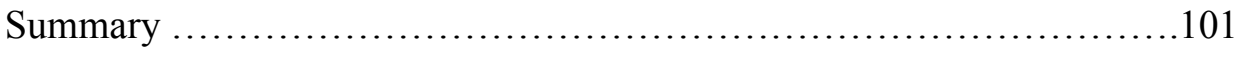

Chapter VI Discussion and Conclusion................................................................ 103

Designing Assessment Activities in Professional Bureaucracies ................103

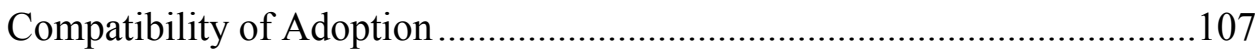

The Relationship between Faculty and Self- and Social Knowledge ...........109

Socio-Demographic Characteristics and Career Preparation.......................111

The Selection of Resources.....................................................................112

Change in Higher Education with Faculty Owned Processes......................112

Suggestions for Higher Education Leaders..............................................117

Suggestions for Faculty Members ......................................................120

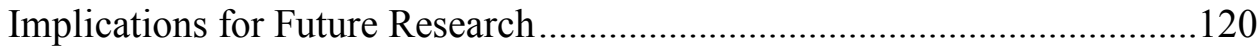

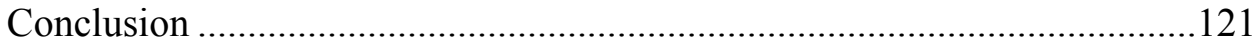

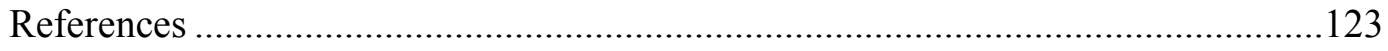


Appendices

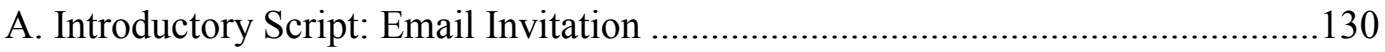

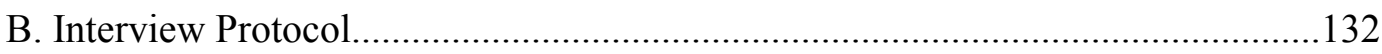

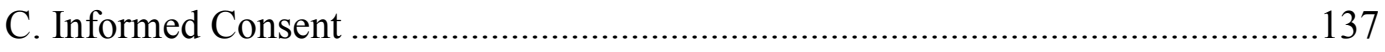

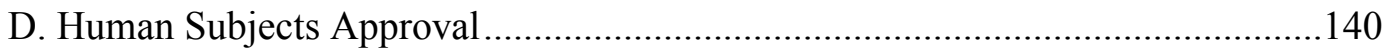




\section{LIST OF TABLES}

Table 1. Comparison of a Teacher Centered- and a Learner-Centered Learning .. 10

Table 2. Comparison of Assessment Paradigms............................................... 11

Table 3. Participants' Demographic Information .............................................50

Table 4. Data Analysis Summary on Faculty Career Characteristics \&

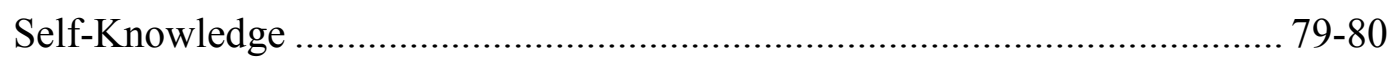

Table 5. The Self Evaluation of Faculty Research Skills ..................................83

Table 6. Data Analysis Summary on Faculty Social-Knowledge...................92-93 


\section{LIST OF FIGURES}

Figure 1. Theoretical Framework on Faculty Behavior \& Productivity................22

Figure 2. Framework for Essential Elements...............................................26

Figure 3. Rogers Adoption/Innovation Curve ..............................................33

Figure 4. The Synthesis of Research Findings ...........................................62

Figure 5. Adaptive Generative Development Model......................................116 


\section{PREFACE}

... On the one hand, look around you. Levels of activity are unprecedented, and very few in higher education are at this point claiming that assessment is a fad that will quickly fade. On the other hand, there are equally apparent indicators that despite two decades of activity, assessment has yet to become a "culture of use" on most campuses, embedded in the lives and work of those who inhabit them. The result is the curious condition that inspired my title for this morning perpetual movement - caught as in the myth of Sisyphus in a task that is never complete, but unable to escape from the task itself. (Ewell, 2002, p. 143)

As Ewell (2002) pointed out, the assessment movement in higher education is

perpetual. On one hand, the institutions face continual problems in making assessment work smoothly; on the other hand, there are places that successfully implement assessment as part of their practices. Comparably, faculty engagement in assessment to improve teaching and learning is perpetual. Leaders, change agents, and/or professional developers on most campuses are challenged by the lack of faculty involvement and seek practical strategies to involve more faculty in order to create sustainable assessment processes for improvement in higher education and student learning.

Today, higher education faces many challenges and changes: paradigm shifts from teacher-centered to student-centered learning, ever-changing student demographics, technological innovations, and accountability demands. Promoting academic improvement in such an environment is crucial and higher education institutions need strategies and tools to be able to do that. How to improve the quality of education systematically has become one of the primary questions of higher education institutions. 
In the last 20 years, different levels of assessment have been introduced to campuses and faculty (Banta \& Associates, 2002; Ewell, 2002). Assessment is one way of identifying problems, gathering data systematically, and working toward curriculum and pedagogical improvement to address these challenges and meet students' needs as well as societal expectations (Angelo, 1999; Astin, 1991; Banta \& Associates, 2002; Ewell, 2002; Gappa, Austin, \& Trice, 2007). Assessment activities can be seen as a form of inquiry leading to teaching and program improvement.

\section{Problem}

As Ewell (2002) stated above, assessment activities may fade due to various reasons and one of those can be the lack of faculty engagement, which in program assessment is problematic in higher education institutions. Driscoll and Noriega (2006) claimed that when the pressure to change assessment practices started, a great deal of resistance was generated by the faculty. Two reasons for such resistance were the fear that assessment would be used for faculty evaluation, and faculty members' discomfort with their own lack of expertise in assessment (Driscoll \& Noriega, 2006). There was also a perception of assessment as a threat to academic freedom (Palomba \& Banta, 1999). Driscoll and Noriega further stated that the lack of experience and/or expertise in assessment was not acknowledged publicly, although there were very few faculty who would claim necessary skills or take the lead in assessment activities.

Besides the confusion about the purpose of assessment and lack of knowledge, there are other factors that impact faculty participation such as beliefs and attitudes toward assessment (Fine \& Nazworth, 1999; Grunwald \& Peterson, 2003). While some 
faculty believe in the benefits of doing assessment for evidence-informed decision making and participate in the process of improving teaching and learning practices, some others will simply ignore the existence of assessment. There is also a well-known trend where faculty are more active in program assessment discussions within their programs through accreditation visit preparations. Right after the visit, the trend shows a decline since there is less pressure for doing assessment at the program and institutional level. In a similar vein, Wright (cited in Banta and Associates, 2002) said that faculty, professional staff and administrators sometimes behave like students who try to get the highest grade for the least investment of effort. Wright defined assessment cynically as: "It is simple. You figure out what they want, find the quickest, least damaging way to respond, send off a report and then forget it" (p. 241). Nevertheless, there are not many studies in the literature that specifically examined the factors impacting faculty participation in program assessment. Exploring some of these factors will help to create more effective system structures and processes for sustainable program assessment activities that are integral to teaching learning and scholarship.

Creating a culture of assessment on campuses is an urgent need because program assessment activities should go beyond improving student learning and/or understanding the program structure (Wright, cited in Banta \& Associates, 2002). Wright asserted that the ultimate purpose of assessment should be to change institutional culture. This ultimate purpose serves the idea of culture of inquiry or learning organizations to which most higher education institutions aspire but have not succeeded in creating (Wright, cited in Banta \& Associates, 2002). Banta (2007) acknowledged that higher education has 
been slow in understanding the need for assessment leading to improvement, but some faculty "in virtually every institution are at least trying it out...At last, colleagues across the country are becoming aware of the potential for positive change offered by the kind of assessment we have championed for all these years" (p. 9).

One of the requirements of creating such a culture is faculty engagement in change initiatives, program assessment activities in this case. To have enduring and sustainable assessment processes, faculty must be involved. According to Hadden and Davies (2002), faculty involvement "lies at the core of developing any successful assessment program" (p. 244). Conversely, the literature indicates that a lack of faculty engagement can be one of the barriers to successful assessment implementation (Banta, 1997; Ewell, 1996; Steele, 1996). Likewise, Bers (2008) stated the absence of faculty involvement in assessing student learning will lead to a weak and tangential action to the business of learning, teaching and institutional improvement.

There are three levels of assessment that need to be discussed to clarify the focus of this study. Banta and Associates (2002) defined assessment on three levels. First, it is the "processes used to determine an individual's mastery of complex abilities generally through observed performance" (p. 9). The second definition of assessment is related to the institutional level where assessment is used to investigate individual learning to create a benchmark of school performance with regard to accountability. Third, assessment is defined as program level evaluation to collect data to improve the curriculum and pedagogy (Banta \& Associates, 2002). In this study, the focus will be on program level 
assessment, which leads to more enduring, and sustainable improvement, and changes in curriculum and pedagogy.

The use of program assessment data is crucial to inform practice and decisionmaking, which promote institutional improvements (Peterson, Einarson, Augustine, \& Vaughan, 1999). Program assessment, or program evaluation as Astin (1991) defined, can be used to enlighten and inform college faculty and administrators on curriculum and instruction. Similarly, Gray (2000) discussed the use of evaluation data and stated that it is to hold programs and institutions accountable for effectiveness in student learning. Astin (1991) further identified the use of assessment results with one primary objective leading to an action that will ultimately enhance the teaching and learning process. Those actions can be changes in curriculum, pedagogy, advising, assessment tools, faculty reward system, or institutional policies and practices.

This study specifically focuses on the use of assessment results for changes in curriculum and pedagogy, which helps to improve student learning and educational programs. Throughout the process, faculty involvement is very crucial. Astin (1991) said that it is possible to collect and even analyze the assessment data without support from administrators or involvement by faculty. Nevertheless, the utilization of assessment results can be problematic within such an environment, because "there is no way that one can hope to make a difference with assessment data without the involvement of faculty..." (Astin, 1991, p. 133).

In this paper, the lack of faculty involvement in program assessment is the problem that needs to be addressed because of the changing nature of higher education 
today. To understand the reasons behind the lack of faculty engagement, it is necessary to explore possible barriers and facilitators that lead to faculty participation in higher education setting. Faculty participation, in this study, means that faculty members are actively taking part in creating assessment systems to collect systematic assessment data. They are engaging in various discussions where assessment tools or data results are used for programmatic decisions. At a higher level of engagement, faculty members are advocates of assessment as part of their roles and responsibilities, and they interact with their colleagues regarding assessment. They also believe in this form of inquiry to reflect teaching and learning within their respective programs and departments.

In summary, it is my purpose to examine and explore the factors that foster or hinder faculty participation. In the next section, I elaborate the contextual factors impacting faculty work and their behavior in terms of participation. 


\section{CHAPTER I \\ BACKGROUND AND OVERVIEW}

Faculty-owned change is critical for higher education institutions as it keeps the change process alive, meaningful and sustainable (Angelo, 1999; Banta \& Associates, 2002; Ewell, 2002). Because faculty members are the operating core of higher education, lack of involvement or commitment to program assessment activities is seen as one of the barriers for having a sustainable process (Banta, 1997; Ewell, 1996; Steele, 1996).

Therefore, it is crucial to be familiar with the past and current factors in higher education that have led to the need for faculty engagement in program assessment.

In this chapter, overall I provide the contextual elements that necessitate faculty engagement in regard to program assessment. First, I discuss the historical factors leading to an increasing emphasis on accreditation and assessment. Second, I will review higher education as an organization because it is the context in which faculty work. Third, I discuss the faculty roles in relation to teaching, learning and assessment. Finally, I talk about the significant changes in teaching and learning environment: shift from teachercentered to student-centered learning, assessment paradigms, and changes in student demographics that could have an impact on faculty perceptions of and engagement in program assessment. 


\section{History of Higher Education in Reference to Assessment}

It is crucial to take an historical perspective in order to understand how assessment has become significant in teaching and learning as well as to learn about a paradigm shift from accountability to improvement in assessment activities, which is discussed in detail later in this paper. Postsecondary education has been expanding since World War II in almost every country in the world (Altbach, 2005). There has been a transition from elite to en-mass and then to universal higher education in industrial societies (Trow, 1974). In today's world, one of the many reasons for this expansion is the increasing complexity of modern societies and economies that requires a highly trained workforce. As a result, postsecondary institutions have been called upon to provide better training and preparation for students (Altbach, 2005).

In the 1960s, U.S. universities undertook modest structural and governance changes (Altbach, 2005). Many of the structural reforms of the 1960s were discarded because of either new experimentation or replacement of administrative arrangements. Through the end of the twentieth century, there was a second wave of reform, a managerial revolution, emphasizing more accountability and efficiency in the management of academic institutions. Vocationalization was an additional trend in higher education spanning the past two decades that has brought about changes in university curricula including relevant training for a variety of complex jobs (Altbach, 2005). This curricular vocationalism was linked to the next wave, which was the close relationship between university and industry. Industrial companies started becoming more interested in knowledge and skills that students were gaining through college education. In the U.S., 
formal contractual arrangements between universities and industries were developed (Altbach, 2005).

Geiger (2005) developed an historical perspective on American higher education that is especially apropos. He identified 10 generations of higher education based on teaching and students' experience via an array of institutions. Before World War I, university education was limited to social and economic elites. Between World War I and World War II, the net number of institutions remained fairly stable while enrollment increased. One reason for this growth was the inclusion and resulting expansion of women in higher education. After World War II, the proportion of young people attending college increased from 15\% to 45\%. Title IX Education Amendments of 1972 increased the government's regulatory control over higher education, changing the relationship between higher education and the federal government (Geiger, 2005).

Today, universities are autonomous environments that are independent of external agencies (Altbach, 2005). However, as universities expand and become more expensive, there is more pressure by those who provide funds for higher education to ensure accountability. This accountability movement creates a tension in universities with regard to autonomy (Altbach, 2005). One of the significant impacts of the movement is the accreditation self-study process in the United States and throughout the world.

The Northwest Commission on Colleges and Universities (NWCCU, n.d.) defines self-study as “an institution's self-analysis of its educational quality and institutional effectiveness in relation to its stated mission and goals" (Retrieved November 22, 2006). Eaton (2003) defined this process as self-regulation in which there are standards 
developed by accrediting bodies for the quality of education. The accrediting body sends a team to review the self-regulation process that a higher education institution undertakes based on the accreditation agency's standards. The team makes an evaluation as to whether accreditation status is achieved, and provides suggestions on areas needing improvement.

Eaton (2003) mentioned that after World War II, there was an increasing demand for higher education, and a resulting increase in federal grant and loan programs. In the course of this expansion, there developed an increased interest in gathering reliable information about the quality of education being provided. This was the first and foremost reason for the emergence of accreditation agencies.

The second and more important reason for self-study is to monitor actual student learning. After the 1992 and 1998 Congressional Reauthorizations of Higher Education Act, in a crucial shift in thinking, federal officials moved from a position that Accrediting organizations are accountable if they do a responsible job of carrying out reviews [ to] Accrediting organizations are accountable if they do a responsible job of carrying out reviews and there is evidence that institutions and programs perform well and that students learn. (Eaton, 2003, p. 6)

With this shift, the focus of the accreditation inquiry became student performance related to learning outcomes. In other words, questions such as

- What are the effects of college on student learning?

○ How well do higher education institutions and programs accomplish their goals?

have become the core of the accreditation process. 
Having briefly summarized the history of postsecondary education and the emergence of accountability, I will now discuss higher education as a structure that shapes faculty roles, responsibilities and their work.

\section{Higher Education as an Organization}

Faculty involvement in assessment activities is one of the essential steps to creating change in higher education; both in terms of addressing the challenges and changes described earlier and improving the quality of education. Therefore, we need to be able to describe how higher education is organized and the significance of its culture in order to understand faculty involvement in assessment in a given context.

Institutions of higher education are considered to be professional bureaucracies. Mintzberg (2000) defined a professional bureaucracy as an organization that has welltrained specialists in their field. These specialists are given significant control over their work and responsibility to work closely with clients or stakeholders as an operating core of the organization. These operating cores could be thought of as administrators, change initiatives, faculty, and academic personnel in institutions of higher education.

As Mintzberg (2000) stated, the professional bureaucracy is a democratic environment where professionals have control over their work as well as an opportunity to be involved in making decisions regarding issues, which affect their work. It would be valid to think of higher education as a professional bureaucracy, because faculty definitely do have control over their work and also they are part of the decision-making process. Faculty have academic freedom to be part of assessment activities although they are expected to participate within the scope of their roles and responsibilities. 


\section{Faculty Roles and Program Assessment}

Faculty is defined as "department teaching a specified subject in a university or college" (p. 110) in the Oxford Popular English Dictionary and Thesaurus. From the definition, it can be inferred that the main responsibility of faculty is seen as teaching. Some will argue that faculty members' primary responsibility is to do research, publish and present in conferences, and others will emphasize the importance of teaching as well as serving the community (Boyer, 1990; Fairweather, 1996). However, these perspectives will vary according to the type of institution and the ways in which this shapes its culture. While research universities are more inclined to place emphasis on research, community colleges or comprehensive universities will focus more on teaching and learning. However, promotion requirements at most universities are based heavily on research and publication (Boyer, 1990; Krahenbuhl, 1998). In that sense, teaching, learning and assessment receive less attention, time and resources. Nonetheless, there are individual faculty members, who are highly motivated toward teaching, learning and assessment activities, and who are among the first to participate. What motivates these early adopters is an important part of my research in addition to what inhibits late adopters from doing assessment, or doing so grudgingly. Do early adopters have more time, resources or just plain motivation to get involved? Do they care more about their students? Are there particular faculty characteristics, which impact their involvement? What makes them participate or not participate in assessment activities? These are some crucial questions to which most higher education leaders, change agents or faculty professional developers are looking for possible answers. 
According to Boyer (1990) faculty members have three main responsibilities in academia: teaching, research and service, however, they are heavily evaluated on their research performance. There are rare occasions when faculty performance is based on all three responsibilities. This can be considered as one of the reasons why faculty are less involved in teaching, learning and assessment. Campus teaching and learning centers are struggling with how to get more faculty engaged in teaching, learning and assessment activities. Fairweather (1996) stated "promises to increase the value of teaching in the academy rely on having faculty pay greater attention to students and to curriculum reform. In sum, faculty comprise the - raw material- for any academic effort requiring expertise whether devoted to training students or carrying out research" (p. 23).

Krahenbuhl (1998) stated that faculty members are underused in teaching and preoccupied with research. He suggested integrating the responsibilities of faculty and institutional needs. This integration has three main elements aligned with Boyer's model; knowledge transmission (teaching), knowledge generation (research) and knowledge application (service). Each of these elements overlaps with each other in certain levels. These overlaps lead to shared discovery (teaching and research), service learning (teaching and service) and community documentation (research and service). In order to put this model into practice, higher education leaders need to be flexible enough while assigning faculty responsibilities and create a climate that encourages the integration of teaching, research and service (Krahenbuhl, 1998). In this model, each area receives equal attention by faculty and administrators rather than a mere research focus. 
Program assessment activities in this picture fall under teaching activities or knowledge transmission, where faculty members are responsible for the full cycle of teaching, student learning and assessment. Therefore, it is expected that faculty will be involved in program assessment activities to revise the curriculum that they teach and make changes if necessary. This involvement requires faculty commitment with respect to resources and intellectual capital. However, the assessment effort is often seen as an additional task that faculty are asked to do and for which insufficient resources are available.

\section{Changes in Teaching and Learning}

There have been significant changes in teaching and learning that requires the transformation of faculty work accordingly. The paradigm shift from teacher-centered learning to student-centered learning, assessment for improvement paradigm or changing student demographics are only three aspects of this transformation. In this section, I discuss each of these aspects and how program assessment fits in this transformation.

\section{Teacher-Centered versus Student-Centered Learning}

Paradigm shifts in teaching and learning have been the most influential change in higher education. Since these paradigm shifts affect assessment practices and faculty roles and responsibilities, it is important to understand their characteristics. The most significant aspect of this shift is the movement from teacher-centered to student-centered pedagogies (Allen, 2004; Barr \& Tagg, 1995; Huba \& Freed, 2000). Allen (2004) discussed the new concepts about student learning and how faculty should promote learning with the definition of these new concepts. Teacher-centered learning is based on 
delivering a subject through lecturing, and students are assumed to listen, read and acquire knowledge. On the other hand, student-centered learning emphasizes the construction of knowledge by the student through integrating new and existent learning. "Learning is a cognitive and social process, in which students construct meaning through reflection and through their interactions with faculty, fellow students, and others" (Allen, 2004, p. 3). Barr and Tagg (1995) described this movement differently as an instructional versus a learning paradigm. The instructional paradigm roots itself in the conceptions of teaching that promote lecture-discussion format with students in a passive, reception position, while the learning paradigm fosters active participation of students in the learning process.

Huba and Freed (2000) did a comparison of teacher-centered and learner-centered paradigms (see the Table 1). Accordingly, a teacher-centered paradigm focuses on knowledge transmission, while a learner-centered paradigm is about constructing one's own knowledge. The teacher-centered paradigm puts students in a passive role, where the acquisition of knowledge outside the context is the purpose. On the other hand, the learner-centered paradigm has students actively engaged in their learning through using and communicating knowledge to address real-life problems. A professor's role in teacher-centered instruction is to be the primary information source and evaluator, while the role in a learner-centered paradigm is expanded to include coaching and facilitating students' learning and evaluating learning together.

In a teacher-centered classroom environment, assessment is mainly used to monitor learning and the emphasis is on the right answer, while in a learner-centered 
approach, assessment is used to improve and contribute to learning, with an emphasis on generating better questions and learning through interaction and reflection. In the teachercentered learning environment, the culture is more competitive and individualistic, while learner-centered learning environments promote cooperation, collaboration, and support. Finally, in a teacher-centered paradigm, only students are viewed as learners, while professors and students learn together in a learner-centered paradigm. This paradigm shift has taken faculty from the center of the classroom to working side by side with students in a shared learning environment. This shift has begun to change the way assessment is being done and being used.

\section{Table 1}

Comparison of a Teacher-Centered and a Learner-Centered Paradigm

\begin{tabular}{|l|l|}
\hline Teacher-Centered Paradigm & Learner-Centered Paradigm \\
\hline Knowledge transmission & Constructing one's own knowledge \\
\hline Students in a passive role & Students actively engaged \\
\hline $\begin{array}{l}\text { Acquisition of knowledge outside the } \\
\text { context }\end{array}$ & $\begin{array}{l}\text { Communicating knowledge to address real- } \\
\text { life problems }\end{array}$ \\
\hline $\begin{array}{l}\text { Professors as primary information source } \\
\text { and evaluator }\end{array}$ & $\begin{array}{l}\text { Professors as facilitator of learning and } \\
\text { evaluate together with students }\end{array}$ \\
\hline $\begin{array}{l}\text { Assessment to monitor learning \& focus } \\
\text { on the right answer }\end{array}$ & $\begin{array}{l}\text { Assessment to improve learning \& emphasis } \\
\text { on learning }\end{array}$ \\
\hline $\begin{array}{l}\text { Competitive \& individualistic } \\
\text { environment }\end{array}$ & Collaborative and supportive environment \\
\hline Students as learners & Both professors \& students learn together \\
\hline
\end{tabular}

Source: Huba and Freed (2000)

\section{Paradigm Changes in Assessment}

Considering this pedagogical change in teaching and learning, the way assessment has been done is changing as well. Formative and authentic assessment methods are promoted in order to improve teaching and learning continuously and productively (Barr 
\& Tagg, 1995). Ewell (2008) discussed the current situation of assessment in higher education at the Assessment Institute in Indianapolis. He talked about two main paradigms: the accountability paradigm and the improvement paradigm (Table 2). The primary purpose of the accountability paradigm is to make a case with policymakers and the public that higher education institutions are effective. On the other hand, the improvement paradigm provides assessment information to enhance teaching and learning in a given institution.

Table 2

Comparison of Assessment Paradigms

\begin{tabular}{|l|c|c|}
\hline & $\begin{array}{c}\text { Assessment for } \\
\text { Continuous Improvement }\end{array}$ & $\begin{array}{c}\text { Assessment for } \\
\text { Accountability }\end{array}$ \\
\hline Purpose & Formative & Summative \\
\hline Stance & Internal & External \\
\hline Predominant Ethos & Engagement & Compliance \\
\hline Instrumentation & Multiple /Triangulation & Standardized \\
\hline Nature of Evidence & Quantitative \& Qualitative & Quantitative \\
\hline Reference Points & $\begin{array}{c}\text { Over time, Comparative, } \\
\text { Established Goals }\end{array}$ & Standard \\
\hline Communication of Results & $\begin{array}{c}\text { Multiple Internal } \\
\text { Channels \& Media }\end{array}$ & Public Communication \\
\hline Uses of Results & Multiple Feedback Loop & Reporting \\
\hline
\end{tabular}

Source: Ewell (2008)

According to this comparison, the process of assessment for continuous improvement is formative, and it is crucial to have stakeholders' engagement since it is for internal purposes. Assessment for accountability is summative and standardized as the process is for external review and is mandatory. The nature of evidence in assessment for continuous improvement comes from both qualitative and quantitative methodologies, 
while in the accountability paradigm the evidence is mainly gathered through quantitative methods. Data for continuous improvement is collected over time to compare the established goals; data for accountability is usually collected at a standard time, such as at the end of the academic year. In the improvement paradigm, results from data analysis are used to feed the next assessment loop to improve the quality of education. Conversely, in the accountability paradigm, data results are used for reporting purposes.

Looking at Table 2, one can conclude that assessment for continuous improvement is a more organic process, while assessment for accountability is more mandatory in its nature. Successful implementation of assessment for improvement paradigm will naturally allow schools to meet the accreditation requirements because assessment would be embedded in organizational climate. With respect to increasing faculty participation, assessment for continuous improvement provides a welcoming environment since its primary purpose is to inform practice.

\section{Changing Student Demographics}

There have been demographic and technological changes in society that directly impact the higher education classroom and its curriculum. Incoming students are more diverse with regard to ethnicity, race, class, socioeconomic status, age, disabilities, and sexual orientation (Fenske, Rund, \& Contento, 2000; Pascarella \& Terenzini, 1998). Fenskeet al. (2000) used terms like graying the campus, more women, more part-timers and racial/ethnic diversity to describe today's students. These characteristics challenge the classroom environment and the way teaching and learning occur. 
Pascarella and Terenzini (1998) stated that the impact of several demographic, institutional, economic, and technological changes may not only change the way we think about what it means to go to college but may also change the methodologies we now use to assess the impact of college. They added that one of the consequences of these demographic, economic, and technological changes has been the reconsideration and redefinition of understanding of faculty and student roles and responsibilities in the teaching and learning process, as well as shifts in the ways students and faculty interact both in and out of the classroom (Pascarella \& Terenzini, 1998). Within this reconsideration and redefinition, faculty need to integrate teaching, learning and assessment in alignment with new paradigms and changes in accountability.

\section{Purpose, Significance and Research Question}

Faculty engagement in any change initiative is one of the initial steps given the fact that faculty members are at the core of teaching and learning activities. By engagement, I mean that faculty members are involved in a decision-making process to plan assessment activities and, most importantly in discussions of assessment data to make necessary adjustments in the curriculum. Astin (1991) said that it is possible to collect and even analyze the assessment data without support from administrators or involvement by faculty. It is the utilization of assessment data by the faculty that is considered to have a direct impact on the educational programs. And the faculty involvement in the utilization of assessment is significant because "there is no way that one can hope to make a difference with assessment data without the involvement of faculty..." (Astin, 1991, p. 133). Therefore, faculty engagement in this study is 
considered as conducting and utilizing the assessment data. In other words, it involves the process of faculty sharing the results of their practices and engaging in discussions on how to improve curriculum and pedagogical practices. Assessment is the "beginning of conversations about learning" (Huba \& Freed, 2000, p. 9). According to Allen (2004), assessment is a series of conversations about expectations on student learning, which might lead to a discussion of alignment of pedagogy and curriculum. Such discussions create the opportunity to make informed decisions on pedagogical and curricular improvement, which will eventually lead to betterment in higher education as learning organizations (Wright, cited in Banta \& Associates, 2002). Gray (1997) pointed out that most faculty are merely aware of the existence of assessment. Peterson and Vaughan (2002) found that individual faculty played key roles in assessment initiatives; however, faculty governance was not seen as very supportive.

While there are multiple factors in the slow adoption of assessment, the purpose of this research is to identify and explore the impact of the following factors on faculty participation in program assessment.

1. Faculty understanding of program assessment

2. Faculty perception of roles and responsibilities

3. Faculty perception of work environment

4. Faculty perception of leadership

5. Faculty perception of resources

6. Faculty socio-demographic characteristics and career preparation More permanent change in the nature of higher education will come through faculty who are truly engaged in these conversations. Driscoll and Noriega (2006) said 
that as the connection between assessment, pedagogy and curriculum gets stronger, there will be less resistance and more engagement. In other words, as faculty become more engaged, they will review and improve their practices, pedagogy and/or curriculum in order to address the recent developments, paradigm shifts and changes. Consequently, they will be part of the culture of assessment movement in higher education culture.

The change in higher education and more specifically in faculty work is inevitable. However, how this type of cultural change in higher education will happen is questionable. Kezar (2001) stated that such a permanent change calls for different types of organizational changes. In her view, any type of change will require some level of examination and analysis before one decides the best way/model to work with. One of the aspects of this analysis is focus of change, which considers finding the part of the organization affected by the change. Kezar later referred to Bergquist's (1992) framework with three main foci: structure, process and attitude. The structure involves the organizational chart, the reward system and institutional policies and procedures. Process is about how people interact with each other within the existing structures. Finally, attitude refers to how people feel about this interaction and the processes. Kezar (2001) said that some models focus on one of these foci, while some others use more than one. Her view on change is extremely useful because it sheds insight on the perpetually difficult problem of assessment in today's higher education institutions. The ultimate goal here is the adoption of program assessment for the benefit of teaching and learning, which may require examining all three dimensions. 
The structural changes in an institution such as creating new positions for assessment, or putting assessment as a priority in the organizational agenda would be beneficial, and some process changes like creating task forces and/initiatives or providing professional development for faculty could encourage the adoption. Moreover, the institution can attempt to change faculty attitude, which may be a continuous revision of teaching and learning practices through assessment in this case. The essence of Kezar's (2001) argument is that any change of those foci will impact others in various degrees. Hence, it is compelling to investigate faculty members' perception of the structure and processes and faculty attitudes to identify possible factors influencing faculty engagement in assessment.

Therefore, a clearer understanding of faculty perception of program assessment can create more meaningful and productive processes as well as better allocation of resources. Studying faculty perception would allow us to grasp the essence of faculty work behavior, faculty involvement in this case. It is also possible that teaching and learning centers may develop more effective and beneficial professional development activities if they have a better understanding of what faculty already know about assessment and whether they believe in the benefits of doing assessment. Yet, there are few studies exploring the possible factors influencing faculty participation in program assessment (Hoviland, Shin, \& Turley, 2009; Peterson \& Einarson, 1998; Peterson \& Vaughan, 2002; Riggs \& Worthley, 1992). Such exploration would help to create a faculty-owned process during the implementation and utilization of program assessment. 
Therefore, the research question is "What are the factors that influence faculty work in program assessment in higher education?" And the subquestions are:

1. How do faculty members' career preparation impact their participation in assessment activities?

2. How does faculty members' self-knowledge impact their participation in assessment activities?

3. How does faculty members' social-knowledge impact their participation in assessment activities?

4. How do faculty evaluate their participation in assessment activities?

\section{Definition of Terms}

Program assessment: program level evaluation to collect data to improve the curriculum and pedagogy.

Faculty: department teaching a specified subject in a university or college.

Innovation: an idea, practice, or object perceived as new by an individual.

Knowledge: the range of one's information or understanding

Belief: a state or habit of mind in which trust or confidence is placed in some person or thing.

Attitude: manner, disposition, feeling, position, etc., with regard to a person or thing.

Involvement: engaging as a participant, the act of taking part in something Self-knowledge: understanding of self, self-referent.

Social-knowledge: perception of environment 


\section{CHAPTER II \\ THEORETICAL FRAMEWORK}

This study is guided by several perspectives from the literature. First, theories on faculty work will help understand faculty behavior. Second, innovation theory provides a framework for program assessment and how assessment as an innovation can be adopted under which conditions. These theories are beneficial to frame faculty involvement in program assessment with respect to faculty and institutional characteristics in addition to characteristics of the profession. The research on faculty involvement in assessment activities in general and a few studies on faculty perception of assessment will also provide the background for this study.

\section{Theories on Faculty Work}

A deeper understanding of faculty behavior and a better exploration of how they make decisions in prioritizing their work load will help to identify possible barriers and facilitators to faculty engagement. In this study, two theories that are interrelated will be used to explore how faculty members' professional background in assessment impact their behavior and to determine in what circumstances faculty become part of an assessment initiative in a given setting. 


\section{Faculty Behavior and Productivity}

The first theoretical framework is Blackburn and Lawrence's (1995) model of faculty behavior and productivity. They rationalized their study of faculty work with faculty being the target of critics in regards to their roles and responsibilities. Faculty members find themselves in a conflicting set of expectations (Blackburn \& Lawrence, 1995, p. 3) and this causes pressure on them. A perspective of administrators or faculty on these set of expectations brings different elements into the picture. Hence, Blackburn and Lawrence (1995) articulated faculty individual characteristics and work environments and analyzed somewhat reciprocal relationships among these elements in an effort to explore faculty behavior and productivity.

Two main factors were found to impact faculty members' behavior and productivity: individual faculty characteristics and the environment. Individual faculty characteristics are considered with regard to socio-demographic characteristics (age, gender, race/ethnicity etc.), career (academic discipline, preparation of career, type of institution, etc.), self-knowledge (understanding of self, self-referent, etc.), and finally social knowledge (how individuals perceive their environment). In terms of properties of environment, they discussed three main features: environmental conditions (the structural and normative features of the university), environmental response (different formal feedback that faculty receive) and social contingencies (events that happen in faculty members' life and affect their work). 


\section{Self-Knowledge}

Self-knowledge category includes self-perceptions of faculty that are directly in relation to behaviors and products in their various academic roles. Unlike sociodemographic characteristics, and career preparation, these perceptions have a potential to change over one's career as a result of environmental conditions. Blackburn and Lawrence (1995) characterized self knowledge in five aspects: (1) interest - how faculty prioritize their work reflects their interests; (2) commitment - faculty interest may transfer into commitment to an activity, which can be a vow or a promise to succeed; (3) efficacy - faculty might develop a sense of ownership and control of choices, options and opportunities; (4) psychological characteristics - faculty personal dispositions may impact conduct of teaching and learning activities; and (5) satisfaction \& moralesatisfaction with work and career may relate to productivity (Blackburn \& Lawrence, 1995).

\section{Social Knowledge}

Blackburn and Lawrence (1995) further analyzed the elements of social knowledge and concluded that faculty build their beliefs based on their experiences with colleagues, administrators, committee decisions, faculty meetings, institutional roles and norms, professional association practices which all constitute their social knowledge. The list of characteristics of social knowledge is defined as: (1) social support - feedback from colleagues, administrators and students may influence faculty decision to act; (2) material support - funding, time and support for conducting research and/or other roles may have an effect on faculty behavior; (3) perceived institutional preference - time 
allocated to teaching, research, scholarship and service may be defined by how faculty perceive institutional preference; (4) institutional values - faculty will be motivated by their perception of what the institution honors, values and rewards (Blackburn \& Lawrence, 1995).

\section{The Relationship between Self and Social Knowledge and Faculty Behavior}

Blackburn and Lawrence (1995) later presented these interactions between self and social knowledge as well as environmental conditions to explain faculty behavior and productivity. Figure 1 depicts this interaction and shows us how such interaction can be transformed into behavior. This research explores and interprets some of these factors and their relationship to faculty behavior - in this case faculty participation. To put it differently, self-knowledge (perception of their knowledge, beliefs and attitudes), socialknowledge (perception of their work environment, leadership, and resources), sociodemographic characteristics (ethnicity, race, gender, age), and career characteristics (years of experience in teaching, academic rank, preparation during graduate experience) have repercussions on the decision making process that go beyond the influence of environmental conditions.

In Figure 1, the thick, heavier arrows represent strong, direct effects of the variables in one category on the variables in the category the arrow points to. The thin arrows signify the weaker effects between several of the principal constructs. In this model, the main impact on faculty behavior and productivity comes from social knowledge, how faculty perceive their environment with regard to their work. According to the framework, there are several factors that have direct effect on social knowledge - 
self-knowledge and environmental responses. Self-knowledge includes self-perceptions of various academic roles - teaching, scholarship, research, and service. In this study, the perception of program assessment as part of faculty teaching, research and service roles, and their beliefs and attitudes related to this role will be investigated.

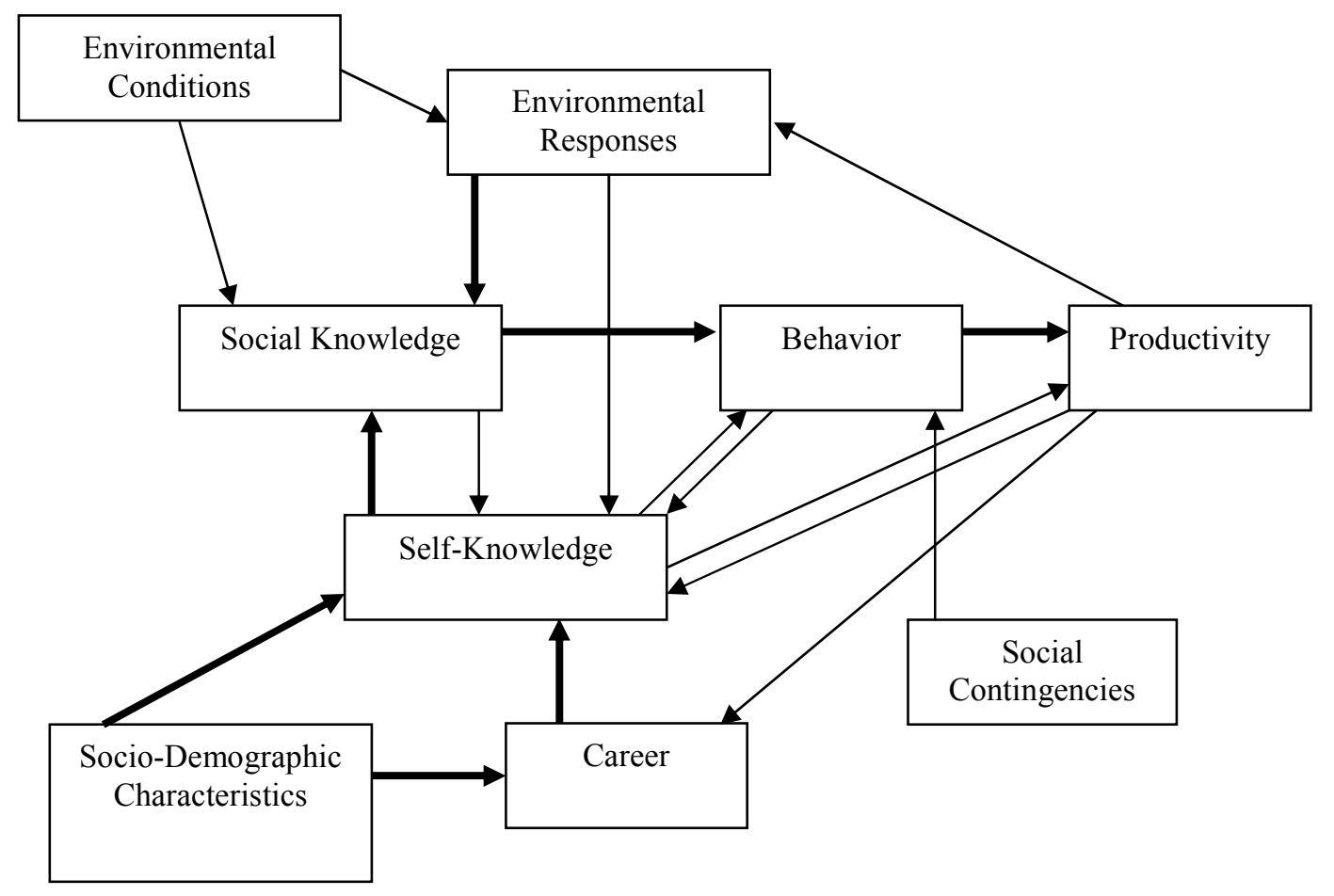

Figure 1. Theoretical framework on faculty behavior and productivity. Source: Blackburn \& Lawrence (1995).

The elements that shape faculty self-knowledge are socio-demographics (i.e., ethnicity/race, gender, age) and career (academic rank, career preparation, or teaching and learning related professional development activity) characteristics. In other words, what faculty value in their teaching and research roles, how much they see benefits of certain practices in their work life or whether they have positive attitude toward work related issues may be formed based on the number of years in teaching, type of institution 
they attend for their graduate education, their race/ethnicity, their attendance to professional development and so on. According to Blackburn and Lawrence, a direct impact on social knowledge is environmental responses - meaning that formal feedback is given to faculty on their participation or non-participation, or they are recognized and awarded for their involvement in program assessment activities.

Some of the key premises of this theoretical model are:

1. Universities/colleges are achievement-laden environments, where there is continuous faculty, student, and administration performance evaluation.

2. Faculty make decisions through assessing themselves and their social contexts, which leads to action.

3. Experience over time can be used to modify faculty members' understanding of their work environments and their self-images.

4. Some self-referential thoughts might change depending on the feedback and experience while others are fairly enduring (Blackburn \& Lawrence, 1995).

These key premises provide a baseline for this study in understanding faculty members' work environment, how they change their self-understanding as well as their selfreferential thoughts. Eventually, these key premises may offer us an explanation of the decision-making process for faculty participation in program assessment.

Behavior in Blackburn and Lawrence's (1995) model is defined as "the specific activities a faculty member engages in as well as the levels of effort expanded [and productivity is] the specific outcomes achieved by individuals" (p. 28). In this study, faculty engagement in assessment activities is considered as behavior. This behavior 
interacts with various factors such as their self-perception (self-knowledge) and their perception of their environment (social-knowledge) in relation to assessment, sociodemographic characteristics as well as their career information. With regard to selfknowledge, faculty members' understanding of assessment - their knowledge, beliefs and attitudes - would give me a more in-depth view regarding faculty involvement in program assessment, while some of the socio-demographic characteristics like academic discipline, age, rank, gender, and ethnicity would bring another perspective to the issue. Finally, career information such as number of years spent in the profession and how faculty were prepared for the profession during their graduate education will offer additional insight.

\section{Framework of Essential Elements}

The second theoretical framework that guided this study is Gappa et al. (2007) Framework of Essential Elements (see Figure 2) for faculty work. They reworked Blackburn and Lawrence's model and included additional elements that are critical in interpreting faculty behavior in the work environment. First of all, they discuss four forces that are affecting faculty work and work places. Those forces are:

1- There are numerous external pressures experienced by higher education institutions. Therefore, these higher education institutions need faculty who can function and survive in this ever-changing environment with limited resources.

2- There are new types of faculty appointments such as adjunct or fixed-term faculty. 
3- Women and people of color have diversified the faculty, with needs that to some extent differ from those of their white male peers.

4- New faculty members are now expecting to balance work and other responsibilities.

Gappa et al. (2007) claimed that if the essential elements are in place, both institutions and faculty will benefit from the work environment. The framework accounts for faculty characteristics and backgrounds that faculty bring to their work as well as institutional characteristics such as mission, culture, history, and the structure in which faculty work in (Gappa et al., 2007). Different from the Blackburn and Lawrence (1995) model, Gappa and colleagues took into consideration some characteristics of the profession that will produce contextual understanding of the work environment. 


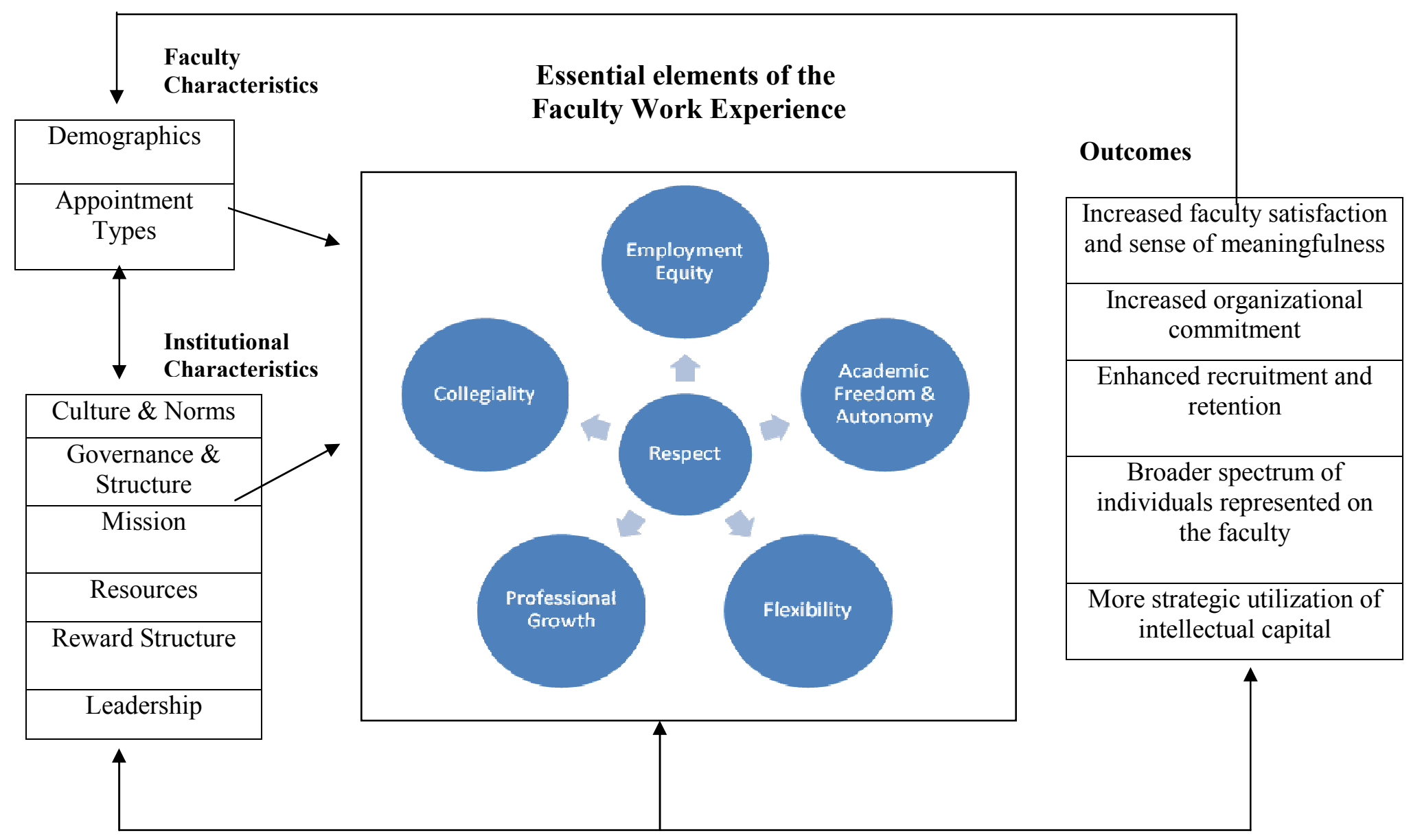

Figure 2. Framework of essential elements of faculty work experience. Source: Gappa et al. (2007). 
These characteristics of faculty professionals are critical in faculty members' work experiences. They are placed in the middle of the framework with another important element, Respect, as a core element. Gappa et al. stated that these elements have always been important to faculty members and are unique attributes to faculty work and faculty workplaces that contribute to the quality of faculty members' experiences (Gappa et al., 2007). These five elements are: employment equity, which is defined as the right of every faculty to be treated fairly; academic freedom and autonomy defined as the right of faculty to express their view on their work; flexibility, allowing faculty members to construct their work to contribute to the institution as well as their own work; professional growth defined as the opportunities to ensure that faculty broaden their knowledge, skills, and abilities to address challenges, changes and needs in their work; and collegiality, defined as opportunities that faculty are provided with to be part of the decision-making process at the departmental, college or institutional level. Respect, in the core of the framework, represents the fundamental entitlement for every faculty member. In an environment of respect, faculty and institutions can benefit from those five essential elements. Finally, the outcomes column represents the possible results of the integration between those elements and characteristics.

According to the framework, if those essential elements are integrated in faculty work and work environment, both faculty and institution will benefit from it. In other words, if faculty members feel that they are included in decision making, if they are given opportunities for professional growth, if they are given flexibility to construct their work, if they are treated respectfully or if they can express their opinions, then they are 
more likely to feel satisfied with their work, committed to the organizational goals, or engaged in various activities and initiatives.

The Gappa et al. (2007) model is comprehensive and inclusive of numerous aspects of faculty work. While Blackburn and Lawrence's (1995) model involves faculty and institutional characteristics to explain faculty behavior and productivity, the Gappa et al. (2007) model adds the five essential elements, reflecting the characteristics of the profession in addition to Blackburn and Lawrence's characteristics. Faculty and institutional characteristics are essential to examine; however, that may not be enough since the essential elements reflect the nature of this profession. To put it differently, faculty may decide whether to participate in assessment activities depending on their perception of themselves or their environment within the scope of their professional characteristics. It would be beneficial to understand whether faculty participate or are committed to program assessment, when they feel that they are respected, included in decision making at various levels, and allowed flexibility to construct their work. Therefore, in this study, these two theories will be utilized to understand the factors affecting faculty participation. Specifically, I will examine factors such as faculty sociodemographic characteristics, their self-perception, and perception of their environments to enhance the understanding of faculty engagement.

\section{Theory of Innovation}

Innovation is defined as "an idea, practice or object perceived as new by an individual" (Rogers, 1968, p. 11). Paradigm changes in teaching, learning and assessment and the recent developments have affected the concept and use of assessment as 
discussed in the previous chapter. In other words, conducting program assessment and more importantly utilizing the results of assessment to make informed decisions on curriculum and pedagogy are fairly new ways of thinking about assessment for faculty. Program assessment, today, is expected to trigger new ideas on and practices of teaching and learning so that improvement in educational programs can happen. Some of the most influential leaders in the field of assessment like Ewell (2002), Banta, and Associates (2002), Angelo (2002), and Gray (1997) or researchers as Hoviland et al. (2009) considered assessment as an educational innovation.

Assessment has been discussed in the literature and conferences for the last 20 years (Ewell, 2008) and most of the faculty members in universities are aware of its existence (Gray, 1997). As Palomba and Banta (1999) mentioned, faculty involvement should go beyond simple awareness to "designing, implementing and carrying out the assessment programs" (p. 10). Assessment should be part of faculty members' daily practice so they can benefit from a better understanding of what is working well and where improvement is needed. However, as mentioned earlier, there are various reasons for the slow adoption of assessment such as institutional culture, leadership, limited resources in addition to faculty perception of assessment. Rogers (1995) discussed several characteristics that affect the rate at which people adopt a given innovation in an organizational setting (pp. 15-16):

Relative advantage is the degree to which an innovation is perceived as better than the idea it supersedes...

Compatibility is the degree to which an innovation is perceived as being consistent with the existing values, past experiences, and needs of potential adopters... 
Complexity is the degree to which an innovation is perceived as difficult to understand and use...

Trialability is the degree to which an innovation may be experimented with on a limited basis...

Observability is the degree to which the results of an innovation are visible to others.

Rogers (1995) later explained the rejection of educational innovations which do not have enough advantage compared to existing ideas; have low compatibility with current values or past experiences; and have low visibility of their results. To better comprehend the adoption of assessment, I would like to speculate on these characteristics with regard to my observation of faculty perception, based on working with faculty in assessment activities over the past 5 years.

Relative Advantage: is the degree to which an innovation is perceived as better than the idea it supersedes. Assessment is not a new idea or practice for faculty. However, we are talking about new paradigms, perspectives and changes in society that influence the way faculty work. With respect to Relative Advantage of innovation, the new way of doing assessment may not be tightly associated with existing practices. New paradigms and shifts change the focus and purpose of teaching, learning and assessment from faculty to students as mentioned previously. Therefore, faculty may need to gain new knowledge and develop new skills in order to change their practices. The level of relative advantage at this point could be limited and faculty may be reluctant to adopt assessment.

Compatibility: is the degree to which an innovation is perceived as being consistent with the existing values, past experiences, and needs of potential adopters. Assessment as an innovation may also not be perceived as consistent with the existing values, since 
faculty are asked to question their pedagogy as well as their practices. In other words, as Huba and Freed (2000) mentioned, a learner-centered environment values student engagement and constructing knowledge while in the traditional learning environment students have a passive role and faculty are the source of information. In that sense, the power dynamics in the classroom change and faculty need to position themselves accordingly.

Complexity: is the degree to which an innovation is perceived as difficult to understand and use. Gray (1997) stated that because of its jargon, assessment is seen as a complex and technical process, which leads to the perception of it as difficult to understand by the faculty. Faculty, who have limited time and resources, may not be willing to spend time on understanding these technical terms. The various levels of assessment can also be perceived as complicated in terms of its purpose. Most of the time, faculty are not clear whether assessment is for improvement or for performance evaluation.

Trialability: is the degree to which an innovation may be experimented with on a limited basis. Faculty might perceive the trial of assessment as difficult for the reasons mentioned in the previous paragraph. Moreover, the way innovation is initiated could affect trialability. In other words, when campuses introduce the idea of assessment through task forces, presidential initiatives, or small grants, faculty develop expectations of such resources being available all the time. Indeed, these resources are used to initiate the idea or try the innovation. Once that support is withdrawn or the resources are lessened, the faculty might discontinue the assessment effort. In response to that, Angelo 
(2002) recommended not awarding faculty for assessment activities because it should be part of faculty regular practice, not extra work that they do.

Observability: is the degree to which the results of an innovation are visible to others. Assessment activities are not visible if there is no actual improvement in learning. Therefore, faculty, who are actually doing assessment, get discouraged rather than motivated. The line of communication and the use of websites or assessment software could solve such problems by making assessment process, including meaningful use of data, more visible.

Rogers (1995) also identified five types of users of innovations, which could assist administrators and change agents in identifying patterns, and in providing appropriate, necessary resources.

1. Innovators (Experimenters): these are the first people in a group who use an innovation.

2. Early Adopters (Visionaries/Risk-takers): these are people by whom innovation may be easily adopted.

3. Early Majority (Pragmatists): these are people who might be comfortable with the idea of innovation but would rather focus on the content of their subject areas, not on the techniques like different ways of doing program assessment.

4. Late Majority (Conservatives/Skeptics): these are people who will adopt an innovation once it has become well established among the majority.

5. Laggards (Antagonists): these are people who are most likely never to adopt the innovation at all. 


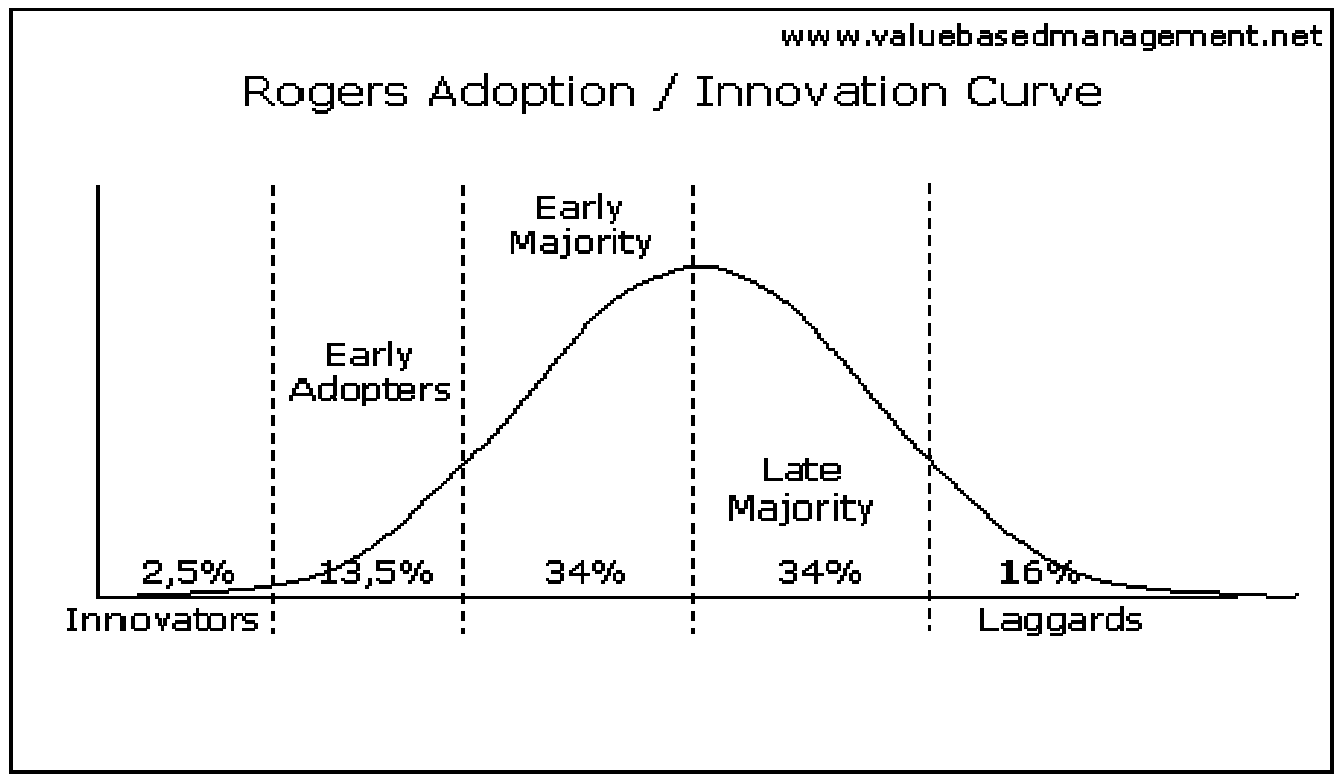

Figure 3. Adoption/innovation curve. Source: Rogers (1995).

Based on the descriptions that Rogers (1995) provided, it is easy to conclude that innovators and early adopters will adjust to the innovation more quickly than those in the early and late majority (68\% in Figure 3), who will then become the target group as leaders attempt to increase the adoption of an innovation. However, this raises the question of the possible reasons why some decide to adopt a particular innovation while others do not. Marcus (cited in Gilbert, 1995) said that an individual decision to adopt an innovation is associated with available resources, the perceived value of innovation, and communication with other adopters. According to this model of individual adoption, resources are controlling variables meaning that although all the other variables exist, without resources, adoption will not occur. The perceived value means that potential adopters contemplate the positive and negative aspects of using an innovation. During this contemplation, the factor of easy use is crucial. Finally, communication with other adopters, which links to social learning theory, becomes important. In other words, 
faculty as adults, learn in a social context in collaboration with others. So, having an opportunity to be in communication with others impacts decision-making.

\section{Summary}

This research focuses on individual faculty characteristics and faculty beliefs and attitudes towards assessment. Moreover, how faculty perceive their work environment regarding assessment will be explored. One reason is that the literature mostly focuses on assessment from an administrative point of view, i.e., faculty members should conduct assessment for improvement in student learning because it is important for accountability and program improvement. My goal in this study is to bring more clarity on how faculty members perceive their role in assessment and how they make decisions to take part in assessment activities.

In the literature, there is not much emphasis on internal factors such as sociodemographic, career characteristics or faculty beliefs and attitudes that faculty bring to their work environment. These characteristics may have direct influence on discussions, decisions and actions that faculty members become part of in any given change initiative. As Driscoll \& Wood (2007) stated, engaging in such dialogue and collaborative processes require faculty to see the value of the initiative, to associate their roles and responsibilities with it and also to be motivated intrinsically. In order to create a meaningful work environment for faculty, higher education leaders and change agents need to learn more about how faculty members value assessment, how they associate their roles with assessment and how much they are motivated intrinsically. Characteristics such as faculty professional background, career preparation; and 
additional factors, such as their beliefs about assessment, perception of their roles and responsibilities or evaluation of their work environment would be valuable to identify. Therefore, in this study, I explored these characteristics and factors in order to produce a better understanding of faculty behavior regarding assessment. 


\section{CHAPTER III LITERATURE REVIEW}

There have been numerous studies that explore and discuss the effect of organizational leadership, institutional culture, administrative support, resources, and accreditation self-study on faculty involvement in institutional change and indirectly assessment (Ewell, 2008; Banta, 1997; Gray, 1997; Lopéz, 2002; Magruder, McManis, \& Young, 1997; Ramaley, 1995; Shipman, Aloi, \& Jones, 2003; Terenzini, 1989; Welsh, \& Metcalf, 2003). However, there are few studies on faculty participation in program assessment. In this chapter, I review the literature on faculty work in general and then focus on the research studies that examined faculty involvement in assessment.

\section{Research on Faculty Work}

In their empirical work, Blackburn and Lawrence (1995) tested their theoretical framework on faculty work and reported the following findings:

1- Socio-demographic Characteristics: Gender was found to be the only predictor variable in research outcomes. Women faculty talked more with their colleagues about their research. Gender also had a direct effect on career and self-knowledge.

2- Career: Career age was found as a predictor meaning that senior faculty publish more and give greater effort to teaching. 
3- Self-Knowledge: Self-efficacy - as a researcher, teacher, and committee member - mattered more than any other variables in this category.

4- Social-Knowledge: Social knowledge was the greatest predictor in faculty work. Support and effort faculty believed their institution desired were two variables found significant in predicting faculty behavior. Grants, having credible colleagues and department chairs and resources were some other variables that predicted faculty performance at work.

Another important work on faculty professional development and career success by Cafferella and Zinn (1999) produced a list of barriers and supports. Cafferella and Zinn (1999) categorized these barriers and supports into four domains: people \& interpersonal relationships, institutional structures, personal considerations / commitments and finally intellectual \& psychosocial characteristics. Under the people \& interpersonal relationships domain, the researchers pointed out personal support systems, positive working relationships with administrators and encouragement by family and friends as supports, while tense relationships with colleagues, opposition to their work by department chairs/other leaders and disapproval from family and friends were barriers in their careers. Within the institutional structures domain, ongoing professional development opportunities, and the availability of resources were viewed as facilitators, while lack of time, access to information and resources were listed as barriers to faculty career success. The Personal considerations / commitments domain included the list of events in faculty members' private life. Finally, the intellectual \& psycho-social characteristics domain included the strong beliefs and values to excellence in one's 
work, perceptions, self-confidence in faculty roles and barriers resulting in feeling discouragement, frustration, discomfort or burnout in faculty roles and reluctance to change. Cafferella and Zinn (1999) articulated that these domains are interrelated and there are remarkable similarities between facilitators and barriers

Another study by Stark, Lowther, Sharp, and Arnold (1997) was built on the assumption that "curriculum planning is the heart of academic work" (p. 100); thereof, it is critical to understand the interpersonal dynamics or institutional contexts affecting faculty involvement. In their study, they examined the epistemological assumptions of faculty that they bring to their academic plans. A total of 59 faculty members from a small private college and a large public university were interviewed. They found that specific discipline, student characteristics, work load, faculty interests, program goals, budget, college goals and faculty beliefs in student learning are some of the factors which strongly influence faculty involvement in curriculum planning activities. Teaching and learning theories, external examinations, faculty pedagogical training, accreditors, traditions, campus politics have modest influence, while faculty members' age, gender, board of trustees, union contracts or advice by campus experts were not found as important factors. The study also revealed that leadership was an important contextual factor in both campuses.

In the study of Feldman and Paulsen (1999), the characteristics of supportive teaching culture were compiled as follows: (a) high level of administrative commitment / support; (b) faculty involvement, shared values, and a sense of ownership; (c) a broader definition of scholarship; (d) a teaching demonstration or pedagogical colloquium as part 
of hiring process; (e) frequent interaction, collaboration, and community among faculty; (f) faculty development program or campus teaching center; (g) supportive and effective department chairs; and (h) connecting rigorous evaluation of teaching to tenure and promotion.

Serow, Brawner, and Demery (1999) studied the case study of BUILD coalition (a pseudonym for one of the eight Engineering Education Coalitions sponsored by the National Science Foundation) which aimed to improve the teaching in undergraduate engineering by awarding grants to faculty in the engineering or other related fields. They examined faculty motivations to become involved in BUILD project and faculty interpretation of their experience within their professional lives. Serow, Brawner, and Demery (1999) found that resource allocation was one of the most common extrinsic motivations mostly for non-tenure-track engineering faculty, where more senior engineering faculty reported intrinsic interest in the coalition's objectives. They also found combined motivations to take part in BUILD coalition. One interesting finding was that faculty regarded this project as "something quite apart from their customary academic role behaviors" (Serow, Brawner, \& Demery, 1999, p. 8).

\section{Research on Faculty Involvement in Assessment / Program Improvement}

Palomba \& Banta (1999) said that "of all the important factors in creating assessment program, none matters more than widespread involvement of those who are affected by it" (p.53). They claimed that faculty should have a strong role in assessment process. They identified three Rs that impact faculty involvement: responsibility, resources and rewards. Faculty members need to have clearly defined roles regarding 
assessment; have resources to learn about and understand assessment and receive rewards for their efforts.

Farmer (1999) surveyed faculty in order to examine their perspective on change. He found six major factors contributing to faculty motivation: (a) a campus culture fostering the idea of effective teaching and student centered educational practices; (b) high expectations for faculty for continuous improvement; (c) a sense of faculty being in control of the implementation process; (d) academic administrators' support for faculty to experiment; (e) faculty confidence in change agents; and (f) intrinsic rewards experienced by faculty as a result of positive feedback from external sources.

Peterson and Vaughan (2002) found a disparity in levels of responsibility for and/or participation in assessment between faculty and administrators. While only $24 \%$ of faculty played key roles in assessment initiatives or planning groups, $72 \%$ of academic administrators, $59 \%$ of chief executive officers and $53 \%$ of student affairs administrators were involved.

Peterson and Einarson (1998) conducted an extensive literature review on student assessment in postsecondary institutions, and found that the involvement of faculty in assessment-related decision-making has been one way of promoting support for student assessment. Riggs and Worthley's (1992) study revealed that faculty involvement in the planning stage was not an important predictor of the success of assessment projects, and that the strongest predictor was faculty participation in the implementation of projects. Peterson and Einarson (1998) also found that institutional support for faculty professional 
development regarding assessment-related topics enhanced faculty involvement in assessment activities.

Gonzalez and Padilla (1999) investigated how faculty members become engaged in and sustain their commitment to organizational reform. As a result of interviews with 17 faculty members, they identified two components of faculty engagement: goal congruence and perceived viability of achieving change. If faculty and institutional goals are congruent, faculty are willing to engage in the process of creating change.

Fine and Nazworth (1999) studied how faculty perceive the benefits of participating in learning communities and found that perceptions vary based on rank, discipline and years of experience. They stated that faculty members serve as conduits between the goals set by academic administrators and student experiences.

This is a dual role for faculty, who then serve as teachers within their area of expertise as well as implementers of administrative initiatives. Understanding faculty perceptions of this role sheds light on a wide array of opinions and attitudes held by what is arguably the population most critical for the success of learning communities' initiatives. (p. 1)

A few studies have been conducted specifically on the lack of faculty participation and/or faculty perception of assessment. Hoviland et al. (2009) studied the impact of faculty professional development on the understanding, confidence and attitudes of faculty with regard to program assessment activities. They found that faculty had improved skills, knowledge, understanding, confidence and attitudes regarding assessment after the workshops. They also highlighted the importance of professional development activities not only for building knowledge and skills in assessment but also 
for creating an environment with sufficient administrative support to facilitate assessment (Hoviland et al., 2009).

Grunwald and Peterson (2003) studied the factors that promote faculty involvement in and satisfaction with institutional and classroom-based student assessment. Institutional involvement in student assessment was found to be related to three predictors: external influences, professional development, and benefits from doing student assessment. The results can be summarized as: faculty are involved with institutional student learning assessment if they perceive the external influences as important, they see value in their institution providing professional development opportunities, and they perceive student learning assessment as having a broad array of benefits. External influences were defined as professional accreditation requirements, self-study, professional associations promoting assessment, or review of institution's assessment efforts. With regard to professional development activities, they talked about supporting faculty attendance at professional conferences, assisting faculty, or external/internal consultant services for faculty on assessment. Finally, the benefits to student learning assessment included improved or enhanced learning, improved quality of education, faculty use of assessment to improve teaching and to meet diverse learning styles. The benefits to student learning assessment specifically were derived from the construct of faculty attitude toward assessment (Grunwald \& Peterson, 2003). This study points out the importance of faculty attitude and how it relates to faculty involvement in assessment. 
Friedlander and Serban (2004) claimed that lack of knowledge might be considered as one of the reasons why faculty are not participating in assessment activities. They may not have enough knowledge of assessment processes, tools and methods at the individual and most importantly at the unit level.

In summary, research studies show that there are institutional characteristics, such as leadership, academic support, and shared governance and faculty characteristics, such as their perception of assessment, professional development that they attend and their attitudes that have some level of impact on their involvement in general and commitment to assessment activities. There are not many studies focused specifically on program assessment leading to improvement in academic programs. Therefore, this study can be a valuable contribution to faculty involvement in program assessment by analyzing the issue from faculty members' perspective. In addition, it may help to develop some meaningful strategies to create faculty-owned processes by identifying the barriers and facilitators to faculty involvement. 


\section{CHAPTER IV \\ RESEARCH METHODOLOGY}

\section{Research Question}

The overall research question for this study is "What are the factors that influence faculty participation in program assessment in higher education?" And the subquestions are:

1. How do faculty members' socio-demographics and career preparation impact their participation in assessment activities?

2. How does faculty members' self-knowledge impact their participation in assessment activities?

3. How does faculty members' social-knowledge impact their participation in assessment activities?

4. How does faculty evaluate their participation in assessment activities?

\section{Rationale for Qualitative Methodology}

This study used a qualitative case study methodology to describe the factors impacting faculty participation and to examine the relationship between those variables and their participation in assessment activities. Berg (2004) stated that the individual case study can be used in various ways. Sometimes, it will be sufficient to conduct one lengthy interview to understand research questions, while other times, it will be necessary to interview several people to be able to explore the aspects of the phenomena. In this 
study, seven one-time interviews were conducted to identify the factors that inhibit or foster faculty participation in assessment activities.

The case study is well explained by Cronbach (1975) as "interpretation in context" (p. 123), which implies that the case study is a way of uncovering the interactions of various dynamics of the phenomenon. In that sense, this study will attempt to uncover the factors that impact faculty participation in a given higher education setting with the contextual factors that faculty members work in. Stake (1995) claimed that the knowledge gathered through case study is different from other research knowledge in four ways:

1. More concrete for it echoes our own experience.

2. More contextual as our experiences are originated within a context and that is what the case study knowledge provides.

3. More developed by the readers' interpretation as the readers bring their own experience and understanding into the case study and that may lead to generalizations.

4. Based more on reference populations determined by the reader, since the case study is interpreted by the reader with population in mind. Lack of faculty involvement in program assessment is ubiquitous in higher education institutions. Since the assessment movement started 20 years ago, higher education leaders are seeking ways to engage faculty in the process. Various contexts have their individual challenges; however, lack of faculty participation is one of the common problems that higher education leaders need to cope with (Banta, 1997; Driscoll 
\& Noriega, 2006; Ewell, 1996; Fine \& Nazworth, 1999; Steele, 1996). The case study allowed collecting concrete and in-depth knowledge of faculty participation in a setting that has had successful assessment implementation. This in-depth knowledge could also be leveraged by many other campuses that may have similar participation issues. In other words, the factors that impact faculty behavior can be also interpreted by faculty members in other campuses through bringing their own experiences and understanding as Stake (1995) mentioned.

\section{Unit of Analysis}

Yin (1994) discussed the unit of analysis as one of the components of case study, which explains the case as what it is. While identifying the case and the unit of analysis, the previous literature provided guidelines. In this manner, this study explored aspects of faculty participation in assessment activities in higher education. The literature states that faculty involvement is one of the most powerful influences on successful assessment implementation. The lack of faculty interest or involvement, on the other hand, is problematic in higher education due to various reasons. Both Blackburn and Lawrence's (1995) and Gappa et. al.'s (2007) extended studies of faculty work and behavior provides the framework for this study. Both studies concluded that two important factors impact faculty behavior and productivity: individual faculty characteristics and the environment or institutional characteristics. Thus, this study explored the impact of these factors on faculty participation behavior specifically in terms of program assessment. The case study produced factors affecting faculty participation, which may not be generalizable to the whole higher education faculty but will provide certain guidelines to work with 
faculty or shape the environment accordingly. Moreover, understanding faculty perspective in this matter will allow higher education to develop some strategies working with faculty. Furthermore, Merriam (2009) defined the case study as an "in-depth description and analysis of a bounded system" (p. 40). In this study, the bounded system is defined as the School of Education. Specifically, the Curriculum \& Instruction (C \& I) department was selected to investigate the faculty members because of its early implementation of program assessment during the accreditation preparation. Some of the assessment tools and practices were piloted first in Curriculum and Instruction department by the Assessment Task Force which is the governance body in the School of Education for leading assessment activities. Also, Eduventure, the Research and Consulting company hired to evaluate the program effectiveness, generated its first yearly report on the teacher licensure program in the Curriculum and Instruction department.

\section{The Role of the Researcher}

We understand, accordingly, that to write social science is not just to passively report findings but to enter into a whole range of power relations. Thus, instead of the disinterested outside observer we sometimes imagine ourselves to be, we are in fact changing what we observe, by the very fact of reporting it, if not in the actual observing itself. (Luker, 2003, p. 8)

Luker (2003) claimed that the position of a researcher in a qualitative study should be actively engaged in a given setting to understand the power dynamics. In this research, my position as a researcher is defined by my prior work experience in the research site.

On the one side, this experience provides me insider perspective on how the assessment initiative was interpreted by the faculty. On the other side, it resulted in having biases, assumptions and attitudes toward the studied subject. 
The qualitative methodology requires researchers to be aware of their roles in the study. Since I, as a researcher, was working at the research site, I was aware of my biases, assumptions, values, attitudes and feelings as listed below during data collection and analysis.

- Most of the faculty do not participate in assessment activities because they may not see the benefits of using assessment.

- $\quad$ Faculty members spend more time on research compared to teaching and learning because of promotion and tenure criteria.

- $\quad$ Faculty may not have the necessary resources or knowledge about assessment.

- $\quad$ Faculty participation will increase before accreditation visits.

- Assessment can be useful and efficient if faculty participate actively.

During my five years of experience in the research site, I worked as Assessment Graduate Assistant and developed some assumptions, values and biases in regard to faculty involvement in assessment. Initially, I had some experience with faculty resisting participation in the assessment activities. At the time, I assumed that these faculty members may not have had enough time and resources to conduct assessment. After being involved in the campus-wide assessment initiative where more resources were allocated, I realized that there could be other reasons why faculty did not participate. Therefore, my assumptions changed over time; lack of faculty participation may not only be related to time and resources, but also to faculty beliefs. Because faculty do not have enough knowledge and experience, they would not see the benefits of using assessment. 
Moreover, they were not seeing it as beneficial to their academic career because it was not part of the promotion and tenure policies which gave more weight to research than teaching and learning.

\section{Research Design}

\section{Sampling Strategy}

In this study, theory or concept sampling as a type of purposeful sampling was used. Theory or concept sampling, in a purposeful sampling, allows researchers to sample individuals or sites because they can help generate or discover a theory or specific concepts within the theory. This study aims to identify factors impacting faculty engagement; therefore, faculty from the Curriculum and Instruction department were selected to help generate specific concepts. Because the Curriculum and Instruction department had a successful implementation of program assessment during the accreditation preparation, exploring faculty perspectives in this environment would provide more in-depth and specific information on faculty engagement. Through purposeful sampling, the faculty members who were exposed to program assessment activities during the last four years of NCATE preparation were selected to be invited for interviews. Faculty members who were hired after 2009 and had no experience in this particular context were not included in the sampling.

\section{Research Population}

In this study, a unit of analysis is the School of Education at a comprehensive university. Specifically, the study will examine faculty views in the Curriculum \& Instruction department. 


\section{Sampling Size}

The research participants were seven faculty members out of 15 in the Curriculum and Instruction Department who volunteered to become part of the study. The overall population of the department is 21 . Because this case study aims to explore the implementation of program assessment in a given setting and specifically the faculty involvement in this implementation, faculty members who were hired after the NCATE Accreditation visit and who did not have experience with program assessment in the given school were excluded. Seven faculty who volunteered to be part of the study were chosen regardless of their academic ranks or administrative positions. Table 3 displays the demographic information on faculty who were interviewed for this study.

Table 3

Participants' Demographic Information

\begin{tabular}{llll}
\hline Gender & 5 Female & 2 Male & \\
\hline Academic Rank & 2 Full Professor & 3 Associate Professor & 2 Senior Instructor \\
\hline Education & 5 Ph.D. & 1 Ed.D. & 1 Master's \\
\hline Administrative Position & 1 No Administrative & 5 Program Coordinator & 1 Other \\
& Position & & Pdministrative \\
& & & \\
\hline $\begin{array}{l}\text { Average number of Years } \\
\text { in Teaching }\end{array}$ & 35.7 years & \\
\hline $\begin{array}{l}\text { Average number of years } \\
\text { in Teaching at the Current }\end{array}$ & 17.4 years & & \\
\begin{tabular}{l} 
University \\
\hline
\end{tabular} & & & \\
\hline
\end{tabular}




\section{Research Site}

The Graduate School of Education is the professional education unit. It is also the most comprehensive education school in the Pacific Northwest with more than 52 degree, licensure, and continuing professional development programs. The school awarded 569 degrees in the 2007-2008 academic year and recommended more than 750 individuals for licensure. It guides the development of teachers who are strong in content knowledge, expert in instructional practice, and committed to educational excellence, social justice, and equity (Graduate School of Education, retrieved February 10, 2010).

The School of Education, which is the unit of analysis for this study, had its previous NCATE visit in 2001. The school received major recommendations regarding its unit-wide assessment system. The accreditation team found the assessment system inconsistent and suggested building a more coherent unit-wide assessment system. In 2006, the leadership in the school experienced major changes including a new Dean, a new Associate Dean for Academic Affairs with greater emphasis on program assessment in the school. In addition, there was a change in the leadership of the Curriculum and Instruction department. Effective and inclusive planning for the preparation of NCATE 2009 visit began with the new leadership. The Dean formed an Assessment Task Force including the associate dean, department chairs, faculty and a graduate assistant and sent this group to the NCATE Conference in Virginia, purchased TK20 assessment software and signed a contract with Eduventure- Research and Consulting company for Higher Education. 
First of all, the Assessment Task Force was responsible for overseeing the assessment activities in the school in addition to implementing the unit-wide assessment system. The Task Force met periodically to revise the conceptual framework of the school, to design the unit wide assessment system and to create assessment tools for various transition points in the programs. In addition, this group led the data collection and analysis in coordination with departments within the school.

Secondly, the purchase of an assessment management system (TK20) was made to collect systematic assessment data. The faculty and students were responsible for inputting data into the system. Data from several transition points such as admission, mid-point, exit and follow-up were collected, and analyzed for decision making. Faculty members were presented data in faculty meetings, and were also included in the assessment conversations in departmental meetings. The school prepared a digital portfolio to share its assessment system, assessment data and other information with faculty, administration, and students within the scope of accreditation preparation.

There were numerous departments and programs implementing the assessment and data management system. However, the Assessment Task Force members first worked closely with the Curriculum and Instruction Department in developing the assessment tools for the Graduate Teacher Education Program which piloted some of the key assessment tools. Another initiative during the accreditation preparation was to work with Eduventure - Research and Consulting Company for Higher Education. The first analysis of program assessment data from the 2005-2006 academic year was conducted by Eduventure for the Curriculum and Instruction Department. This analysis provided in- 
depth information on the teacher licensure program including admission, mid-point, exit and follow-up data. Similar work was later repeated for two other major licensure programs.

The teacher licensure program required student teachers to prepare two work samples during student teaching, and included additional key assignments to earn the teaching licensure. Therefore, work sample evaluations and field experience evaluations were designed by the Assessment Task Force to collect data on student teachers' knowledge, skills and performance through assessment software. As a result of these actions, assessment data were used to make programmatic decisions by the Curriculum and Instruction department. Similar steps were followed after the Curriculum and Instruction Department implementation of assessment tools by other major licensure programs. In addition to the Assessment Task Force initiative, the Associate Dean and one Graduate Assistant guided individual programs in the School in designing assessment tools and implementing them to collect data. The Associate Dean and Graduate Assistant supported the program coordinators through providing assessment tools and coordinating the data collection and analysis. As one of the interviewees said, the work with the Curriculum and Instruction Department was used as a role model to implement assessment activities in other programs in the School of Education.

After a successful implementation of program assessment for four years, the school had its accreditation visit in 2009 . The state-wide and nation-wide accreditation agencies had a joint visit to the school and stated that the school has accomplished accreditation requirements with some minor changes. Right after the accreditation visit 
was over, a new Associate Dean for Academic Affairs was appointed with similar charges and a full-time Assessment Associate was hired.

\section{Data Collection Strategies}

The interview protocol included several categories (See Appendix A - Interview Protocol) derived from the literature on program assessment, faculty work, and faculty participation in assessment activities: Demographic Information, Individual Faculty Characteristics, Environmental/Institutional Characteristics and Educational Innovation.

Demographic Information included questions on gender, years of experience, academic rank, career preparation, and professional development. In Gappa et al.'s (2007) and Blackburn and Lawrence's (1995) works, the socio-demographic characteristics are shown as one of the essential elements in explaining faculty behavior or faculty members' organizational commitment.

The individual characteristics section was comprised of the questions on faculty perception of themselves or certain individual characteristics that may impact their behavior. Blackburn and Lawrence (1995) stated that understanding of self for faculty especially with regard to their roles, is crucial to exploring faculty behavior toward certain phenomena. Under this category, faculty knowledge and philosophy of assessment (Friedlander \& Serban, 2004), faculty beliefs (Grunwald \& Peterson, 2003) and attitudes (Hoviland et al., 2009; Grunwald \& Peterson, 2003; Kezar, 2001) toward program assessment were examined.

The environmental/Institutional Characteristics section consisted of questions regarding environmental features (Blackburn \& Lawrence, 1995; Kezar, 2001) that may 
impact their behavior. These questions reflected faculty members' perception of their work environment (Gonzalez \& Padilla, 1999), perception of resources (Gonzalez \& Padilla, 1999), and perception of leadership (Ewell, 2008; Farmer, 1999; Riggs \& Worthley, 1992) in a given institution again in relation to assessment.

In the literature, researchers define program assessment as an educational innovation, therefore, in order to retrieve information on participation, I posed questions that represented some features of the type of users that Rogers defined. Specifically, I solicited faculty members' own statements on how they think about assessment, under what conditions they are/would be part of the process or what specific barriers/facilitators that they perceive as impacting their behaviors.

\section{Data Collection Procedures}

Structured one-to-one interviews were conducted to collect data. First, the Human Subject Approval (Appendix D) was submitted. After the approval was received, fifteen faculty members were identified who had worked in the School of Education for more than three years. Identified faculty members in the Curriculum and Instruction department were sent an email invitation. The faculty members who were recently hired by the department were not invited to the interviews because they would not have had enough experience or knowledge about the program assessment activities in the School of Education. The faculty, who were selected through purposeful sampling, were sent email (see Appendix B) three times within a 2-month period. Out of 15, 7 faculty members agreed to participate in the study. No academic rank were considered in the selection of faculty members. Each interview was scheduled based on faculty members' availability 
and conducted in a year and a half after the NCATE visit in the school. Based on faculty members' preference, the interviews were mostly conducted in their university office. Only one participant requested to meet at another location which was more appropriate for the faculty member. Interview durations varied from 1 hour to 1 hour and 45 minutes.

Each interview started with informing the participant about the interview. The interview protocol (see Appendix C) was provided to the participants who were requested to sign the protocol before the session, if they agreed with the terms and conditions. The permission for recording was obtained from each participant. The structured interviews were conducted according to the interview protocol.

\section{Data Analysis}

Bogdan and Biklen's (2007) 10 suggestions for qualitative data analysis guided this process.

1. Force yourself to make decisions that narrow the study.

2. Force yourself to make decisions concerning the type of study you want to accomplish.

3. Develop analytic questions.

4. Plan data collection sessions according to what you find in previous observations.

5. Write many observers' comments as you go.

6. Write memos to yourself about what you are learning.

7. Try out ideas and themes on participants.

8. Begin exploring the literature while you are in the field.

9. Play with metaphors, analogies and concepts 
10. Use visual devices.

Moreover, Luker's (2008) guidelines for interview data analysis were used to capture observer's comments mentioned above. The data analysis process started right after each interview was conducted. Interview reflections were made according to Luker's following questions:

1. What surprised me about the interview?

2. What worried me about the interview?

3. How does this interview change the theory?

These questions helped me as a researcher to identify areas that I needed to pay attention to while conducting the interviews, to be conscious about my biases and assumptions that are mentioned earlier. By answering these questions, I also ensured that I conducted the interviews along the lines of my interview protocol. This process also initiated the data analysis earlier in the process which brought a useful perspective to data collection.

The interview results were transcribed by the researcher. Data analysis of interview results was done through open coding (Seidman, 1998). Open coding consisted of reading the interviews and looking for patterns and themes that illustrate faculty perceptions of assessment as well as influences that determine levels of participation. To interpret the categories derived from the analysis, I used Luborsky's (1994) thematic analysis. Luborsky's thematic analysis provided in-depth information on faculty self- and social-knowledge as well as their perception on adoption of educational innovation. The thematic analysis consisted of two steps: identifying the themes from verbatim interview; 
and categorizing themes into topics. After transcribing the interviews, each verbatim transcript was reviewed and notes were taken throughout the reading process to capture the overall themes. Then, these themes were categorized into topics based on the theoretical frameworks. The interview reflections and other memos were also taken into consideration while the topics were identified.

\section{Validity and Reliability}

Merriam (2009) stated that no matter what the research type is, validity and reliability should be approached through careful attention to data collection, analysis and interpretation. For this reason, I started the data analysis early in the process while conducting the interviews. Merriam defined internal validity as the degree to which research findings match reality (Merriam, 2009). Moreover, it is about the findings being congruent with reality. Because it is almost impossible to capture truth or reality, she suggested triangulation as one strategy to ensure internal validity in qualitative research (Merriam, 2009).

As mentioned earlier, multiple theories were utilized in the development of this study. The data on faculty self- and social-knowledge as well as participation were collected through face to face interviews. Multiple theories, i.e., theories on faculty behavior, context in higher education institutions, and innovation theory helped explain faculty engagement from various perspectives. My knowledge and experience within the research site also allowed me to consider the contextual factors and interpret the interview data. 


\section{Limitations}

There are several limitations to the study. First, the study was limited in terms of its generalizability to the faculty in higher education institutions with regard to the type, size, resources available and context. As discussed earlier, program assessment is strongly associated with accreditation self-studies. At the research site, the focus on assessment due to the self-study preparations may have impacted the faculty perspectives and result in high participation in assessment. Therefore, the faculty members' perception may differ since the research site experienced the accreditation visit before the interviews were conducted. Also, the resources that were provided during the preparations in a given setting may have influenced how faculty evaluate the environmental factors.

Another important limitation of this study is that the participants only represented the Early Adapters or Early Majority who were already motivated and interested in adopting the educational innovation. The range of participants might have influenced the data results in terms of identifying the factors that inhibit faculty participation. 


\section{CHAPTER V}

FINDINGS

In this section, the research findings are presented in order to explore the

following research questions. The overall research question is "What are the factors that influence faculty participation in program assessment in higher education?" And the subquestions are:

1. How do faculty members' career preparation impact their adoption of assessment activities?

2. How do faculty members' self-knowledge impact their participation in assessment activities?

3. How do faculty members' social-knowledge impact their participation in assessment activities?

4. How do faculty evaluate their participation in program assessment activities? In this study, it is particularly essential to have a better grasp of the context that may have had a direct impact on faculty perception of program assessment. As mentioned in the Research Methodology section, the accreditation preparations in the School of Education were considered in the process of data analysis. In this section, I present the key findings to answer the overall research question and then discuss the findings with regard to sub-questions. 
The Synthesis of Research Findings in Figure 4 summarizes the findings based on the two theoretical frameworks used in the design of this study. According to the synthesis, the following factors were related to faculty participation:

- Faculty professional background,

- Faculty beliefs, attitudes and practices of assessment

- Leadership

- The connection to faculty beliefs

- Work environment

- School Vision

- Systematic Assessment Framework

- Resources and Reward Structure

- Collegiality

- Professional growth

- Academic freedom

- The use of educational innovation

- Type of users of innovation 


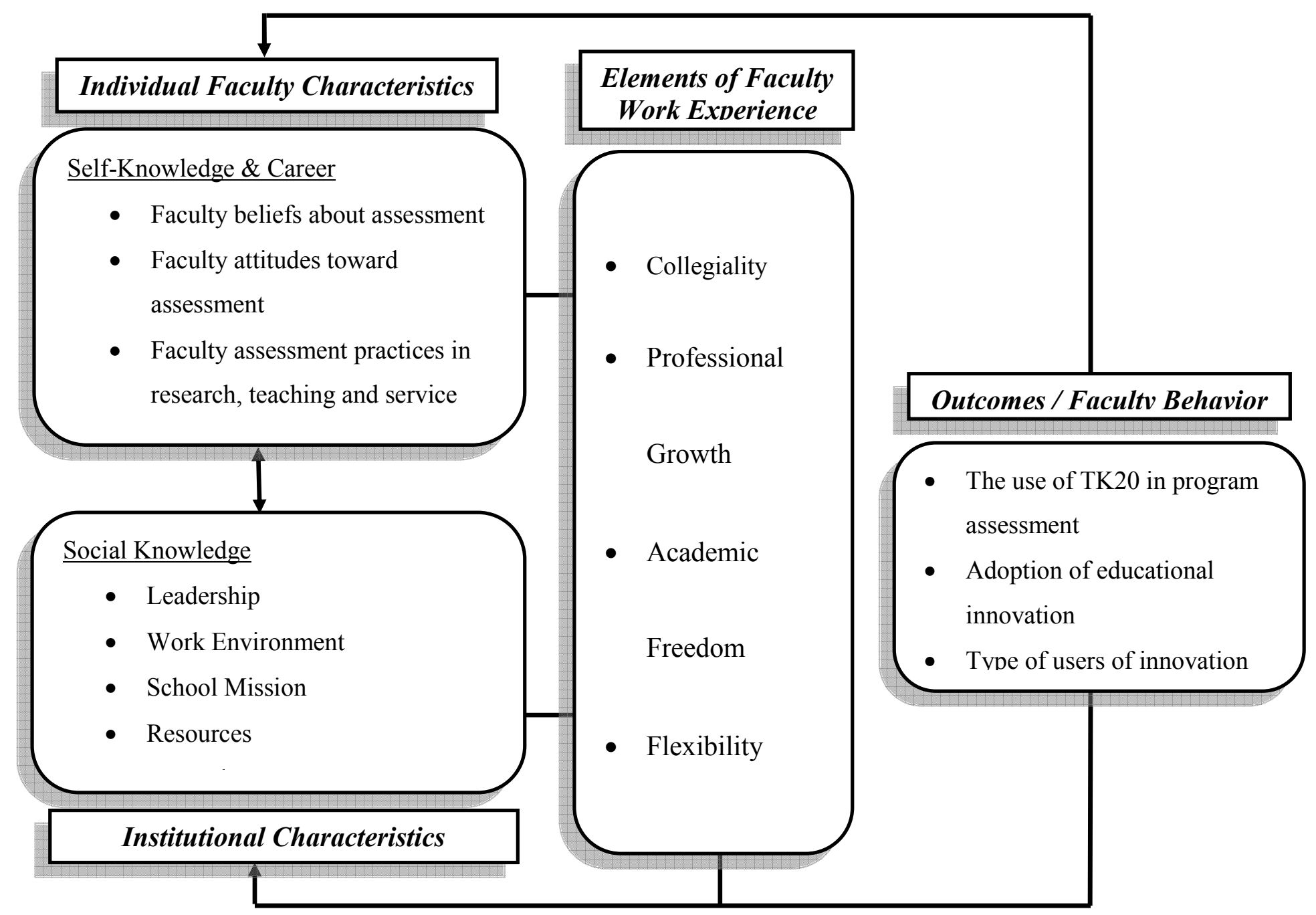

Figure 4. The Synthesis of Research Findings based on Blackburn \& Lawrence (1995) \& Gappa et.al. (2005) models 
These factors were categorized under Individual Faculty Characteristics, Institutional Characteristics, Elements of the Work Experience and Faculty Behavior based on the two theoretical frameworks. Under the Individual Faculty Characteristics, faculty beliefs and attitudes toward assessment, in other words, whether they perceive assessment to assess student learning, use assessment to improve their own practices or evaluate the effectiveness of the program, were found to be influential in their participation. Their assessment practices in teaching, research and service roles directly showed their commitment to and participation in assessment activities. Faculty professional background such as their teaching experience previous to academic life, administrative roles and their graduate school experience impacted the level of participation.

Under the institutional characteristics, faculty self-report on leadership, work environment, conceptual framework (school mission), resources and reward structure revealed a level of interaction with faculty participation. In the Elements of Work Experience category, expectation for a collegial work environment where assessment leads to professional growth with academic freedom and flexibility appeared essential for faculty members. Finally, the use of TK20 to collect assessment data, adoption of educational innovation and faculty self-report on the type of users of assessment innovation provided information on actual faculty behavior regarding assessment.

While some of these factors had significant and direct impact on faculty behavior, some others were considered as having indirect impact based on faculty self-report. 
For example, work environment impacted faculty members' decision making on assessment since the organizational culture is an essential part of faculty's daily life. The continuous exposure to assessment topics in the School of Education and in the departmental meetings was recognized by the faculty. Increased number of assessment activities during the preparations was reported as influential on faculty perception. Similarly, the new leadership and their commitment to program assessment were visible to the faculty and helped them grasp the importance of assessment.

Collegiality, on the other hand, may have indirectly impacted faculty participation in assessment activities. Even though faculty members were involved in assessment activities in their department, they did not think that there were enough interactions among faculty in regards to assessment. They stated that they would like to have more collegiality which might increase the level of participation.

In addition, two faculty members in the interviews mentioned that the notion of academic freedom may affect some faculty's decision on engaging in assessment because there are no consequences of not being involving in assessment. Another faculty brought up the nature of academic work and said that she would like to be part of any programmatic decision that is related to teaching and learning because faculty members should have control over their work.

Besides the fact that these factors have a range of impact on faculty behavior, they are also interrelated. For instance, faculty members' willingness to leverage assessment in their research, teaching and service are also indicators of their beliefs and attitudes. For some faculty, the rationale for conducting assessment and using the data for decision 
making comes from the desire for professional growth. They believed that assessment was important to improve their teaching practices and reflect necessary changes in their programs. The commitment of leadership to assessment activities is another interrelated factor on faculty beliefs, perception of their work environment and resources. It is important to acknowledge the interrelatedness of these factors because they play a key role in shaping work environment that is meaningful, structured, collegial, and respectful to academic freedom where faculty will be more likely to participate in program assessment activities.

\section{Overall Research Question}

What are the factors that influence faculty participation in program assessment in higher education?

Five key findings were identified as the factors that influence faculty participation in program assessment in a given setting. These five factors are: leadership, philosophical dissonance, systematic and ongoing assessment framework, perception of work environment, and technology.

\section{Leadership}

One of the significant findings of the study is that leadership and administrative support have an impact on faculty work life in terms of participating in assessment. Similar to Farmer's (1999) findings on motivation for institutional improvement, the research studies of Einarson (1998) on professional development regarding assessment and of Grunwald and Peterson (2003) on the factors promoting faculty involvement, the strong existence of leadership and administrative support were found to be the most 
effective factor on faculty participation. Six faculty members clearly stated that after the new Dean, and the Associate Dean for Academic Affairs came in, they felt that there was clearer sense of direction for program assessment activities. Ultimately, faculty members felt that organizational climate fostered program improvement through assessment data mostly due to the accreditation preparation. .

I feel like there is a very clear climate of program improvement. I attribute that to our Dean, Associate Dean, my program chair and program coordinator for GTEP. I think for one, our Dean has been very clear, for me at least he communicated this well and over time that our accreditation was about program improvement and we were also getting accredited.

I think we have great leadership right now. I think we are in the healthiest place we have been for years.

I think [the department chair's name] had the opportunity to do that because the department chair was getting the support that the department chair needed from the Dean's vision and leadership. It definitely trickled down.

The school mission and conceptual framework were also perceived as guidelines to program assessment activities. In addition to organizational climate, faculty pointed out the infrastructure and resources that were made available by the leadership (e.g., assessment task force and assessment software, assessment graduate assistant to support the implementation of assessment system).

Well, I think we are very lucky. We have a cadre of people who were willing to take the lead. They are full time, tenure, fixed term, staff and administrators who were willing to serve in the Assessment Task Force to get up and running. To me they really moved us not having an assessment system to systematic...

I think that they have been doing great jobs of getting us through our TSPC/NCATE reviews... I think that did best, going through those programs gave us some direction and some ways that would take the program or areas that we don't do a good job yet or could do better. 
I was impressed with it [TK20] simply because I realized that it was an investment required resources, commitment to investing in a system that would make program assessment and data gathering at the time more manageable showed me that the vision of the Dean's leadership.

I truly think that and I believe that it was a mandate to take a course objective, and align conceptual framework, align the national state standards you know like a grid and then look at the evidence if your student are getting on things. It forces me to do some thinking that makes it stronger.

I think the conversations that [Graduate Assistant's name] and [the Associate Dean's name] had really helped. I think they were really successful especially during the NCATE preparation, and having us think about as first of all as part of the journey and naturalistic part that we needed to do.

\section{Connection to Faculty Beliefs}

Exploring how faculty define assessment, what their beliefs are and how much they value assessment are some of the important elements of understanding faculty work and behavior (Blackburn \& Lawrence, 1995). In addition, Gonzalez and Padilla (1999) found that one of the components of faculty engagement is goal congruence. What goal congruence really means is that if faculty and institutional goals are congruent, faculty are willing to engage in the process of creating change. Within this scope, interview data indicated that each faculty member viewed assessment in numerous ways which may directly affect their level of engagement in assessment activities. These varied differences provide a baseline for higher education leaders to create an environment where faculty feel connected and engage in assessment activities. Some of the examples of faculty perspective on assessment are:

I think the only way you can truly be an ongoing learner, life-long learner is to continue to assess. I look at it as reflection in some ways... I would say that my philosophy of assessment is incredibly valuable on multiple levels. I am always trying to do a better job in being clear in what my expectations and how I can best 
guide them towards those in or what kinds of activities or measure can I put in place to learn whether or not they learn.

I think we all do assessment. That does not mean that it is always good but we do it all the time... it should be useful, it should be plain language, and it should be in cooperative spirit...

It is what we should be modeling as teacher educators...I think there is always things you can figure out to be more effective in teacher education..it has to be continually.

You have to have a clear purpose for what the assessment is going to measure. There has to be an articulate path between the objective of assessment and the evaluation criteria.

It would be to help all the participants determine their values and then to gather evidence about the effectiveness of their programs in terms of getting those values. And I am looking at merit and impacts as well as getting at their values.

We need to have multiple data sources for assessment... Yes, quantitative data gives us one bit of information but it is not sufficient by itself. So we need to have for any assessment design or plan, we need to have multiple ways of assessing individual students, faculty and course evaluations.

It is broad. I don't think myself as assessment person.

While two faculty only thought of classroom assessment, others distinguished program assessment activities with their own practices and talked about what assessment should be or how it should be conducted. Relatedly, three faculty who thought that program assessment is an integral part of what they do and they should be role modeling their students are more likely to be intrinsically motivated to conduct program assessment than the ones who thought it is an interference to faculty roles and responsibilities. Faculty members said:

...there is a lot of motivation but in different areas. That is one of the challenges for this kind of program-wide assessment is that we have to have buy in. Faculty need to see how it is going to benefit their learning and their job in certain ways. 
We got to model that. We got to know if this is working or now. I think part of my passion is about this.

It ought to be integral part of what we do... I cannot think of separate kind of not noticing what is going on and what you are doing.

Another important finding on faculty beliefs toward assessment is the use of terminology. It is crucial to understand the kind of language that faculty use to explain their assessment knowledge and ideas. This would allow us to create more meaningful work environment for faculty. For instance, one faculty member explicitly said that the assessment should have plain language. Two faculty members used the term program evaluation instead of program assessment which also affects the way assessment is being performed. One faculty member disagreed with the discrepancy evaluation of the goals against the standards that are currently in place. Instead of measuring the program against the pre-defined standards and goals, this faculty member claimed that program evaluation should start with collecting data on values defined by the members of the organization. The faculty member stated that this type of discrepancy analysis misleads the program. Instead the program should collect data on the merit and value to examine how much the program addresses the needs of students.

I consider myself a program evaluator. And a difference for me assessment and evaluation is considerable... Assessment, I think, would be more the collecting data and measurement pretty directly following the term assessment. Program evaluation would certainly depend on program assessment but it would go with evaluation's middle name, which is the value, the merit value and the impact of those data. And one of the problems I have working with program assessment is I think it hides the fact that it is an evaluative activity. 
The faculty members also defined assessment based on their career preparation, knowledge and experience in regards to the given topic. While three faculty may only consider classroom assessment, others interpret assessment on multiple levels including self-evaluation and professional growth.

To me, assessment feels more fluid. Maybe that has just been the assessment has been talked about since forever in my life actually... It feels more ongoing and more temporary...fluid assessment is part of a process, where evaluation could be part of the process.

I certainly value assessment. I think that the only way you can truly be an ongoing learner, lifelong learner is to continue to assess... I am always trying to do a better job in being clear in what my expectations and how I can best guide them towards those in or what kinds of activities/measures can I put in place to learn whether or not they learn

The data also revealed that faculty members have various research paradigms that are directly in relation to conducting assessment. For example, three out of seven faculty members evaluated their quantitative skills either nonexistent or weak; one faculty preferred qualitative research in their profession and three faculty members stated that their research skills in both areas are either improving or good to conduct both type of research studies. The following comments on the multiple or different ways of collecting data showed that faculty members expect to have a connection with the way assessment is being conducted. To put it differently, aligning with faculty members' research paradigms and preferences will be a gateway to faculty involvement. The faculty members said:

My problem with a lot of program assessment data is that you cannot put a face on it. I do policy work... when I go for legislatures, you can provide numbers, bars and graphs. But until you begin to put a face on it, they do not connect with it. If they don't connect with it, you don't get your policy moves on. 
...we need to have multiple data sources for assessment...Yes, quantitative data gives us one bit of information but it is not sufficient by itself. So we need to have for any program assessment design or plan, we need to have multiple ways of assessing individual students, and faculty and course evaluations.

As a result of faculty interviews, data analysis showed that faculty members held a wide range of philosophical understanding of assessment. The congruency between faculty and the school's understanding of program assessment becomes a critical component in faculty participation. To put it succinctly, if there is compatibility and connection between faculty beliefs and the organization with regard to their perspective on program assessment, faculty will more likely engage in those activities which justify Gappa et al.'s (2007) claim that if the essential elements of faculty work are in place, both institutions and faculty members will benefit from work environment. Driscoll

\section{Systematic and Ongoing Assessment Structures}

In addition to leadership and connection to faculty beliefs, assessment activities needed to be in a systematic and ongoing structure. Faculty members expected leadership to build the systematic and cyclical assessment framework. In other words, they stated that continuous assessment conversations and presentations by the Associate Dean were very helpful and wanted to have these activities continue. Three faculty members voiced their concerns on losing this structured conversations and work after the NCATE visit was over.

And without [the Associate Dean name] on a routine basis presenting at a faculty meeting, we could not even articulate. 
I am concerned that it is let off but I personally think that it has been a tremendous benefit. The school is much stronger after [the Dean's name] came in with this push.

They need to have a clear sense. I think we got that during the NCATE and we just go back to the old stuff.

I think [the department chair's name] had the opportunity to do that because the department chair was getting the support that the department chair needed from the Dean's vision and leadership. It definitely trickled down.

I think there is more time provided but it was run up to the NCATE...the program gets back to other things that have been put on hold.

Although faculty members agreed that there was some kind of structure to conduct assessment, five faculty members said that there needs to be more conversations on assessment data to build an ongoing and systematic assessment.

I don't feel like it is intentional and systematic... It might be intentional at the moment, but not in the sense of let's talk about assessment.

I think it needs to be more structuring and especially structurally faculty is like herding cats. If you put too much structure, they will run away and they don't want to be told but they need to be. They need to have a clear sense I think we got that during the NCATE and then we just go back to the old stuff.

I think basically creating professional learning community here one and which we work collaboratively in an ongoing fashion.

I wish we could do organizationally more of that... I mean creating organizational ethos...

We ramped up crazy and everybody was relieved and happy. Then we went down the hill. Everybody backed up.

They also valued the existence of the Assessment Task Force with representatives from various departments that carried over the messages across the school. Another 
faculty said that assessment should be fluid meaning that it should be a part of a process together with evaluation.

Interestingly, unlike what Wright (2002) claimed, faculty members see accreditation self-study as a positive means to collect data systematically, to create culture change in an organization and to promote ongoing assessment framework.

...it is a mandate. We were mandated to gather program assessment data...I also saw the value and benefit what data can tell us in making program decisions.

I am just glad NCATE requires it.

Culture, leadership, and skills. I think assessment dynamic can become second nature. It is what we do here in the sense of culture being what we do here which periodically show itself as we prepare ourselves for accreditation.

\section{Faculty Perception of Work Environment}

Blackburn and Lawrence's (1995) model explained that the main influence on faculty behavior and productivity comes from social knowledge, how faculty perceive their work environment. Therefore, how faculty evaluate the organizational climate, how they perceive leadership, school vision, available resources and structures are investigated in this study and found that they have impact on faculty participation.

Six out of seven faculty members were highly cognizant of the increased number of program assessment activities due to accreditation preparation as well as the decrease in assessment after the visit. They claimed that there was an organizational climate to pursue assessment during the preparation; however, the effort given to program assessment has been decreasing since then. One faculty member openly said that assessment should be integrated in the organizational culture regardless of accreditation. 
Now the question of NCATE for example, I think depending on the climate and leadership within an academic institution and the skills... I think assessment can become second nature. It is what we do here in the sense that culture being what we do here periodically shows itself as we prepare ourselves for accreditation.

The overall data analysis showed that depending on faculty members' perception of the leadership, department chair, collaboration with colleagues and their own position in the department, they may value assessment activities, appreciate provided resources and they may also recognize the effort of leadership or vice versa. For instance, 5 faculty members thought that there are enough resources, and structures provided for conducting assessment because of the new dean, the associate dean and the department chair, while two faculty members did not have any interaction with their colleagues on assessment or did not see any resources and leadership support available because of their academic rank or their position in the department. One of those faculty members, who self-evaluated both quantitative and qualitative research skills superb, replied to the question on sharing assessment with colleagues as:

...the biggest one would be I have not taught any evaluation courses at PSU... I have never taught a Statistics course...I have taught all these courses in other places and I do my evaluation outside of the GSE.

Another good example is while four faculty members underrated the TK20 assessment software, 1 faculty member thought that it is an investment that proves the commitment of leadership One faculty member who was not involved in any of the current assessment activities claimed that there are not enough resources, leadership or vision provided to conduct assessment particularly in the school of education. 
Furthermore, as Gappa et al. (2007) articulated, it is critical for faculty to have collegiality, academic freedom/autonomy, professional growth and flexibility in their work experience. Along this line, faculty members expressed their opinion on the work environment being autonomous, needing more collaboration, or contributing to their professional growth in relation to program assessment activities.

Because faculty are so autonomous and do their own course syllabi the way they want to teach, there has been very little collaboration.

...one of the things that we [are] particularly bad about is asking questions that connect us with others...that we developed the models and paradigms for assessment that have not brought us to wider assessment.

I certainly value assessment. I think that the only way you can truly be an ongoing learner, lifelong learner is to continue to assess, I look at it as reflection in some ways.

Another place to go is the intractability of faculty and academic freedom and sort of what you are going to do, if I don't do it?

\section{The Use of Resources}

The use of resources in assessment activities, particularly technology chosen for data gathering, had an impact on faculty members' perception of program assessment. Four faculty members reported their frustration and stress that they have experienced with TK20. It was found to be time-consuming, dysfunctional and unnatural to the way

that faculty operate. Moreover, two faculty members openly said that the software did not provide useful data in terms of student learning.

I don't think TK20 is useful for my teaching so far.

In terms of program assessment, when you say before everybody uploads, everybody has to be proficient for instance and you cannot pass the student teaching, if you cannot get proficient. It gives you no information for program assessment. 
It is a disaster and becoming an unethical disaster.

TK20 is very onerous...the students don't like it, faculty don't like, I find it hard to be supportive...

Two faculty members associate their TK20 experience with program assessment and accreditation, which caused a somewhat negative attitude toward program assessment activities. The faculty members stated:

It is an accreditation evaluation. I think it is our accreditation want and won a word of accreditors... accreditation is a very narrow kind of evaluation and essentially is largely goal bound discrepancy evaluation.

I see assessment necessary for betterment of student learning. Unfortunately, I don't know if we always apply it in appropriate manner. For example, I think TK20 could provide some really good parameters but it has been way off marks so far in my opinion.

Six out of seven faculty members acknowledged the existence of other resources provided in the school such as human resources, assessment data collection methods and the infrastructure.

In summary, the following key findings were found to answer the overall research question:

- Leadership was one of the strongest factors that impacted faculty involvement in program assessment.

- Faculty members had a diverse range of perspectives of assessment which needs to be associated with assessment initiatives.

- Faculty members were expecting structured conversations, systematic and ongoing assessment framework. 
- The perception of organizational climate regarding assessment influenced faculty behavior.

- The use of resources, particularly technology, had an impact on faculty perception of assessment.

Faculty who sought out support from staff or colleagues to use TK20 had a greater tendency to utilize the program even though they thought TK20 was hard to use. Another faculty suggested that the school should have piloted the software before it was purchased. The faculty said:

It should have been run without harm with two or three cohorts, for 3-4 years and then you decide.

Next, I present the findings on the subquestions. The data are presented through the amalgamation of Gappa et al. (2007) and Blackburn and Lawrence (1994) models on faculty work (Figure 4). In Table 4, the data analysis summary on faculty career characteristics and self-knowledge is provided. The very first findings from the table as follows:

- The average number of years in overall teaching including K-12, and other higher education institutions is 32.4 years, while the average number of years in teaching at the current university is 17.4 years.

- All faculty members have previous experience as teachers and 6 of them have served in an administrative positions.

- Out of seven faculty members, three faculty reported that they have had formal training on assessment via working with an assessment expert, graduate level courses or some professional development activities. Four faculty members, on 
the other hand, said that they have not had any formal training because they defined formal training like a course or specific program on assessment.

- Faculty members' research skills range from nonexistent to proficient in qualitative and proficient in both quantitative and qualitative skills.

- All faculty members thought that assessment is essential. Four faculty members talked about classroom assessment specifically, while the rest of the faculty members discuss assessment at a more general level.

- Only two faculty members thought that assessment is an add-on or interference to faculty work life, while five faculty affirmed that assessment is an integral part of faculty roles for various reasons such as to inform one's practice, to bring outside voice, to provide coherence in the program, to communicate the merit value and impact of the program.

- All faculty members stated that they have been using assessment in their teaching practices, while two of them did not provide specific examples of assessment.

- In terms of using assessment in their research practices, four faculty disclosed that they have presented at a conference, or published articles by using program assessment data. While two faculty said that they have not used assessment data in their research practices, one faculty member reported the current status of research project developed based on program assessment data.

- Five faculty members talked about their service roles and how they integrated the use of program assessment data to make improvement in programs while two faculty members did not provide any specific examples. 
Table 4.

Data Analysis Summary on Faculty Career Characteristics \& Self-Knowledge

\begin{tabular}{|c|c|c|c|c|c|c|c|c|}
\hline & $\begin{array}{l}\text { Professional } \\
\text { Background }\end{array}$ & $\begin{array}{c}\text { Formal } \\
\text { Training on } \\
\text { Assessment }\end{array}$ & $\begin{array}{l}\text { Evaluation } \\
\text { of Research } \\
\text { Skills }\end{array}$ & Philosophy of Assessment & $\begin{array}{l}\text { Role of Assessment } \\
\text { in Faculty Life }\end{array}$ & $\begin{array}{c}\text { Use of } \\
\text { Assessment in } \\
\text { Teaching }\end{array}$ & $\begin{array}{c}\text { Use of } \\
\text { Assessment in } \\
\text { Research }\end{array}$ & $\begin{array}{c}\text { Use of } \\
\text { Assessment } \\
\text { in Service }\end{array}$ \\
\hline$\# 1$ & $\begin{array}{l}\text { Former teacher; } \\
\text { Ed.D; Fixed } \\
\text { Term; Program } \\
\text { Coordinator; } 31 \\
\text { years in overall } \\
\text { teaching; and } 11 \\
\text { years at the } \\
\text { current university }\end{array}$ & $\begin{array}{l}\text { No. Only } \\
\text { research } \\
\text { courses in } \\
\text { doctoral } \\
\text { program }\end{array}$ & $\begin{array}{l}\text { Improving in } \\
\text { both } \\
\text { Quantitative \& } \\
\text { Qualitative } \\
\text { research }\end{array}$ & $\begin{array}{l}\text { A.is essential; Role model } \\
\text { students in A.; Brings } \\
\text { coherency; Systematic } \\
\text { Classroom A.; Data to make } \\
\text { program changes }\end{array}$ & $\begin{array}{l}\text { To inform one's } \\
\text { practice to do } \\
\text { effective job }\end{array}$ & $\begin{array}{l}\text { Yes - pre and } \\
\text { post-assessment } \\
\text { and exit surveys }\end{array}$ & $\begin{array}{l}\text { Yes- used the } \\
\text { program exit } \\
\text { survey data } \\
\text { and published } \\
2 \text { articles }\end{array}$ & $\begin{array}{l}\text { Yes- to } \\
\text { measure the } \\
\text { added value } \\
\text { of mentor } \\
\text { teachers }\end{array}$ \\
\hline$\# 2$ & $\begin{array}{l}\text { Former teacher; } \\
\text { Ph.D; Associate } \\
\text { Professor; } \\
\text { Administrative } \\
\text { positions; } 36 \text { years } \\
\text { in overall } \\
\text { teaching; and } 19 \\
\text { years at the } \\
\text { current university }\end{array}$ & $\begin{array}{l}\text { Yes. Graduate } \\
\text { level course and } \\
\text { workshops on } \\
\text { Assessment }\end{array}$ & $\begin{array}{l}\text { Pretty good in } \\
\text { both; Prefer } \\
\text { Qualitative }\end{array}$ & $\begin{array}{l}\text { Useful, plain language in a } \\
\text { cooperative spirit; Not serve } \\
\text { a power differential; Can be } \\
\text { good for student learning } \\
\text { and collegial work }\end{array}$ & $\begin{array}{l}\text { Essential; Bring } \\
\text { outside voice and } \\
\text { others' perspective; } \\
\text { should be } \\
\text { collaborative }\end{array}$ & $\begin{array}{l}\text { Yes - no } \\
\text { specific } \\
\text { examples given }\end{array}$ & $\begin{array}{l}\text { No-program } \\
\text { assessment } \\
\text { data is not } \\
\text { used. }\end{array}$ & $\begin{array}{l}\text { No }- \text { no } \\
\text { specific } \\
\text { example } \\
\text { given }\end{array}$ \\
\hline$\# \mathbf{3}$ & $\begin{array}{l}\text { Former teacher; } \\
\text { Ph.D; Full } \\
\text { Professor; } \\
\text { Program } \\
\text { Coordinator; } 35 \\
\text { years in overall } \\
\text { teaching; and } 13 \\
\text { years at the } \\
\text { current university }\end{array}$ & $\begin{array}{l}\text { Yes.Undergrad. } \\
\text { \& Grad } \\
\text { Courses, } \\
\text { Conferences, } \\
\text { Books and } \\
\text { Workshops }\end{array}$ & $\begin{array}{l}\text { Adequate to } \\
\text { conduct both } \\
\text { Quantitative \& } \\
\text { Qualitative } \\
\text { research }\end{array}$ & $\begin{array}{l}\text { Assessment cannot be } \\
\text { divorced from instruction; } \\
\text { Clear purpose of A.; } \\
\text { Articulate the objective of } \\
\text { A and the evaluation } \\
\text { criteria; Connects to } \\
\text { conceptual framework, and } \\
\text { national standards }\end{array}$ & $\begin{array}{l}\text { A is on a } \\
\text { developmental } \\
\text { continuum; Integral } \\
\text { part of faculty work; } \\
\text { Provides } \\
\text { cohesiveness }\end{array}$ & $\begin{array}{l}\text { Yes - pre- and } \\
\text { post-assessment, } \\
\text { mid-course } \\
\text { evaluation }\end{array}$ & $\begin{array}{l}\text { Yes - } \\
\text { presented } \\
\text { program } \\
\text { assessment } \\
\text { data and will } \\
\text { publish }\end{array}$ & $\begin{array}{l}\text { Yes - in the } \\
\text { board that } \\
\text { the faculty } \\
\text { serves }\end{array}$ \\
\hline \#4 & $\begin{array}{l}\text { Former teacher; } \\
\text { Ph.D; Full } \\
\text { Professor; No } \\
\text { administrative } \\
\text { position; } 20 \text { years } \\
\text { in overall } \\
\text { teaching; and } 23 \\
\text { years at the } \\
\text { current university }\end{array}$ & $\begin{array}{l}\text { Yes. Training } \\
\text { from Program } \\
\text { Evaluation } \\
\text { Specialist }\end{array}$ & Superb both & $\begin{array}{l}\text { Determine value; Evidence } \\
\text { on the effectiveness of the } \\
\text { program; Merit, impact and } \\
\text { getting value; No } \\
\text { discrepancy evaluation. }\end{array}$ & $\begin{array}{l}\text { Integral part of } \\
\text { faculty work life; } \\
\text { Communicating the } \\
\text { merit value and } \\
\text { impact }\end{array}$ & $\begin{array}{l}\text { Yes - pre-and } \\
\text { post-assessment, } \\
\text { performance } \\
\text { assessment }\end{array}$ & $\begin{array}{l}\text { Yes- has } \\
\text { numerous } \\
\text { scholarly work } \\
\text { on program } \\
\text { evaluation }\end{array}$ & $\begin{array}{l}\text { Yes }- \text { in the } \\
\text { board that } \\
\text { the faculty } \\
\text { serves }\end{array}$ \\
\hline
\end{tabular}




\begin{tabular}{|c|c|c|c|c|c|c|c|c|}
\hline & $\begin{array}{l}\text { Professional } \\
\text { Background }\end{array}$ & $\begin{array}{c}\text { Formal } \\
\text { Training on } \\
\text { Assessment }\end{array}$ & $\begin{array}{l}\text { Evaluation of } \\
\text { Research } \\
\text { Skills }\end{array}$ & Philosophy of Assessment & $\begin{array}{c}\text { Role of } \\
\text { Assessment in } \\
\text { Faculty Life }\end{array}$ & $\begin{array}{c}\text { Use of } \\
\text { Assessment in } \\
\text { Teaching }\end{array}$ & $\begin{array}{c}\text { Use of } \\
\text { Assessment in } \\
\text { Research }\end{array}$ & $\begin{array}{c}\text { Use of } \\
\text { Assessment } \\
\text { in Service }\end{array}$ \\
\hline$\# 5$ & $\begin{array}{l}\text { Former teacher; } \\
\text { M.Sc.; Fixed- } \\
\text { Term; } \\
\text { Administrative } \\
\text { positions; } 34 \\
\text { years in overall } \\
\text { teaching; and } 21 \\
\text { years at the } \\
\text { current university }\end{array}$ & $\begin{array}{l}\text { No. Only through } \\
\text { faculty instructor } \\
\text { background }\end{array}$ & Non-Existent & $\begin{array}{l}\text { Value assessment to be } \\
\text { life-long learner; } \\
\text { Reflection; Valuable at } \\
\text { multiple level; Necessary } \\
\text { for betterment in student } \\
\text { learning }\end{array}$ & $\begin{array}{l}\text { Valuable; } \\
\text { Technology } \\
\text { should be helpful }\end{array}$ & $\begin{array}{l}\text { Y- Authentic } \\
\text { assessment and } \\
\text { exit slips }\end{array}$ & $\begin{array}{l}\mathrm{N}-\text { more } \\
\text { focused on the } \\
\text { content }\end{array}$ & $\begin{array}{l}\mathrm{Y}-\text { in } \\
\text { partnership } \\
\text { activities }\end{array}$ \\
\hline \#6 & $\begin{array}{l}\text { Former teacher; } \\
\text { Ph.D; Associate } \\
\text { Professor; } \\
\text { Program } \\
\text { Coordinator; } 34 \\
\text { years in overall } \\
\text { teaching; and } 21 \\
\text { years at the } \\
\text { current university }\end{array}$ & $\begin{array}{l}\text { No. Only some } \\
\text { knowledge } \\
\text { because of } \\
\text { teaching } \\
\text { background }\end{array}$ & $\begin{array}{l}\text { Zero in } \\
\text { Quantitative } \\
\text { and experienced } \\
\text { in Qualitative }\end{array}$ & $\begin{array}{l}\text { Assessment is essential. } \\
\text { Multiple data sources; } \\
\text { Quantitative is good but } \\
\text { not sufficient }\end{array}$ & $\begin{array}{l}\text { Painful and } \\
\text { interference in } \\
\text { faculty's work } \\
\text { life; Faculty's job } \\
\text { is to teach }\end{array}$ & $\begin{array}{l}\text { Y- No specific } \\
\text { examples given. }\end{array}$ & $\begin{array}{l}Y-\text { not until } \\
\text { recently. In 2-3 } \\
\text { years presented } \\
\text { at conferences }\end{array}$ & $\begin{array}{l}\mathrm{Y}-\text { in school } \\
\text { partnership } \\
\text { projects }\end{array}$ \\
\hline \#7 & $\begin{array}{l}\text { Former Teacher; } \\
\text { Ph.D; Associate } \\
\text { Professor; } \\
\text { Program } \\
\text { Coordinator; } 42 \\
\text { years in overall } \\
\text { teaching; and } 17 \\
\text { years at the } \\
\text { current university }\end{array}$ & $\begin{array}{l}\text { No. No formal } \\
\text { training }\end{array}$ & $\begin{array}{l}\text { Firm } \\
\text { background in } \\
\text { Qualitative and } \\
\text { weak in } \\
\text { Quantitative }\end{array}$ & $\begin{array}{l}\text { Assessment is essential \& } \\
\text { mandatory; Value-added; } \\
\text { should be part of } \\
\text { organizational climate }\end{array}$ & $\begin{array}{l}\text { It is an add-on to } \\
\text { faculty life; } \\
\text { Though it has } \\
\text { great promises for } \\
\text { improvement }\end{array}$ & $\begin{array}{l}\text { Y-Standard } \\
\text { assessment, exit } \\
\text { surveys; non- } \\
\text { formal open- } \\
\text { ended questions }\end{array}$ & $\begin{array}{l}\mathrm{N} \text {-not yet but } \\
\text { working on the } \\
\text { program data to } \\
\text { publish }\end{array}$ & $\begin{array}{l}\mathrm{N}-\text { no } \\
\text { specific } \\
\text { examples }\end{array}$ \\
\hline
\end{tabular}




\section{Individual Faculty Characteristics}

Subquestion 1. How do faculty members' career preparation impact their adoption of assessment activities

Blackburn and Lawrence (1995) stated that career preparation affect one's values, beliefs and evaluation of their knowledge on certain topics. Faculty professional background data including their graduate education, and previous work experience is presented in the Table 4. Interview results with respect to the number of years in teaching, formal training on assessment are displayed below.

\section{1a. Overall number of years in teaching / number of years in teaching in}

current role. The average years of teaching experience including both K-12 and higher education was 35.7 years, while the average time of teaching at the given setting was 17.4 years.

1b. Formal training on assessment. Three faculty members said that they have never had any formal training on assessment. Four faculty members stated that they had assessment training in the form of taking research courses during their graduate programs or attending professional development sessions in conferences on their content areas. Among those four faculty members, only one mentioned having a formal program evaluation training from an assessment expert.

1c. Administrative roles. Except one faculty, six faculty members have had administrative roles or are currently playing that role. Administrative roles affect their perception of assessment. For instance, faculty who have played program coordinator roles are more open to the idea of program assessment. 
Subquestion 2. How do faculty members' self-knowledge impact their participation in assessment activities?

Blackburn and Lawrence (1995) explained self-knowledge as the self-perceptions that are related to behaviors and products in faculty members' various academic roles teaching, scholarship, research and service. Therefore, the self-perception of faculty on assessment with regard to these roles, and responsibilities will be presented in this section. In particular, this section consists of the interview questions that reflected faculty members' ideas and opinions on how they evaluate their research skills, how they integrate assessment in their roles and responsibilities, how assessment should be conducted, who should be responsible for program assessment, or their philosophy of assessment.

2a. Evaluation of research skills. Interviewees were asked to evaluate their quantitative and qualitative skills. The results in Table 5 display that faculty members' research skills range from nonexistent to proficient in qualitative and proficient in both quantitative and qualitative skills. The range of research skills and preferred research methodologies will have a direct impact on assessment data collection. In the table, the type of users of assessment as an educational innovation was also presented. 
Table 5

The Self-Evaluation of Faculty on Research Skills.

\begin{tabular}{|c|l|}
\hline $\begin{array}{l}\text { The type of users of } \\
\text { Assessment Innovation }\end{array}$ & Evaluation of Research Skills \\
\hline Early Majority & $\begin{array}{l}\text { Zero experience in Quantitative \& Experienced in } \\
\text { Qualitative }\end{array}$ \\
\hline Early Majority & Firm in Qualitative \& Weak in Quantitative \\
\hline Early Adopter & Non Existent \\
\hline Early Adopter & Both Skills are Improving \\
\hline Early Adopter & Adequate in both \& conducted research in both \\
\hline Early Adopter & Pretty good in both \& Prefer Qualitative \\
\hline Early Adopter & Superb Both \\
\hline
\end{tabular}

2b. Experience in using assessment in research, teaching and service faculty

roles. According to Boyer (1990) faculty members have three main responsibilities in academia: teaching, research and service. Exploring how faculty members' use assessment in those roles would provide a perspective on the level of commitment, interest and specific examples on their actual behaviors in regards to assessment. First of all, faculty members were asked to talk about how they use assessment in their teaching. Overall, most of the faculty were very explicit on this question and provided very detailed description of the steps that they take for classroom assessment. With regard to beliefs, almost all of the faculty members stated that assessment is essential and integral part of faculty members' roles.

I think it is imperative that faculty look at their own teaching... Well I don't think that you can divorce assessment from instruction. 
Most of the faculty members had a very clear idea of the purposes of assessment which are effectiveness of teaching, continuous measure of student learning and creating consistency among the programs through decision making based on assessment data.

I really see three purposes of assessment...most obvious and most commonly understood is to assess the degree to which students have achieved the learning. And the second part of that is in looking at the ways [in] and which students demonstrate learning...the third one is relating to that assessment then is using that assessment, using both of those assessment data and then you look at them and make decision about how to teach the course.

To inform my practice to do a more effective job; that is what it should be doing. Systematic planning including pre-, mid- and post-assessment to determine teaching effectiveness and various ways of assessing such as formative, summative or performance assessment show that faculty members are knowledgeable and experienced in classroom assessment.

Well, I use different levels of assessment, formative and summative assessment. I try and do every one of my classes.

... so I have direct reports from them. Prior to just the last couple of years, I would be also supervisor of student teacher. So, I could be in the field with them and see how they are performing there. As a cohort leader, student teacher cohort leader, I would see all my student teachers once a quarter all of the students that I work within the cohort. So my assessment is largely performance in the setting that they are preparing to work in. That would inform my teaching.

Another important finding from this question was that almost all of them stated that they design their own course evaluations because the university's bubble forms would come late, and they do not provide the kind of feedback faculty are looking for in order to improve their teaching and learning practices.

I don't get them in 2-3 months, it gets delayed, it has no impact on the courses and it frequently can't impact for a full year because the course is not taught until the next year. I find as with a lot of that kind of assessment, you have some 
extremes on the both sides...it does not give you any kind of viable data that you can grow from. So I find it very disappointing and as an instructor I care about doing a good job and having that course be better.

But student evaluations should be part of the assessment process to help faculty and programs to see the effectiveness of program and what is going on.

Because these faculty members are educators in pre service teacher training programs, they also believe that it is crucial to role model assessment in the classroom for students. One faculty member stated that:

It is what we should be modeling as teacher educators because our teacher candidates should go out knowing that they should be continually questioning whether what they are doing is effective for kids. They should be doing program assessment of their own practices and how could... we got to model that.

I think it is imperative that, as a faculty member in the Graduate School of Education, I model practices.

With regard to use of program assessment data in research, four faculty members said that they have been using data to publish and to present in various meetings and conferences. One faculty member was not using the program assessment data because of different academic interest until recently; however, the shift in assessment culture in the department has led to some research and presentations.

I have systematically collected a research data in the form of surveys from my students at first were pre- and post-assessment and but eventually became formalized research studies.

My scholarly interest would be more about how to learn teaching process... and I did not use assessment data as research data. But more recently, as we have started thinking about revising the program and doing things at the program level, now my focus is at the program level. I have done some work and presentations on how program evolves.

I have published two articles using the data from our program assessment. 
Two faculty members, who are not using assessment in their scholarly work mentioned specifically that their academic focus is not assessment or they have a problem with the data type.

My problem with assessment data is that you cannot put a face on it.

Finally, five faculty members out of seven declared that they have been using program assessment data within their service roles particularly in partnership activities with school districts, schools or other nonprofit organizations to reflect on program quality.

And it has been really great partnership. In that conversations, we made adoptions in our program because they need...

We are doing a lot of partnership with schools and certainly part of that negotiation process is to talk about our program...

2c. Philosophy of assessment. Faculty members were asked to explain their philosophy of assessment. Some faculty members found this question hard to answer for they are not the experts in assessment. Almost all participants stated that assessment is essential for effectiveness of teaching. First of all, faculty self-reports were analyzed to identify common themes around assessment. Faculty members' philosophy of assessment - their knowledge, beliefs, and attitudes with regard to assessment - was characterized by a main theme for each interviewee. For example, interviewee I was mainly speaking about the significance of conducting program assessment for effective teaching. The participant communicated the importance of collecting assessment data for effective teaching. The faculty said:

We got to know what is working or not...to inform my practice to do a more effective job. That is what it should be doing... 
For interview 2, collegiality in assessment was the main theme because the faculty mainly emphasized the importance of working collaboratively with other schools. According to interviewee 2, assessment should connect faculty with each other. The faculty said:

My philosophy of assessment is that...it should be in a cooperative spirit which means it should not serve a power differential... I think it [assessment] can be good for student learning, for collegial work and good for improvement.

Interview 3 was characterized by the concept of assessment as a developmental continuum. In this interview, the participant mentioned that faculty has started to see that their work on assessment as part of the whole.

Faculty need to think of program assessment on a developmental continuum... developmental continuum is that now faculty is beginning to see that the work that they are doing from the beginning, the middle and the end is what makes a program assessment...we know our entry data and we know our mid data and end. Now what we need to do is it is time to say: let's take the midterm assessment...let's have everybody look at the score and see what does this tell us.

The fourth interview was dominated by the distinction between program assessment and program evaluation. The faculty member underlined the fact that assessment is mere data, while evaluation involves merit value and impact which are determined through data.

I consider myself a program evaluator and a difference for me assessment and evaluation is considerable... one of the problems I have working with program assessment is I think it hides the fact that it is an evaluative activity...determining values is the most interesting parts of the program evaluation.

Interview 5 was categorized as assessment for professional growth mainly dominated by the idea of using assessment for effective teaching, having viable data that one can grow from. 
I obviously using the results of exit slips measure to see whether the course was effective... it [course evaluation] does not give you any kind of viable data that you can grow from... I certainly value assessment, I think the only way you can truly be an ongoing learner, lifelong learner is to continue to assess.

Interview 6 can be characterized by the importance of leadership in the process.

Faculty member put great emphasis on how new leadership presented program

assessment and structured the assessment activities and provided resources. The faculty

stated:

In a way I was not aware that we had done in the past. In the end, I saw the value and benefit what data can tell us in making program decisions...I think it was very timely to have new dean with his new vision, a new department chair, who operated on a very different scale than my perceptions of previous chairs....it was very timely... More visible and there was a transparent process. There was accountability and there were resources, none of which, I was aware of in the past.

Finally, the interview 7 was overshadowed by faculty members' perspective on the necessity of ongoing, cyclical and systematic assessment. The faculty member said that assessment activities should be more intentional and systematic where faculty discuss the data and come up with a suggestion for the program.

I don't feel like it is intentional and systematic...I would particularly people come together around the table and look at what we know about our program, and make some decisions about that...it feels more ongoing.

2d. The role of program assessment in faculty work life. The responses to the question of the role of program assessment in faculty members' work life were grouped under two themes. The first group of faculty declared that the program assessment is part of faculty work life and should be seen as a tool to improve oneself and the program as well. They stated: 
I certainly value assessment. I think that the only way one can truly be an ongoing learner, lifelong learner is to continue to assess. I look at it as reflection in some ways.

Well, I think faculty need to think of program assessment on a developmental continuum... now faculty is beginning to see that the work they are doing from the beginning, the middle and the end is what makes a program assessment. Because, it cannot be just at the end. We need that midpoint assessment and what will affect the decisions that faculty will make collectively.

It ought to be integral part of what we do. I think people have a burden to communicate the merit value and impact to other audiences. That is one of the things that we should be doing.

I think it is essential. I think let's take the department. To have a really, really, really good program assessment can be a wonderful tool for doing better. Number 1 , it shakes you up. It makes you relook at both questions and answers to do things better. And if you really do it right, you are bringing in the outside voice, others' perspective...

The second group of faculty pointed out assessment as an add-on to faculty members' work life even though one of them mentioned that is promising and exciting. They did not think program assessment should be included in faculty members' roles and responsibilities indicating that faculty members' primary responsibility is to teach. They said:

...many faculty perceive as add-on to their work life. For just the things you get earlier, we do because of accreditation... I think actually it has great promise for being really exciting. In this world of more cyclical assessment, to me in a teacher education context or program, educator program context in master's and doctoral program, this could be really exciting road. Because, it engenders real, authentic conversations between faculty.

I think it is a pain. I think again this does how to do with my recent vent in terms of looking at the big picture... My goal was to do the best that I could to teach courses I taught... Yes, I will be happy to about the program. But in terms of program assessment as part of my faculty work life, it seems like interference. 
Overall, it can be concluded that all faculty members believe in improvement through program assessment. However, it is arguable that whether faculty see it among their responsibilities to perform program assessment and analyze the data on the programs. One of the faculty members said:

...I think faculty want it somebody else doing assessment of the program, like exit surveys. I want somebody else interview human relations directors or principals so we know that our students are doing well. But that is just somebody else for me.

Table 6 summarizes the data on faculty perception of institutional characteristics, i.e., work environment. The following initial findings are presented in the table:

- Five faculty members said there has been some level of conversations about assessment, while two faculty members did not see any interaction.

- Six faculty members did see the relationship between the conceptual framework and assessment.

- Three faculty members stated that there have been more support, attention and human resources during the accreditation preparation; however, they did not find it sufficient to create a culture of assessment in the school.

- No reward structure has been perceived by any of the participants.

- All faculty, except one, commented on the great leadership, organizational climate and positive environment for assessment activities.

- All faculty members believed in the necessity of having electronic data system, even though TK20 was questioned in terms of its usability. 
- Five faculty members evaluated themselves as risk-takers in adopting an educational innovation, while two faculty mentioned that they would like to observe first.

- Five faculty members identified themselves as Early Adopter and two faculty as Early Majority. 
Table 6.

Data Analysis Summary on Faculty Social-Knowledge \& Participation

\begin{tabular}{|c|c|c|c|c|c|c|c|c|c|}
\hline & $\begin{array}{l}\text { Professional } \\
\text { Background }\end{array}$ & $\begin{array}{l}\text { Interaction with } \\
\text { Colleagues }\end{array}$ & $\begin{array}{l}\text { Contribution of } \\
\text { School Mission }\end{array}$ & $\begin{array}{c}\text { Perception of } \\
\text { Resources }\end{array}$ & $\begin{array}{l}\text { Perception of } \\
\text { Reward } \\
\text { Structure }\end{array}$ & $\begin{array}{c}\text { Perception of } \\
\text { Leadership }\end{array}$ & The use of TK20 & $\begin{array}{l}\text { Adoption of } \\
\text { Educational } \\
\text { Innovation }\end{array}$ & $\begin{array}{l}\text { Type of } \\
\text { Adopter }\end{array}$ \\
\hline$\# 1$ & $\begin{array}{l}\text { Former teacher; } \\
\text { Ed.D; Fixed } \\
\text { Term; Program } \\
\text { Coordinator; } 31 \\
\text { years in overall } \\
\text { teaching; and } 11 \\
\text { years at the } \\
\text { current university }\end{array}$ & $\begin{array}{l}\text { Yes, within my } \\
\text { program. Little } \\
\text { more attempt in } \\
\text { the last two years } \\
\text { at the } \\
\text { departmental } \\
\text { level. }\end{array}$ & $\begin{array}{l}\text { Mandate to align the } \\
\text { Conceptual } \\
\text { framework \& course } \\
\text { objectives; Need to } \\
\text { be assessed for } \\
\text { program } \\
\text { improvement. }\end{array}$ & $\begin{array}{l}\text { Yes there was } \\
\text { an assessment } \\
\text { team. }\end{array}$ & $\begin{array}{l}\text { No reward } \\
\text { structure. Don't } \\
\text { think that there is } \\
\text { any reward for } \\
\text { program } \\
\text { assessment. P \& } \\
\text { T should honor } \\
\text { assessment. }\end{array}$ & $\begin{array}{l}\text { Positive leadership } \\
\text { by the dean, } \\
\text { department chair and } \\
\text { program. }\end{array}$ & $\begin{array}{l}\text { Laborious, } \\
\text { poorly designed; } \\
\text { having data base } \\
\text { is good idea but } \\
\text { program } \\
\text { technically poor } \\
\text { and hard to use. }\end{array}$ & $\begin{array}{l}\text { Tend to jump } \\
\text { in whatever } \\
\text { the fad, risk- } \\
\text { taker. }\end{array}$ & $\begin{array}{l}\text { Early } \\
\text { Adopter }\end{array}$ \\
\hline$\# 2$ & $\begin{array}{l}\text { Former teacher; } \\
\text { Ph.D; Associate } \\
\text { Professor; } \\
\text { Administrative } \\
\text { positions; } 36 \\
\text { years in overall } \\
\text { teaching; and } 19 \\
\text { years at the } \\
\text { current university }\end{array}$ & $\begin{array}{l}\text { Not much } \\
\text { conversation on } \\
\text { classroom } \\
\text { assessment; some } \\
\text { at the program } \\
\text { level assessment } \\
\text { but not } \\
\text { systematically. }\end{array}$ & $\begin{array}{l}\text { The conversations by } \\
\text { the Associate Dean } \\
\text { were helpful. }\end{array}$ & $\begin{array}{l}\text { Assessment is } \\
\text { not part of the } \\
\text { agenda; We } \\
\text { don't have } \\
\text { tribal rituals. }\end{array}$ & $\begin{array}{l}\text { No reward } \\
\text { structure is really } \\
\text { available. } \\
\text { Program \& } \\
\text { Policy work and } \\
\text { their collegial } \\
\text { determination } \\
\text { was helpful. }\end{array}$ & $\begin{array}{l}\text { Need to be more } \\
\text { structured; Got it } \\
\text { during the NCATE } \\
\text { and went back to old } \\
\text { stuff; Decentralized } \\
\text { approach at the } \\
\text { university level was } \\
\text { not helpful. }\end{array}$ & $\begin{array}{l}\text { Like the concept; } \\
\text { Needs to have } \\
\text { natural way of } \\
\text { operating; Starts } \\
\text { the conversation } \\
\text { but not results } \\
\text { yet. }\end{array}$ & $\begin{array}{l}\text { Old fossil } \\
\text { but like the } \\
\text { new things; } \\
\text { risk-taker. }\end{array}$ & $\begin{array}{l}\text { Early } \\
\text { Adopter }\end{array}$ \\
\hline$\# 3$ & $\begin{array}{l}\text { Former teacher; } \\
\text { Ph.D; Full } \\
\text { Professor; } \\
\text { Program } \\
\text { Coordinator; } 35 \\
\text { years in overall } \\
\text { teaching; and } 13 \\
\text { years at the } \\
\text { current university }\end{array}$ & $\begin{array}{l}\text { Not enough } \\
\text { forums to talk } \\
\text { about A.; some } \\
\text { conversations on } \\
\text { program } \\
\text { assessment; More } \\
\text { informal. }\end{array}$ & $\begin{array}{l}\text { Both the university } \\
\text { and the school } \\
\text { mission contribute } \\
\text { assessment; } \\
\text { Assessment \& } \\
\text { Research are } \\
\text { imperatives; Need to } \\
\text { look for evidence of } \\
\text { change. }\end{array}$ & $\begin{array}{l}\text { Not enough } \\
\text { time; need } \\
\text { assessment } \\
\text { systems and } \\
\text { better tools; } \\
\text { Assessment } \\
\text { Team was } \\
\text { helpful. }\end{array}$ & $\begin{array}{l}\text { No reward } \\
\text { structure is } \\
\text { available to } \\
\text { conduct } \\
\text { assessment. Get } \\
\text { rewards through } \\
\text { other means. }\end{array}$ & $\begin{array}{l}\text { Lucky in terms of } \\
\text { leadership; a cadre of } \\
\text { people to take the } \\
\text { lead; very good } \\
\text { leadership. }\end{array}$ & $\begin{array}{l}\text { Had some } \\
\text { reticence and my } \\
\text { opinion has been } \\
\text { validated; } \\
\text { Clunky, and } \\
\text { more facile than } \\
\text { paper. Helpful to } \\
\text { collect data. }\end{array}$ & $\begin{array}{l}\text { Risk-taker \& } \\
\text { not willing to } \\
\text { jump in } \\
\text { without } \\
\text { seeing the } \\
\text { evidence. }\end{array}$ & $\begin{array}{l}\text { Early } \\
\text { Adopter }\end{array}$ \\
\hline$\# 4$ & $\begin{array}{l}\text { Former teacher; } \\
\text { Ph.D; Full } \\
\text { Professor; No } \\
\text { administrative } \\
\text { position; } 20 \\
\text { years in overall } \\
\text { teaching; and } 23 \\
\text { years at the } \\
\text { current university }\end{array}$ & $\begin{array}{l}\text { Have no } \\
\text { interaction within } \\
\text { the department } \\
\text { even though has } \\
\text { knowledge in } \\
\text { program } \\
\text { evaluation }\end{array}$ & $\begin{array}{l}\text { Not seen any } \\
\text { connection. }\end{array}$ & $\begin{array}{l}\text { Did all program } \\
\text { evaluation work } \\
\text { outside the } \\
\text { school. }\end{array}$ & $\begin{array}{l}\text { Not seen any } \\
\text { reward structure. }\end{array}$ & $\begin{array}{l}\text { Did not know; Not } \\
\text { involved in what is } \\
\text { going on; }\end{array}$ & $\begin{array}{l}\text { Unethical } \\
\text { disaster; } \\
\text { understands the } \\
\text { concept but not } \\
\text { useful to } \\
\text { teaching and } \\
\text { learning. }\end{array}$ & $\begin{array}{l}\text { Faculty's job } \\
\text { is to } \\
\text { integrate } \\
\text { innovation; } \\
\text { part of the } \\
\text { work; Front } \\
\text { line } \\
\text { practitioner }\end{array}$ & $\begin{array}{l}\text { Early } \\
\text { Adopter }\end{array}$ \\
\hline
\end{tabular}




\begin{tabular}{|c|c|c|c|c|c|c|c|c|c|}
\hline & $\begin{array}{l}\text { Professional } \\
\text { Background }\end{array}$ & $\begin{array}{c}\text { Interaction with } \\
\text { Colleagues }\end{array}$ & $\begin{array}{l}\text { Contribution of } \\
\text { School Mission }\end{array}$ & $\begin{array}{c}\text { Perception of } \\
\text { Resources }\end{array}$ & $\begin{array}{c}\text { Perception of } \\
\text { Reward } \\
\text { Structure }\end{array}$ & $\begin{array}{l}\text { Perception of } \\
\text { Leadership }\end{array}$ & The use of TK20 & $\begin{array}{c}\text { Adoption of } \\
\text { Educational } \\
\text { Innovation }\end{array}$ & $\begin{array}{r}\text { Type of } \\
\text { Adopter }\end{array}$ \\
\hline \#5 & $\begin{array}{l}\text { Former teacher; } \\
\text { M.Sc.; Fixed- } \\
\text { Term; } \\
\text { Administrative } \\
\text { positions; } 34 \\
\text { years in overall } \\
\text { teaching; and } \\
21 \text { years at the } \\
\text { current } \\
\text { university } \\
\end{array}$ & $\begin{array}{l}\text { More push back } \\
\text { than positive } \\
\text { impact among } \\
\text { faculty; the } \\
\text { Assessment Team } \\
\text { did well but not } \\
\text { enough. }\end{array}$ & $\begin{array}{l}\text { Don't know much; } \\
\text { Directed and tied } \\
\text { course objectives to } \\
\text { conceptual } \\
\text { framework but no } \\
\text { evidence of learning. }\end{array}$ & $\begin{array}{l}\text { Not aware of } \\
\text { the available } \\
\text { resources; }\end{array}$ & $\begin{array}{l}\text { No reward } \\
\text { structure. }\end{array}$ & $\begin{array}{l}\text { Have been doing } \\
\text { great job to get the } \\
\text { school through } \\
\text { accreditation; }\end{array}$ & $\begin{array}{l}\text { Thrilled with the } \\
\text { idea but was off } \\
\text { the marks; Does } \\
\text { not provide good } \\
\text { parameters; } \\
\text { teaches us } \\
\text { nothing. }\end{array}$ & $\begin{array}{l}\text { Eager to } \\
\text { learn new } \\
\text { things; Jump } \\
\text { in front end } \\
\text { of the curve; } \\
\text { Risk-taker. }\end{array}$ & $\begin{array}{l}\text { Early } \\
\text { Majority }\end{array}$ \\
\hline \#6 & $\begin{array}{l}\text { Former teacher; } \\
\text { Ph.D; Associate } \\
\text { Professor; } \\
\text { Program } \\
\text { Coordinator; } 34 \\
\text { years in overall } \\
\text { teaching; and } \\
21 \text { years at the } \\
\text { current } \\
\text { university }\end{array}$ & $\begin{array}{l}\text { Clear message } \\
\text { about assessment; } \\
\text { Conversations at } \\
\text { the data collection } \\
\text { level. }\end{array}$ & $\begin{array}{l}\text { Very much; } \\
\text { Research-based } \\
\text { practices \& Evidence } \\
\text { informed decision } \\
\text { making come a lot in } \\
\text { conversations. }\end{array}$ & $\begin{array}{l}\text { Yes, support } \\
\text { and resources; } \\
\text { TK20 and } \\
\text { Human } \\
\text { Resources. }\end{array}$ & $\begin{array}{l}\text { Not aware of } \\
\text { one; Doing it } \\
\text { because we are } \\
\text { told to and } \\
\text { provided with } \\
\text { rationale. }\end{array}$ & $\begin{array}{l}\text { Great leadership; } \\
\text { Healthiest place; } \\
\text { Flexibility; } \\
\text { Leadership exceed } \\
\text { the expectations; }\end{array}$ & $\begin{array}{l}\text { Was impressed } \\
\text { by the decision; } \\
\text { Glad to have it } \\
\text { but hard to use; } \\
\text { Get necessary } \\
\text { support; }\end{array}$ & $\begin{array}{l}\text { Open to new } \\
\text { ideas and } \\
\text { innovation; } \\
\text { Observer and } \\
\text { Risk-taker at } \\
\text { the same } \\
\text { time. }\end{array}$ & $\begin{array}{l}\text { Early } \\
\text { Majority }\end{array}$ \\
\hline \#7 & $\begin{array}{l}\text { Former } \\
\text { Teacher; Ph.D; } \\
\text { Associate } \\
\text { Professor; } \\
\text { Program } \\
\text { Coordinator; } 42 \\
\text { years in overall } \\
\text { teaching; and } \\
17 \text { years at the } \\
\text { current } \\
\text { university }\end{array}$ & $\begin{array}{l}\text { Collegial } \\
\text { conversations in } \\
\text { the offices or in } \\
\text { the hall; individual } \\
\text { initiation of formal } \\
\text { meetings; not } \\
\text { intentional \& } \\
\text { systematic }\end{array}$ & $\begin{array}{l}\text { Yes Research-based } \\
\text { practices. }\end{array}$ & $\begin{array}{l}\text { More time } \\
\text { provided before } \\
\text { NCATE; } \\
\text { Attention to } \\
\text { assessment is } \\
\text { not grounded. }\end{array}$ & Not much. & $\begin{array}{l}\text { Very clear climate of } \\
\text { program } \\
\text { improvement due to } \\
\text { the new leadership; It } \\
\text { was a huge help; } \\
\text { Feel positive about } \\
\text { the leadership. }\end{array}$ & $\begin{array}{l}\text { Needed really } \\
\text { good database; } \\
\text { Little less person } \\
\text { in electronic } \\
\text { environment. }\end{array}$ & $\begin{array}{l}\text { More } \\
\text { reflective; } \\
\text { Would like } \\
\text { to wait and } \\
\text { see; Go with } \\
\text { the ideal } \\
\text { possibility. }\end{array}$ & $\begin{array}{l}\text { Early } \\
\text { Adopter }\end{array}$ \\
\hline
\end{tabular}




\section{Institutional Characteristics}

Subquestion 3. How do faculty members' social-knowledge impact their participation in assessment activities?

3a. Interaction with colleagues in regards to assessment. Faculty members were asked about their interaction with colleagues on assessment related topics and interview results revealed that most faculty members did see some levels of interaction happening among their colleagues but it is certainly not enough, not intentional or systematic.

There are not enough forums to talk about assessment. We find our department meetings are devoted to other pragmatic concerns. That said, we still have some conversation every year about program assessment... it is still coming.

We talk more about the problem students and the problem areas and I can understand that but sometimes the problem areas are too big. We need questions to dig some of these...

Yes but don't feel like it is intentional and systematic...I think myself small groups, program levels are at the stage of saying, what is it that the data we have and what we can learn from it and what is to come of that or what should be learning more about and then in creating occasions where we talk about our students learning and programs for the purpose of program improvement.

Contrary to those faculty, two participants thought that there is a negative attitude toward assessment among faculty members. They said:

...you say the word 'assessment' and a growl goes up from... we look at assessment as somebody is going to beat us with a stick. All the joy of that anticipation, please please don't break a bone.

I think there is some push back more so than positive. And I think that built over time. I think [Associate Dean name] did a wonderful job of winning faculty back over. And it I don't know there is some negative connotations that people will just jump in and say ohh look there is some work I am going to do that.

One faculty member said that the small program within the Curriculum and Instruction department share the results among its faculty but not at the teacher education 
program level. Another faculty admitted that he/she uses the excuse of time for not sharing the assessment results with others. In terms of working with a colleague, two faculty members affirmed that they collaborate with another colleague to conduct assessment. Another faculty pointed out the synergy to help each other especially about the use of TK20. One faculty member did not see any climate to work together with a colleague within the department.

\section{3b. The perception of school mission / conceptual framework in relation to}

program assessment. Almost all faculty members agree that the school mission and the conceptual framework for the school of education contribute to the idea of assessment. In particular, one of the faculty members said that there are elements of assessment in the conceptual framework, while another one stated that research and assessment are imperatives. Also, another faculty member pointed out that the connection between assessment and conceptual framework was clearer when there was a conversation initiated by the Associate Dean and continuous conversation helped. There was only one faculty member who did not see any connection between these two.

Yes, very much so. It is another example of how mandating the structural elements, everybody put the Conceptual Framework in their syllabi... all that familiarity when you start talking about it, it does make you think about it.

I think for some of my colleagues really, it helped them to think about assessment differently.

I think it serves. Think about our university mission... as far as [school name] vision statement, I also think assessment and research are imperatives.

3c. The perception of resources provided for program assessment. In their model to explore faculty productivity, Blackburn and Lawrence (1995) claimed that the main 
impact on the faculty behavior and productivity comes from social knowledge, how faculty perceive their environment particularly leadership, administrative support and resources. The interview results showed that faculty members find it valuable to have human resources, structures and other investments to support the assessment activities. ... an assessment task force, and support from the department chair... the use of more staff to be able to input and export data, so there could be whole cadre of people...

Well there has been certainly support and resources devoted to use for program key assignments, program conduct exit surveys. It was mostly human resources.

Moreover, two faculty members think that the focus on assessment shifts after the accreditation visit; therefore, it should be built into organizational culture.

There is still more support needed by faculty; calendar for program assessment strategies.

Well, I think there is more time provided but it was a run up to NCATE... I think what happened after the visit is that the program gets...gets back to other things that have been put on hold... So I sort of separated those two, accreditation and getting back to other program matters.

....as far as I can tell, no one is taking over what the Assessment Task force was doing and which is really concerning. The resources have to be there, they have to have that support system to keep us going.

what do we use faculty members' time to do? I am spending my time to do clerical work. I could spend my time for analyzing the data. I think sometimes it is good to have that staff level support.

Three faculty stated that they are not provided with necessary resources and assessment is not really being a focus in the school.

They are not even in our agenda. Assessment is not our real business.

Not aware of it. Will have some grant money in collaboration with another faculty and will have grad assistant to help in partnership project that the faculty is 
working on. I am excited to know that I may have support... In the past, whatever I looked at, I did it my own. I did my own research.

I do all my program evaluation work outside the school of education. Not aware of the resources.

3d. The perception of reward structure for program assessment. Five out of seven faculty members reported that there is no reward structure available for conducting program assessment in the school. They said:

What reward structure? ...I don't think there is any reward structure for program assessment. There is certainly for publication which is not necessarily for assessment.

I am not aware of any reward structure. Is there any reward structure currently?

I don't think there is much incentive to do that.

While one faculty said that program assessment should be part of the tenure and promotion criteria to encourage faculty motivation, another faculty member articulated that conducting assessment is part of faculty members' job, therefore, there is no need to have additional reward structure for faculty to do their job.

I don't think there is a reward structure set up for doing our jobs other than the fact that we get self-satisfaction for.

It was also pointed out that it should be integrated in one's work but since [university name] is not a top-tier research university such environment is not encouraged.

...that is a good think to be able to connect one's research agenda and one's work. That to me like an integrated life but to actually have time to do that research and analyze that data and to find time to write about it, not supported by this institution given the credited work load that is expected.

One faculty member stated that there used to be resources in the past but not seeing it anymore. 
I have not seen. I came in here in ' 87 and how many years is that? Twenty-three years. I have not seen any. When I first came here there were those connections.

3e. The perception of leadership on program assessment. Leadership was found

to be one of the key factors that influence faculty members' behavior similar to

Blackburn and Lawrence's (1995) findings. In this study, the new leadership's vision, a

persistent message on assessment, the conceptual framework, the provision of resources

and structures to support assessment activities were acknowledged by the faculty. Four

faculty referred to leadership as doing a great job, inclusive, flexible, and supportive.

It is always people, cause [Dean's Name] led it was a big part. I think having [graduate assistant's name] and [the Associate Dean's name] those were huge components to having us the buy in. The matter of work [the Associate Dean's name and graduate assistant's name] do it those kinds of things, it would not happen.

...it would not have happened without the department chair's leadership saying let's try this [case studies] and see what happens. And I think that my perception is that she also had the opportunity to do because the department chair was getting the support she needed from the Dean's vision and leadership.

Besides, the support from the leadership was seen more broad base approach to move forward in assessment activities including people from various levels.

I think there has been leadership and that leadership from the like the Dean's office, through coordinating council through our chairs. But this has been also from the staff and a fixed term and other faculty who agreed to serve Task Force.

While some faculty members acknowledged the existing work, they also stated that there needs to be more structuring from upper administration to create sustainable assessment systems. They commented on the amount of focus that has been given to assessment for accreditation visit and said that the work has been slowed down. 
I think we pay attention when the accreditation is coming and again it kinda trails down.

I think we ramped up crazy and everybody was relieved and happy then we went down the hill. Everybody backed up and then all of our focus back on whatever your personal assignment.

\section{Outcomes}

Subquestion 4. How do faculty evaluate their participation in program assessment activities?

4a. The use of TK20 in program assessment. Faculty members were asked their first reaction to TK20 and almost all faculty said that they understood and liked the idea of assessment software and they were excited to have electronic data gathering tool.

However, their reaction has changed over time as a result of their experience with TK20.

I like the concept... I am not sure if TK20 is the product. I become more and more sensitive to some of the issues...accessing TK20, the confidentiality of TK20.

When I hear about we are going to have online record, I was thrilled. I was actually glad to think ok finally we are moving to technology age. It is going to support our admission and all of this work. But it has not been that way.

I was impressed with it simply because I realized that it was an investment that required resources... I am very glad we have it... I think it is hard to use.

Five faculty members out of seven disagreed with the use of TK20 as an assessment software in the school of education. They described TK20 as hard to use and not the right product to collect program assessment data. Even though faculty are in favor of using technology to systematically collect data on student learning, they did not find TK20 effective and easy to manipulate the data.

I like the concept, the concept of a portfolio and having a place electronic repository where you can have the information that you need is to me still and I 
know it is still evolving. It has not quite achieved but I like the concept. I am not sure if TK20 is the product.

I know what they are trying to do with it. It is kind of data gathering approach. So, it has got a lot of problems with it.

Some of the language that they used to disclose their opinions is laborious, timeconsuming, waste of time, unethical disaster, poorly designed. Even though faculty members were in favor of using a database to collect data on student learning, they mentioned that besides its technical glitches, TK20 is far from providing quality data on the level of student knowledge, skills or performance.

It takes me longer to use that system that it would take me on paper-pencil to evaluate my students' work...I have been using TK20 for couple of year and I have not found it gets remarkably faster... it is still clunky.

I think TK20 could provide some really good parameters but it has been way off the marks so far in my opinion. I have learned nothing viable from it.

I think it has more to do with laborious, poorly designed aspect of it than the intent... It is a very good idea, but very poor program, poor technically...

Faculty members were also asked about the usefulness of TK20 to teaching, learning and program assessment. Four out of seven faculty members declared that TK20 was not very useful to teaching and learning, while two faculty expressed some of the benefits of using TK20 for program assessment. Data gathered on key assignments, work sample, and field experience were among examples given for program assessment activities. One faculty believed that faculty were still trying to figure out how to best utilize TK20 and that the school is just getting to that point.

4b. Adoption of educational innovation. Roger (1968) discussed that there are various reasons why people adopt a new idea or practice. It could be related to the relative advantage of innovation, consistency with the existing values, or simply could be 
related to the complexity, trialability or visibility of an innovation. To identify some of these reasons, two questions were directed to the faculty members. In the first question, which is at a more general level, most faculty members were acquainted with the idea of innovation and stated that they are open to new ideas and like to try new innovations in the field of education. With this question, faculty members mostly evaluated their ability to adopt a new technology in this case TK20. Faculty members claimed that their roles and responsibilities require using innovation or integrating innovation into their teaching practices.

I tend to be the one who would like to jump in front end of the curve. So, I think I am eager in learning new things.

I would like to consider myself as pretty open to new ideas and innovation...I do pride myself being an effective teacher so I think in order to do that I need to constantly improve my teaching.

I think my job is to use innovation, to incorporate innovation as quickly as I can. So again, that is part of the job to do that.

In response to the second question which specifically focuses on the adoption of assessment activities, most faculty members, identified themselves as either Early Adapter or Early Majority in relation to program assessment activities.

\section{Summary}

According to the data analysis, the following factors were found to be in relation to faculty participation:

- Faculty professional background,

- Faculty beliefs, attitudes and practices of assessment

- Leadership 
- The connection to faculty beliefs

- Work environment

- School Vision

- Systematic Assessment Framework

- Resources and Reward Structure

- Collegiality

- Professional growth

- Academic freedom

- The use of educational innovation

- Type of users of innovation

These factors were categorized under Individual Faculty Characteristics, Institutional Characteristics, Elements of the Work Experience and Faculty Behavior based on the two theoretical frameworks. In the next section, I elaborate how these factors impact faculty behavior and further analyze the implications of these factors on faculty participation. I also present the strategies/suggestions to create meaningful and effective work environment for faculty. 


\section{CHAPTER VI \\ DISCUSSION AND CONCLUSION}

The purpose of this study was to explore the factors that impact faculty decision making in participating in assessment activities. In an effort to create assessment activities that are built in organizational cultures for program improvement, higher education leaders, change agents and faculty themselves need to be more reflective on the process. In this regard, findings of this study provided certain perspective on what faculty beliefs were, and how their attitudes were shaped by certain factors in addition to their actual assessment practices. This perspective will help higher education leaders, faculty and academic staff to design sustainable, meaningful and systematic structures for faculty members that have direct impact on faculty decision making as Blackburn and Lawrence (1995) claimed. Therefore, in this chapter, I discuss the implications of these factors in higher education institutions. I further develop suggestions to higher education leaders that will lead to more meaningful and sustainable assessment systems.

\section{Designing Assessment Activities in Professional Bureaucracies}

Higher education institutions are defined as professional bureaucracies, which have trained specialists in their field with a significant control over their work and responsibilities (Mintzberg, 2000). Gappa et al. (2007) also considered faculty academic 
freedom and autonomy in the classroom, research and in service areas as essential elements of faculty work. Even though faculty are autonomous and value academic freedom and flexibility in their work environment (Gappa et al., 2007), they also seek leadership, systematic and an ongoing framework to carry on certain roles and responsibilities of which they are being asked. Faculty interviews in this study indicated that faculty members value leadership as one of the most significant factors for them to perform various roles.

Gappa et al. (2007) also listed leadership within the institutional characteristics as one of the elements to be considered in apprehending faculty work life. Similarly, Blackburn and Lawrence (1995) stated that in order to comprehend how faculty make decisions in their work life, one should look into how faculty evaluate their work environment within a given institution. In the literature, there are numerous research studies that have examined the impact of leadership on faculty involvement in academic initiatives. Farmer's (1999) findings on motivation for institutional improvement, the research studies of Eainarson (1998) on professional development regarding assessment and of Grunwald and Peterson (2003) on the factors promoting faculty involvement also showed that strong existence of leadership and administrative support were effective on the faculty decision-making process in their work life. Faculty members in this study also stated that after the new Dean and the Associate Dean for Academic Affairs came in, they felt that there was a clearer sense of direction for program assessment activities. Organizational climate supported by the school mission, conceptual framework, human resources, assessment software and the new infrastructure was clearly recognized by 
faculty and impacted their decision making on involvement in program assessment discussions and activities. Two faculty members specifically pointed out the difference between the previous deans and the current ones and recognized the visibility of leadership in program assessment activities. Consistent messages and presentations on assessment were also appreciated by faculty members. Even though faculty members recognized the effort by the new leadership, and some level of conversations on assessment data, they indicated that there needs to be more structure for building an ongoing and systematic assessment. They also valued the existence of the Assessment Task Force with representatives from various departments that carried over the messages across the school.

Considering my seven years of experience at the research site, it was evident to me that leadership played a key role in the adoption of assessment activities both at the university and school/college level. When I first started working at the Center for Academic Excellence in 2004 at the university level, numerous assessment initiatives had already occurred and faculty members were very resistant to those initiatives. As a result of my encounter with faculty members from different academic disciplines, I observed that this resistance was rooted in the nature of the processes rather than the assessment itself. First, the rationale behind assessment was not clear to some faculty members; they were not clear about what they were being asked to do. Furthermore, faculty members did not feel connected to assessment activities because of terminology that was used. Second, due to several leadership changes in the Center, the faculty members thought that they were being asked for something new every time there was a new assessment initiative. 
The lack of planning and information, in addition to miscommunication, resulted in faculty resistance. Assessment was seen as an additional task that faculty members were expected to do to meet the accreditation requirements. In other words, faculty beliefs of assessment were based on some of the misguided processes rather than on the benefits of assessment for student learning. After the regional accreditation recommendations, the university assessment council was formed to provide centralized leadership and guidance on assessment which was a more structured and inclusive attempt by the university leadership.

A similar situation occurred at this research site with the new leadership as mentioned earlier. Before the leadership change, there were more individual efforts at the administrator level. The assessment activities could have been perceived as top-down to meet the requirements of the national and regional accreditation. After the change in leadership, the immediate infrastructure and the necessary resources and assessment activities were planned with the inclusion of various departments and programs. There were more consistent messages, clear vision, and focus on the idea of assessment for improvement. Then, the actions of the new leadership followed this vision which provided a structured framework in faculty members' eyes for ongoing assessment activities. In summary, the paradigm shift from assessment for accountability to assessment for improvement was initiated in the School of Education. It is important to note that faculty members explicitly stated that leadership should continue working on this paradigm shift particularly after the accreditation visit was over. 


\section{Compatibility of Adoption}

The need for connectedness of faculty beliefs regarding the program assessment activities has been another important finding that may accelerate faculty participation. Exploring how faculty members define assessment, what their beliefs are and how much they value assessment are indicators to interpret faculty behavior and productivity (Blackburn \& Lawrence, 1995). Knowing how faculty interpret the given initiative or their roles gives an opportunity to relate this perspective to the institutional one. This can be a critical component in creating meaningful work experience for faculty and promoting faculty engagement.

Given that faculty members represent "the intellectual capital" (Gappa et al., 2007, p. 323) to achieve institutional missions, they need to be in line with their institutions at the intellectual and philosophical level to a certain degree. If faculty members define program assessment differently from the institution itself, a gap in communication may result. In this case study, it was found that faculty members define assessment based on their career preparation, knowledge and experience with regard to assessment. While some faculty may only consider classroom assessment, others interpret assessment on multiple levels including self-evaluation and professional growth. As one faculty claimed, faculty members were not involved in assessment because they may not have distinguished the difference between individual student assessment and program assessment. Another example from my experience is the terminology that we use while introducing or talking about assessment. Depending on the discipline, faculty members may have different terminology regarding assessment, which becomes may be 
challenging to create meaningful work environment for faculty where they feel connected with the work they have been asked for.

In this study, it was found that the definition of assessment and the use of terminology could be different for every faculty. The difference described by faculty members between program evaluation and program assessment affects the way assessment is being designed and consequently the faculty participation. Considering that program assessment and research require similar knowledge and skills, the data on faculty members' skills and research paradigms becomes important to determine what kinds of assessment tools should be used in a given setting.

All these findings regarding the connection to faculty beliefs bring us to Rogers' (1968) characteristics that affect the rate at which people adopt an innovation. According to Rogers (1968) compatibility, the degree to which an innovation is perceived as being consistent with the existing values, past experiences and needs of potential adopters, is one of the factors that explains the rate of adoption. In this case study, compatibility helps determine the impact of philosophical dissonance on faculty adoption of program assessment. With regard to existing values, the compatibility of faculty members' research paradigm and preferences with the school's values draws some attention. If the existing values of faculty in terms of collecting assessment data do not fit the current paradigm in the school, this would result in a low adoption rate. Considering that most faculty interviewed in this study prefer or feel confident in qualitative research, numerical assessment data provided by TK20 can be problematic. Two faculty members mentioned that they would like to have multiple data sources or qualitative data in assessment 
activities. That is why the case studies in the Curriculum and Instruction program, indicated by faculty members, might have an important role in increasing faculty involvement in assessment. After a year of TK20 implementation, the department chair introduced the idea of case studies where faculty could develop research questions related to the program and explore those questions through case studies. Faculty in this study reported that as a result, they conducted research that is meaningful to them; they analyzed and presented assessment data in conferences which is an ideal scenario for embedding assessment in faculty members' professional lives.

Rogers also considered the impact of past experiences in adoption of an innovation. In other words, career preparation or past experiences of faculty in assessment may affect their adoption of program assessment. For example, in the interviews, most faculty members talked about their research courses as evidence of formal training on assessment, while some others brought up their assessment knowledge from their K-12 teaching experience. If we are to accept the difference between program and classroom assessment, then this conveys another area of incompatibility regarding program assessment and it needs to be clarified through professional development.

\section{The Relationship between Faculty Self- and Social Knowledge}

In Blackburn and Lawrence's (1995) model, self - and social- knowledge are interrelated; that is, self-knowledge has a strong and direct effect on social-knowledge. Furthermore, social knowledge may have a slightly weaker impact on self-knowledge, while social knowledge has a strong and direct impact on faculty behavior. The application of this relationship to the idea of faculty participation would be that their 
definition of program assessment, their actual practices, and beliefs about the role of assessment in their work life affect the way they interpret their work environments. Based on self and social knowledge, faculty members make decisions that are most meaningful to them within their circumstances.

When we look at the interview results, there is no doubt that faculty members have an interest in and beliefs about the benefits of assessment in their work life for various reasons such as student learning, effective teaching, getting feedback, professional growth, role modeling student teachers. They are also committed to using different methods of data collection on student learning: formative and summative assessment, prior knowledge, performance, and midpoint assessment, exit slips and course evaluations. Aside from teaching, faculty self-reports show that they use assessment in their research and service responsibilities, implying a further commitment to program assessment no matter what their academic rank.

Most important, faculty members explicitly said that program assessment is part of their work life and should be seen as a way to improve oneself, their teaching and learning practices and student learning. Comments on accreditation self-study also proved that did not feel the program assessment required by accrediting bodies but as a key process to ensure that the school is examining their practices to improve the curriculum and student learning.

Considering those faculty members' interest, commitment, beliefs and actual practices regarding assessment, it is not surprising to find that almost all faculty members, who were interviewed, see the school mission and the conceptual framework 
contributing to the idea of assessment. They highly value the clear vision and leadership in addition to human resources, structures and other investments to support the assessment activities. In this case, the positive work environment obviously had an impact on faculty participation in assessment activities even though they saw no reward structure available for conducting assessment.

\section{Socio-Demographic Characteristics and Career Preparation}

Blackburn and Lawrence (1995) stated that socio-demographic characteristics and career preparation are two of the variables in their models over which higher education leaders have less control. For instance, the finding on faculty members who have had more teaching experience in K-12 education compared to higher education is a less controllable variable. Due to the nature of the school in this study, faculty members were very experienced in overall teaching which may be interpreted as a facilitator by some in understanding the dynamics of assessment and the necessities of program assessment activities.

However, there was only one faculty who had formal training in assessment, which directly impacted the faculty's participation. Most faculty members mentioned the research methodology courses from their graduate education. Weidman, Twale, and Stein (2001) compiled the literature on graduate student socialization and they found that graduate school plays a key role for future faculty in the sense that they acquire knowledge and skills necessary for their roles as scholars. Similarly, Blackburn and Lawrence (1995) interpreted the socialization theory for faculty which predicts that norms and values faculty hold are products of graduate school experience. They further 
discussed the impact of this experience on faculty development of academic freedom, and their desire to control the conditions of work environment. These beliefs, attitudes and values, they said, endure throughout one's academic career. Therefore, this finding has a vital implication for the current graduate education programs where they need to prepare professionals to have better background in teaching, learning and assessment. Because the research site was the School of Education, its faculty already had a good grasp of teaching, and learning theories as well as assessment practices.

\section{The Selection of Resources}

In this study, it was found that the selection of resources, particularly technology, needs to be considered carefully. Technology to collect assessment data was another factor impacting program assessment involvement in this case. Faculty in this study reported the complexity of the software interfered with the purpose of using technology for easy management of data collection. Even if technology was not defined as an innovation in this study, it was definitely associated with program assessment by most faculty in this study who said that TK20 was hard to use and understand, which resulted in developing negative connotations about program assessment. Therefore, the complexity of TK20, as Rogers (1968) discussed, has become a barrier to faculty adoption of program assessment. Here, it is important to note that faculty members were not against the idea of using technology but the product itself.

\section{Change in Higher Education with Faculty Owned Processes}

As mentioned earlier, any type of change will require some level of examination and analysis, before choosing a change model (Kezar, 2001). This study can be perceived 
as that level of examination where structure, process and attitude related elements of a given organization were explored. The next step would be to identify a change model that embraces these elements or factors in this study. Exploring the factors affecting faculty behavior is substantial for several reasons. First, it helps higher education leaders learn about their faculty, who they are and how they make decision. Second, it provides a baseline for any given change initiative. Third, it fosters the development of strategies to work effectively with faculty members. Faculty are the operating core of higher education, and they can contribute to the organizational change the most. Change in higher education with faculty owned processes will be more enduring and sustainable.

In this study, one of the assumptions was that program assessment can be used as a reflective tool that will lead to curricular changes with the ownership of faculty members. Because assessment movement on most campuses has resulted in limited faculty participation, my intention was to identify possible factors for limited faculty involvement and to develop strategies for higher education leaders. Knowing some of the possible factors impacting faculty involvement will not be sufficient to have successful implementation of assessment practices. Higher education leaders will also need a bigger framework where they can integrate those factors into an existing culture. Ewell (1997) and Angelo (1999) stated that limited faculty participation also happens because the effort is too mechanistic and the model of assessment is additive. A more transformative assessment model would bring a culture of change rather than mandatory and temporary assessment activities. 
Senge's (1994) system thinking model offers a participative approach throughout the levels of an organization rather than a top-down approach. In order to achieve a certain goal, Senge suggested that one needs to comprehend system structure, which is defined as "the pattern of interrelationships among key components of the system" (p. 90). System structure involves hierarchy and process flows as well as attitudes and perceptions held by members of an organization. If an institution embraces a systems thinking approach, there are multiple layers to be worked with in order to create change in assessment culture - in this case increasing faculty participation.

Parallel to Senge's (1994) model, this study found that faculty members' beliefs and attitudes carry more weight than in some other constructs; thus, administrators and change agents need to ascertain faculty knowledge, attitude and beliefs toward assessment and to take this into account as they build structures within the organization. Without sufficient or accurate knowledge as to what faculty know and believe in and their beliefs toward assessment, there is less probability of creating a sustainable assessment system. Consequently, the structures developed will not respond to faculty needs, which will, in turn, continue to inhibit participation.

Another comprehensive model guiding change and innovation in higher education is provided by Lueddeke (1999) called the Adaptive-Generative Development Model (AGDM). Lueddeke stated that Senge's adaptive or survival learning may not be enough as we approach the next millennium. Lueddeke commented that choosing only one or two lenses, depending on the nature of change intended, might be misleading or result in unexpected consequences. Therefore, he proposed a multidimensional model. According 
to Lueddeke (1999), “in today's world, higher education must learn not only how to adapt to external and internal circumstances but also to act [sic] creatively - with increasing resolve -in generating solutions to problems, pedagogical or otherwise" (p. 241). A-GDM is an open/verbal model rather than a predictive or mathematical one. It is considered to be an organic rather than mechanistic process that is based on observations and reflecting on enacting change in higher education. As seen in Figure 5, the model has six main categories: needs analysis, research development, strategy formation and development, resource support, implementation and dissemination, and evaluation. Each category has subcategories that explain various aspects of change. Needs analysis is related to academics where change in existing human knowledge, skills or attitudes can bring about the desired performance (Morrison, 1976). Research and Development explores how different people address the same problem, once the need is defined. Strategy Formation and Development is the phase where people who are impacted by change discuss the options. This is a collaborative decision making process. Resource support is providing resources based on evidence of need after appropriate research has been conducted. Implementation and Development and Evaluation are the phases where actual implementation of suggested change and sharing the results of implementation and evaluation occur. 


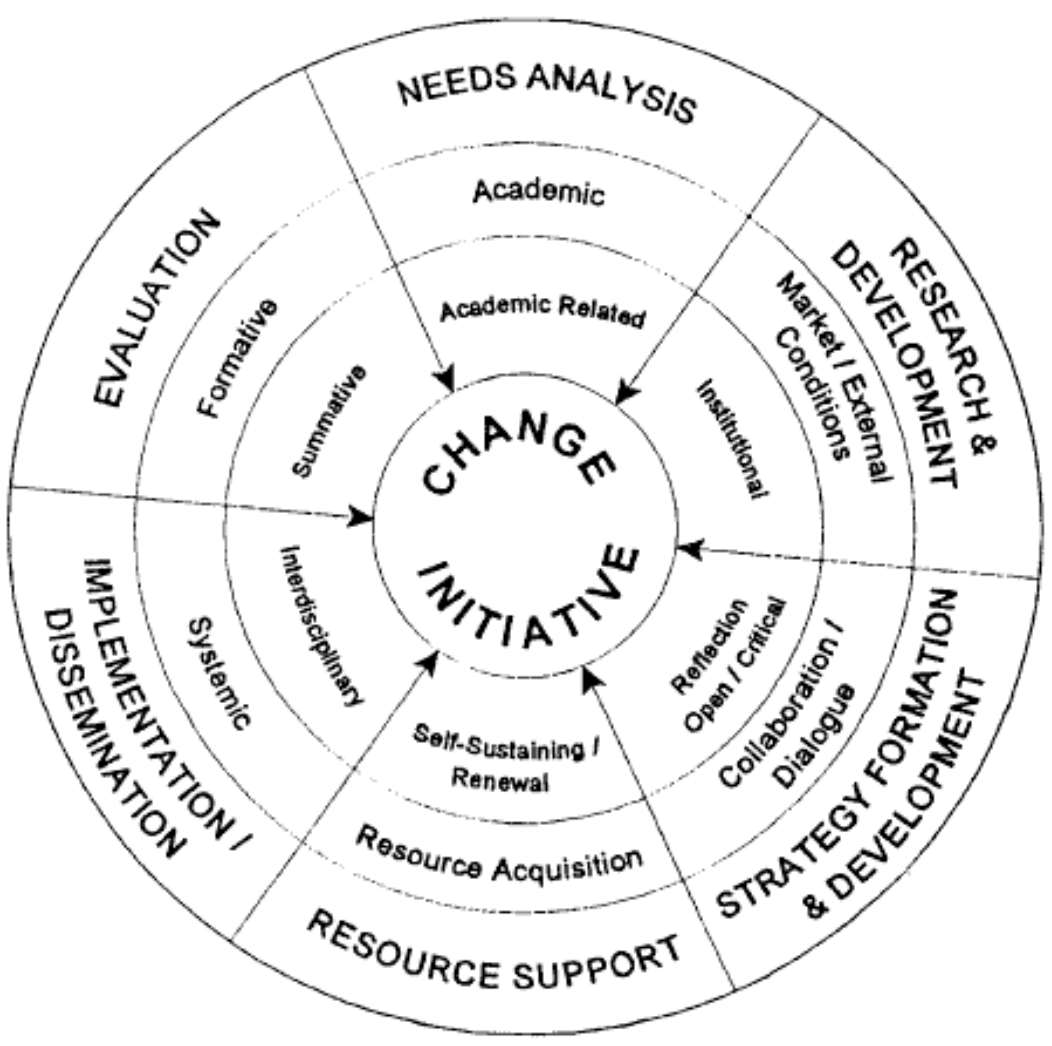

Figure 5. Adaptive-Generative Development Model. Source: Lueddeke (1999).

This model could be particularly useful for assessment activities since it provides a whole-system approach. It involves the various stages of the change process and provides enough flexibility for contextual factors. Regarding the focus of this study, faculty involvement and perceptions around assessment, the model advocates less reliance on objective data and more concerns about the inclusion of change participants in the developmental and implementation process (Lueddeke, 1999). Specifically, the Needs Analysis phase ensures that higher education leaders or change agents start with exploring and understanding the need for change, existing systems, values, beliefs, knowledge and attitude of participants toward the suggested change or innovation. Also, this model was designed to consider challenges in teaching improvements in academia 
such as resource constraints, function of political dynamics, human resources and collegial dimensions. The findings of this case study clearly support the idea of the Needs Analysis phase for it displays the faculty members' previous knowledge, career preparation, their beliefs, and actual practices of assessment. Furthermore, the study reflects on how faculty evaluate the resources, leadership, and other work environment characteristics that have impact on faculty participation.

Kezar (2001) summarized that A-GDM was structured to address unique environments of higher education, where shared governance and academic values are highly valued. I believe that faculty involvement in any change process needs this type of sensitive, thoughtful approach that appreciates and honors academic values. Kezar (2001) also mentioned the importance of attitudes in the change process, where attitudes "focus on how people feel about working within the existing structures and processes of the organization" (p. 19). She added that change in attitude is linked to change in culture. Thus, deeper understanding of faculty attitude would provide a reflective perspective on efforts to instigate change within the institutional structure and practices. Both of the organizational change theories described are comprehensive in the sense that they include various dimensions of a change effort.

\section{Suggestions for Higher Education Leaders}

One of the purposes of this study is to generate strategies for higher education leaders to ensure organizational climate and systematic processes to create sustainable and meaningful work environment for faculty. The following recommendations are 
developed based on the factors that impact faculty behavior and productivity in program assessment.

Recommendation 1- Higher education leaders need to be aware that faculty members expect administrative support and systematic structure to pursue their roles and responsibilities.

A clear vision and an ongoing framework through which faculty can conceptualize the overall task are some ways to support assessment practices. Specifically, the leaders can structure assessment committees, or councils including representatives of various programs and departments within the school. They can also provide conceptual framework outlines for assessment activities in a given setting.

Recommendation 2 -Higher education leaders need to continue assessment activities especially after an accreditation visit which will send a strong message of commitment to faculty members.

This is a critical time to prove to faculty that assessment is valued and performed for improvement in education rather than for accountability or accreditation. Because more effort, time, and resources are provided during the self-study process, assessment may not be perceived as part of the organizational culture but an add-on to faculty roles and responsibilities.

Recommendation 3 - Higher education leaders could use the notion of repeated exposure to an idea.

Some of the practices that leaders can perform to fulfill this notion are consistent messages, assessment presentations in faculty meetings, connecting various tasks forces 
with assessment and continuous individual assistance to programs. Repeated exposure to an idea will create faculty understanding that assessment is an ongoing effort supported by the leadership, not a fad.

Recommendation 4 - Higher education leaders may perform needs analysis to identify faculty beliefs, knowledge and skills, and areas for professional development and to learn about their previous experience pertaining to a given initiative.

As Rogers characterized the adoption of an innovation, the compatibility with the existing values, beliefs and practices will have substantial effect on faculty members' adoption of assessment. Performing needs analysis would assist higher education leaders to identify areas to connect with faculty experiences of assessment. The information from a possible need analysis of faculty expectations of assessment data collection methods, use of assessment data or work environment would be integrated in a given assessment initiative and would accelerate the adoption process.

Recommendation 5 - Higher education leaders should also be aware that unlike career and socio-demographic characteristics, self-perception of faculty, which is directly related to behavior, can be influenced through environmental conditions. Therefore, creating collegial, respectful and compatible work environment is crucial.

Regular faculty department meetings devoted to assessment only, where faculty members can collaborate with their colleagues, discuss assessment data results and make decisions on programmatic changes, would have great advantages in terms of creating such a collegial work environment in addition to all the other suggestions made above. 
Recommendation 6 - Higher education leaders need to pay special attention to the selection process of any technology. Piloting the technology and gathering faculty feedback before decision making will later accelerate the adoption process.

\section{Suggestions for Faculty Members}

The following recommendations based on the literature and the findings of this study are developed for faculty.

Recommendation 1- Faculty may consider how to link their teaching and scholarship with assessment efforts, because it is congruent with their own values and beliefs and becomes part of their professional work.

Recommendation 2 - Faculty members may perceive program assessment as the reflection of who they are and how they are doing as an institution and through developing a sense of ownership and control over program assessment, they can create sustainable processes especially if they do not feel connected with the program assessment activities.

Recommendation 3 - Faculty members may be more intentional in collaborating with their colleagues on assessment work where they can share the workload and bring different perspectives into their teaching.

\section{Implications for Future Research}

Several directions for future research have been identified as a result of this study. First of all, this study was conducted with a program in a professional development school in a comprehensive university where there are scholars from the field of education. Exploring faculty views on program assessment from various academic 
disciplines may provide different results which also allow researchers to determine the impact of academic discipline on faculty behavior. Such information on faculty would provide great benefit to numerous campus initiatives.

An in-depth case study of faculty participation is another direction that can be taken for future research. Since this study is based on faculty self-report, it would be beneficial to collect data on administrators' perspective, and contextual factors through participatory observation, interviews and document analysis regarding program assessment in a given setting. This would also allow researchers to triangulate the data.

A survey questionnaire can be developed to examine the relationships between identified variables and faculty participation in different campuses. This survey could also be adjusted to investigate faculty participation in other similar initiatives related to teaching and learning. As suggested in the set of recommendations to higher education leaders, it can also be used in possible needs analysis to determine where faculty members stand in a given institution.

Another study on faculty work can be the exploration of psychological characteristics of faculty behavior. Specifically, the role of motivation and self-efficacy on faculty work life can be investigated.

\section{Conclusion}

Why is faculty participation in assessment so important? Because it is an essential element of creating faculty-owned change processes in higher education institutions. Paradigm shifts in teaching, learning and assessment, changing student demographics, technology and accountability are some of the many challenges and changes that require 
higher education institutions to continuously transform. Addressing those challenges and reflecting the current changes in actual classrooms take more than resources and established organizational culture. They require a transformation into more dynamic, ongoing and systematic processes, leadership, and most importantly active faculty involvement in institutional change practices.

This case study was conducted to examine the factors impacting faculty involvement in program assessment. It was found that administrative support, leadership, systematic and ongoing assessment framework, compatibility of values, beliefs and philosophy of assessment with existing organizational culture, use of technology and faculty perception of their roles and work environment have impact on faculty participation.

One of the key premises of the Blackburn and Lawrence model was that faculty make decisions through assessing themselves and their social contexts. It can be concluded that the premise is confirmed with this study meaning that faculty members decide to become part of assessment activities based on their professional backgrounds, perceptions of themselves and their work environment. This premise will play a key role in forming any change initiatives that are connected to faculty's self- and social contexts. 


\section{REFERENCES}

Allen, M. J. (2004). Assessing academic programs in higher education. US: Anker Publishing Company Inc.

Altbach, P. G. (2005). Patterns in higher education development. In P. G. Altbach, R. O. Berdhal, \& P. J. Gumport. American higher education in the twenty-first century: Social, political, and economic challenges. Baltimore, MD: Johns Hopkins University Press.

American Association of Colleges and Universities. (2007). College learning for the new global century: Liberal education and America's promise. Washington, DC: The National Leadership Council.

Angelo, T. A. (2002). Engaging and supporting faculty in the scholarship of assessment: Guidelines from research and best practices. In T. W. Banta and Associates, Building a scholarship of assessment (pp. 185-200). San Francisco, CA: JosseyBass.

Angelo, T. A. (1999). Doing assessment as if learning matters most. AAHE Bulletin, 51(9), 3-6.

Astin, A. E. (1991). Faculty values, faculty cultures. In W. Tierney (Ed.), Assessing academic climates and cultures (New Directions for Institutional Research Series, No. 68). San Francisco, CA: Jossey-Bass.

Axinn, W. G., \& Pearce, L. D. (2006). Mixed method data collection strategies. New York, NY: Cambridge University Press.

Banta, T. W. (2007). Can assessment for accountability complement assessment for improvement? Peer Review, 9(2), 9-12.

Banta, T. W. (1997). Moving assessment forward: Enabling conditions and stumbling blocks. New Directions for Higher Education, 100, 79-91.

Banta, T. (1993), Summary and conclusions: Are we making a difference? In T. Banta (Ed.), Making a difference: Outcomes of a decade of assessment in higher Education (pp. 357-376). San Francisco, CA: Jossey-Bass

Banta, T. W., \& Associates. (2002). Building a scholarship of assessment. San Francisco, CA: Jossey-Bass.

Barr, R., \& Tagg, J.T. (1995). From teaching to learning: A new paradigm for undergraduate education. Change, 27, 12-25. 
Berg, B. L. (2004). Qualitative research methods for the social sciences. Boston,MD: Pearson Education Inc.

Bergquist, W. (1992). The four cultures of the academy: Insights and strategies for improving leadership in collegiate organizations. San Francisco, CA: JosseyBass.

Bers, T. H. (2008). The role of institutional assessment in assessing student learning outcomes. New Directions for Higher Education, 141, 31-39.

Blackburn, R. T., \& Lawrence, J. H. (1995). Faculty at work: Motivation, expectation, satisfaction. London, England: The John Hopkins University Press.

Bogdan, R. C., \& Biklen, S. K. (2007). Qualitative research for education: An introduction to theories and methods. Boston, MA: Pearson.

Boyer, E. L. (1990). Scholarship reconsidered: Priorities of professoriate. Princeton University Press.

Cafferella, R. S., \& Zinn, L. F. (1999). Professional development for faculty: A conceptual framework of barriers and supports. Innovative Higher Education, 23(4), 241-254.

Cronbach, L. J. (1975). Beyond the two disciplines of scientific psychology. American Psychologist, 30(2), 116-127.

Denzin, N. K. (1978). The research act: A theoretical introduction to sociological methods. New York, NY: McGraw-Hill.

Driscoll, A., \& de Noriega, D. C. (2006). Taking ownership of accreditation: Assessment processes that promote institutional improvement and faculty engagement. Sterling, VA: Stylus Publishing.

Driscoll, A., \& Wood, S. (2007). Outcomes-based assessment for learner-centered education: A faculty introduction. Sterling, VA: Stylus Publishing.

Eaton, J. S. (2003). Is accreditation accountable? The continuing conversation between accreditation and the federal government. Council for Higher Education Accreditation, 1, 1-22.

Ewell, P. (2008). Assessment and accountability in America today: background and context. Indianapolis, MN: Indiana University-Purdue University, Assessment Institute. 
Ewell, P. (2002). Perpetual movement: Assessment after twenty years. Keynote address to the American Association for Higher Education (AAHE) Assessment Forum, Boston, MA.

Ewell, P. (1997). The role of states and accreditors in shaping assessment practice. In T. W. Banta \& Associates, Making a difference: Outcomes of a decade of assessment in higher education (pp. 3-25). San Francisco, CA: Jossey-Bass.

Ewell, P. (1996). The current pattern of state-level assessment: Results of a national inventory. Assessment Update, 8(3), 1-2, 12-13, 15.

Ewell, P. (1993). A preliminary study of the feasibility and utility for national policy of instructional 'good practice' indicators in undergraduate education. Boulder, $\mathrm{CO}$ : National Center for Education Management Systems.

Farmer, D. W. (1999). Institutional improvement and motivated faculty: A case study. New Directions for Teaching and Learning, 70, 87-95.

Fairweather, J. (1996). Faculty work and public trust: Restoring the value of teaching and public service in American academic life. Needham Heights,MA: Allyn and Bacon.

Feldman, K. A., \& Paulsen, M. B. (1999). Faculty motivation: The role of a supportive teaching culture. New Directions for Teaching and Learning, 78, 71-78.

Fenske, R. H., Rund, J. A., \& Contento, J. M. (2000). Who are the new students? In M. J. Barr \& M. K. Desler (Eds.), The handbook of student affairs administration $\left(2^{\text {nd }}\right.$ ed.; pp. 557-579). San Francisco, CA: Jossey-Bass.

Fine, S. T., \& Nazworth, N. (1999). Learning communities and the academic career: Perspectives on faculty participation. A paper presented at the Creating and Sustaining Learning Communities: Connections, Collaboration, and Crossing Boarders Symposium, Tampa, Florida.

Friedlander, J., \& Serban, A. M. (2004). Meeting the challenges of assessing student learning outcomes. In. A. M. Serban \& J. Friedlander (Eds.), New directions for two-year colleges, No. 126: Developing and implementing assessment of student learning outcomes (pp. 5-16). San Francisco, CA: Jossey-Bass.

Gappa, J. M., Austin, A. E., \& Trice, A. G. (2007). Rethinking faculty work and workplaces: Higher education's strategic imperative. San Francisco, CA: JosseyBass. 
Geiger, R. L. (2005). Ten generations of American higher education. In P. G. Altbach, R. O., Berdhal, \& P. J., Gumport, American higher education in the twenty-first century: Social, political, and economic challenges. Baltimore, MD: Johns Hopkins University Press.

Gilbert, S. (1995). Education, technology and transformation. Community College Journal, 66(2), 14-18.

Gonzalez, K. P., \& Padilla, R. V. (1999, November). Faculty commitment and engagement in organizational reform. A paper presented at the Annual Meeting of the Association for Study of Higher Education, San Antonio, TX.

Gray, P. J. (1997). Viewing assessment as an innovation: Leadership and the change process. New Directions for Higher Education, 100, 5-15.

Gray, P. J. (2000). Campus profiles: Assessment and learning communities: Three examples. Assessment Update, 12(2), 10-11, 15.

Grunwald, S., \& Peterson, M. W. (2003). Factors that promote faculty involvement in and satisfaction with institutional and classroom student assessment. Research in Higher Education, 44(2), 173-204.

Hadden, C., \& Davies, T. G. (2002). From innovation to institutionalization: The role of administrative leadership in the assessment process. Community College Journal of Research and Practice. 26, 243-260.

Hoviland, D., Shin, S., \& Turley, S. (2009). The impact of faculty development on faculty concerns with assessment. A paper presented at the Annual Meeting of American Educational Research Association, San Diego, California.

Huba, M. E., \& Freed, J. E. (2000). Learner-centered assessment on college campuses: Shifting the focus from teaching to learning. Needham Heights, MA: Alynn and Bacon.

Johnson, B., \& Christensen, L. (2004). Educational research: Quantitative, qualitative, and mixed approaches ( $2^{\text {nd }}$ ed.). Boston, MA: Pearson Education Inc.

Kezar, A. J. (2001). Understanding and facilitating organizational change in the $21^{\text {st }}$ century: Recent research and conceptualizations: The ASHE-ERIC Higher Education Report. San Francisco, CA: Jossey-Bass.

Krahenbuhl, G. S. (1998, November/December). Faculty work: Integrating responsibilities and institutional needs. Change, 30(6), 18-25. 
Lopéz, C.L. (2002). Assessment of student learning: Challenges and strategies. The Journal of Academic Leadership, 28(6), 356-367.

Luborsky, M. R. (1994). Qualitative methods in aging research. In J. F. Gubrium, \& A. Sankar (Eds.), Qualitative methods in aging research (pp.189-210). Thousand Oaks, CA: Sage.

Lueddeke, G.R. (1999). Toward a constructivist framework for guiding change and innovation in higher education. The Journal of Higher Education, 70(3), 235-260.

Luker, K. (2008). Salsa dancing into the social sciences: Research in an age of info-glut. USA: Harvard University Press.

Magruder, J., McManis, M. A., \& Young, C. C. (1997). The right idea at the right time: Development of a transformational assessment culture. New Directions for Higher Education, 100, 17-29.

Merriam, S. B. (2009). Qualitative research: A guide to design and implementation. San Francisco, CA: Jossey-Bass.

Mintzberg, H. (2000). The professional bureaucracy. In M.C. Brown II (Ed.), ASHE reader series: Organization and governance in higher education ( $5^{\text {th }}$ ed.; pp. 5070). Boston, MA: Pearson Custom. (Original work published in 1979).

Morgan, D. L. (2006). Integrating qualitative and quantitative methods: A basic framework. Unpublished manuscript. Portland State University, Portland, OR.

Morrison, J. (1976). Determining training needs. In R. Craig (Ed.), Training and development handbook ( ${ }^{\text {nd }}$ ed, pp. 9.1-9.17). New York, NY: McGraw-Hill.

Northwest Commission on Colleges and Universities. (n.d.). title of what was retrieved. Retrieved November 22, 2006 from http://www.nwccu.org

Palomba, C. A., \& Banta, T. W. (1999). Assessment essentials: Planning, implementing, and improving assessment in higher education. San Francisco, CA: Jossey-Bass.

Pascarella, E. T., \& Terenzini, P. T. (1998). Studying college students in the $21^{\text {st }}$ century: Meeting new challenges. Review of Higher Education, 21, 151-165.

Peterson, M. W., Einarson, M. K., Augustine, C. H ., \& Vaughan, D. S . (1999). The institutional support for student assessment: Methodology and results of a national survey. Washington, DC: Office of Educational Research and Improvement. 
Peterson, M. W., \& Einarson, M. K. (1998, April). Analytic framework of institutional support for student assessment. A paper presented at the Annual Meeting of the American Education Research Association, San Diego, California.

Peterson, M. W., \& Vaughan, D. S. (2002). Promoting academic improvement: Organizational and administrative dynamics that support student assessment. In T. W. Banta \& Associates, Building a scholarship of assessment (pp. 26-48). San Francisco, CA: Jossey-Bass.

Portland State University, Graduate School of Education Assessment Website. (n.d.)., Title of what was retrieved. Retrieved on February 10, 2010 from http://www.pdx.edu/gse_assessment/gse

Ramaley, J. A. (1995, January). From "my work" to "our work": Realigning faculty work with college and university purposes. A paper presented at the Association of American Higher Education Conference, Phoenix, Arizona.

Riggs, M. L., \& Worthley, J. S. (1992). Evaluation of student outcomes assessment pilot projects in the California State University. In Student outcomes assessment: What makes it work?. Long Beach, CA: California State University, Institute for Teaching and Learning.

Rogers, E. M. (1968, Winter). The communications of innovations in a complex institution. Educational Record, 67-77.

Rogers, E. M. (1995). The diffusion of innovations $\left(4^{\text {th }}\right.$ ed). New York, NY: The Free Press.

Schulman, P. (2004). Course anatomy: The dissection and analysis of knowledge through teaching. In P. Hutchings (Ed.), Teaching as community property: Essays on higher education (pp. 191-202). San Francisco, CA: Jossey-Bass.

Seidman, I. (1998). Interviewing as qualitative research: A guide for researchers in education and the social sciences $\left(2^{\text {nd }}\right.$ ed.). New York, NY: Teachers College Press.

Senge, P. M. (1994). The fifth discipline: The art and the practice of the learning organization. New York, NK: Currency \& Doubleday.

Serow, R. C., Brawner, C. E., \& Demery, J. (1999). Instructional reform at research universities: Studying faculty motivation. The Review of Higher Education, 22(4), 411-423. 
Shipman, D., Aloi, S. L., \& Jones, E. A. (2003). Addressing key challenges in higher education assessment. The Journal of General Education, 52 (4), 335-346.

Stake, R. (1995). The art of case study research. Thousand Oaks, CA: Sage.

Stark, J. S. Lowther, M.A., Sharp, S., \& Arnold, G. L. (1997). Program-level curriculum planning: An exploration of faculty perspectives on two different campuses. Research in Higher Education, 38(1), 99-130.

Steele, J. M. (1996). Postsecondary assessment needs: Implications for state policy. Assessment Update, 8(2), 1-2, 12-13, 15.

Tashakkori, A., \& Teddlie, C. (2003). Handbook of mixed methods in social and behavioral research. Thousand Oaks, CA: Sage.

Terenzini, P. T. (1989). Assessment with open eyes: Pitfalls in studying student outcomes. Journal of Higher Education, 60(6), 644-664.

Tuckman, B. W. (1978). Conducting educational research. New York,NY: Harcourt Brace Jovanovich.

Trow, M. (1974). The transition from elite to mass higher education. Paris: OECD.

Vanderstoep, S. W., \& Johnston, D. D. (2009). Research methods for everyday life: Blending qualitative and quantitative approaches. San Francisco, CA: JosseyBass.

Weidman, J. C., Twale, D. J., \& Stein, E. L. (2001). Socialization of graduate and professional students in higher education - A perilous pasasage? (ASHE-ERIC higher education report, No.28, 3). Washington, DC: The George Washington University, School of Education and Human Development.

Welsh, J. F., \& Metcalf, J. (2003). Cultivating faculty support for institutional effectiveness activities: Benchmarking best practices. Assessment and Evaluation in Higher Education, 28(1), 33-45.

Wright, B. (2002). Accreditation and the scholarship of assessment. In T.W. Banta \& Associates, Building a scholarship of assessment (pp. 240-2458). San Francisco, CA: Jossey-Bass.

Yin, R. K. (1994). Case study research: Design and methods ( $2^{\text {nd }}$ ed.). Thousand Oaks, CA: Sage. 
APPENDIX A

INTRODUCTORY SCRIPT: EMAIL INVITATION 
Dear

I am a doctoral student from the Graduate School of Education at Portland State University. I am contacting you to request your participation in my dissertation research study, which is a study of higher education faculty in respect to assessment activities. This project has the potential to make a significant contribution to help higher education leaders identify some strategies while working with faculty. The ultimate goal of this study is to elaborate some strategies for higher education leaders

Your participation is voluntary. If you agree to participate in this research project, your confidentiality will be protected and your name and school will not be identified. Your participation in the research process would involve one audio taped interview lasting approximately 60-90 minutes each. Before the first interview, you will be asked to fill out the demographic information sheet.

If you agree to participate, you will be presented with and asked to sign an Informed Consent Letter which explains the specifics of your involvement in more detail. Please let me know if you are interested in participating in this project. For more information, you can contact me by phone at 971-222-9459 or by e-mail at semil@pdx.edu

Thank you for your consideration.

Serap Emil

Doctoral Student

Curriculum \& Instruction

The Graduate School of Education at Portland State University 
APPENDIX B INTERVIEW PROTOCOL 
The presenting statement to begin the first interview is:

- Before we start, I would like to give you a couple of minutes to read and sign the informed consent. I also want to let you know that I will be recording the session, if that is fine with you. Thanks.

- As you may already know your participation in this study is voluntary and you may withdraw from the study at any time. Your name will not be used in the study and your confidentiality will be maintained throughout and following the study.

- Because this study aims to explore faculty members' understanding of teaching, learning and particularly assessment, I believe that it is essential to ask them about these topics. Throughout the interview, I will be using assessment and program assessment interchangeably and by that I mean assessment feeds the decision making process and produce betterment in student learning in the end.

- Therefore, in this interview, I would like to hear your experience in Graduate School of Education with respect to assessment activities.

\section{$\underline{\text { Individual Faculty Characteristics }}$}

1. Tell me briefly about your professional background:

a. What degree have you got and from which institution?

b. How many years have you been teaching?

c. How many years have you been teaching at PSU?

d. Would you mind telling me your gender?

e. What is your academic rank? 
f. Have you worked for any administrative position in the past or currently?

2. Have you had any formal training on assessment? When, where?

3. How would you evaluate your qualitative and quantitative research skills?

4. How do you use program assessment in your teaching practices? Research? Service?

5. How would you describe your philosophy of assessment?

a. Do you believe that assessment is a mandatory activity by the accrediting bodies? Or do you think that it is essential because for betterment in student learning?

b. What do you think about the role of program assessment in faculty members' work life?

6. Let's briefly talk about your TK20 experience within your program.

a. What was your initial reaction to TK20, when it was introduced?

b. Has it changed over time?

c. In what ways, was the implementation of TK20 useful to your teaching and learning practices? To the program improvement?

\section{Organizational Environment Characteristics:}

7. Tell me about your interaction with your colleagues with regard to TK20 and other assessment activities?

a. Do you talk about the assessment results with your colleagues?

b. Do you feel that there is an encouragement from your colleagues to take part in assessment initiatives? 
8. Considering your work environment, do you see the school mission contributing to the idea of assessment in the program improvement?

9. Do you find the resources provided in your school enough to conduct assessment activities? Please explain.

10. Do you think that there is sufficient reward structure for faculty who are engaged in assessment activities? Please explain.

11. How do you feel about the leadership provided within the school and your department for program assessment?

\section{Faculty Participation:}

12. How would you identify yourself as a faculty in adopting a new educational innovation?

- For example, are you more risk-taker or observer of the innovation to see the results of applications when it is first introduced?

- Do you identify yourself as self-sufficient or need support to try a new idea?

\section{Closing questions:}

13. Could you please take a look at this figure classifying the type of users of innovation in any given situation, and tell me where you see yourself as a faculty with regard to assessment activities? 


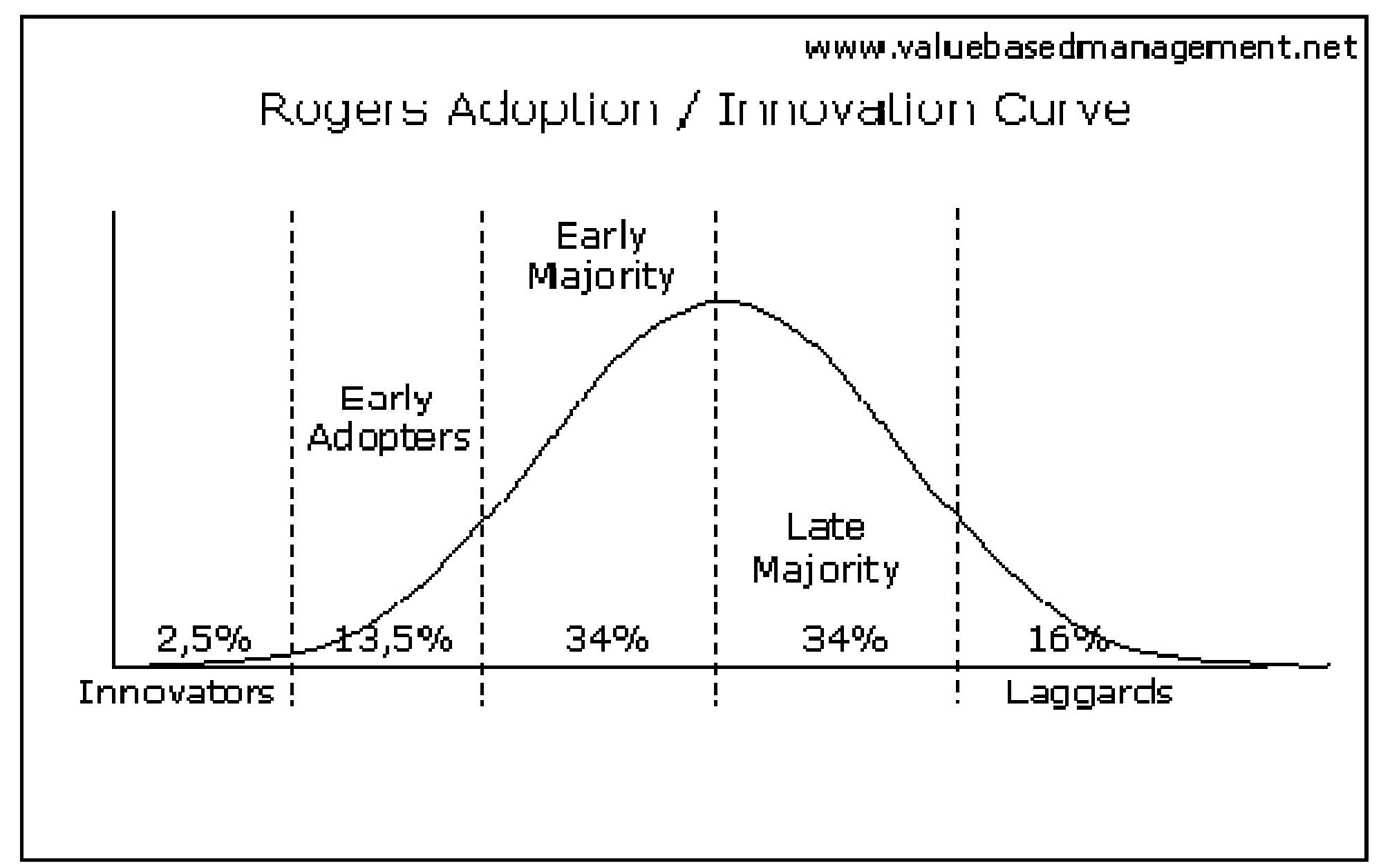


APPENDIX C

INFORMED CONSENT 


\title{
Doctoral Program in Educational Leadership Graduate School of Education \\ Department of Curriculum and Instruction (CI) \\ Portland, Oregon
}

\section{ASSESSMENT FOR IMPROVEMENT IN HIGHER EDUCATION: FACULTY PERCEPTION OF AND PARTICIPATION IN PROGRAM ASSESSMENT}

\author{
Dear Prospective Subject,
}

You are invited to participate in a research study conducted by Serap Emil, a doctoral student from Portland State University in the Curriculum and Instruction program, the Graduate School of Education. The researcher is conducting this study in partial fulfillment of the requirements for the doctoral degree in Educational Leadership. The study is being conducted under the supervision of Dr. Christine Cress, Associate Professor of Education. You were selected based on your willingness to participate in this study.

If you decide to participate, you will be asked to be interviewed once. In the interviews, you will be verbally responding to questions that I ask. The interview will take approximately 60 to 90 minutes. You may feel uncomfortable with some of the questions, but you are free to skip any questions or withdraw at any time.

The interview will be held at PSU. The interviews will be audio taped, but the audiotapes used to record the interviews will be kept in a locked safe place where they are only accessible to the researcher. These audiotapes will be destroyed after the study is completed. The result of the inventory will also be kept in a safe place, and will be destroyed after this study is completed.

Audiotapes of interviews will be fully transcribed by the researcher. You will have an opportunity to review the transcript and suggest any necessary revisions, changes, additions, or clarifications to the transcript in order to insure that the transcript accurately reflects your responses. All data and records will be kept on file for three years following completion of the research, as required by federal regulations, and then will be destroyed. Your participation in this study will inconvenience you by taking up a small amount of your time, but it does not involve any other potential risks or discomforts. You may not receive any direct benefit from taking part in this study, but the study may help to increase knowledge, which could benefit others in the future. I am available to answer any questions you may have about the study and what you would be expected to do. Any information that is obtained in connection with this study and that could be linked to you or your identity will be kept confidential. Your name and identity will be kept completely confidential. You will be identified in the dissertation report by a pseudonym only. The audiotaped recording of your voice will be erased following completion of the study. Information collected from you in audio taped form will not be reported to your 
supervisor or evaluator in any way. The list of names and contact information, which includes your name will be kept in a file in a locked file cabinet at the home of the researcher.

Your participation is voluntary. You do not have to take part in this study, and it will not affect your relationship with Portland State University or anyone else. You may also withdraw from the study at any time without affecting your course grade or relationship with your instructors at Portland State University.

If you have any concerns or questions about your participation in this study or your rights as a research subject, please contact the Human Subjects Research Review Committee, Office of Research and Sponsored Projects, Unitus Building, 6th Floor, Portland State University, (503)725-4288 or 1-877-480-4400. If you have any questions about the study itself, contact Serap Emil at (971) 222-9459 or semil@pdx.edu.

Your signature indicates that you have read and understand the above information and agree to take part in this study. Please understand that you may withdraw your consent at any time without penalty, and that, by signing, you are not waiving any legal claims or rights. The researcher will provide you with a copy of this consent form for your records. 
APPENDIX D

HRRSC APPROVAL 
Human Subjects Research Review Committee

December 10, 2010

To: Serap Emil

From: Mary Oschwald, HSRRC Chair

Re: Approval of your application titled, "Assessment for Improvement in Higher Education:

Faculty Perception \& Participation in Program Assessment" (HSRRC Proposal \# 101542).

Dear Serap,

In accordance with your request, the Human Subjects Research Review Committee has reviewed your proposal referenced above for compliance with DHHS policies and regulations covering the protection of human subjects. The committee is satisfied that your provisions for protecting the rights and welfare of all subjects participating in the research are adequate, and your project is approved. Please note the following requirements:

Changes to Protocol: Any changes in the proposed study, whether to procedures, survey instruments, consent forms or cover letters, must be outlined and submitted to the Chair of the HSRRC immediately. The proposed changes cannot be implemented before they have been reviewed and approved by the Committee.

Continuing Review: This approval will expire on December 10.2011 It is the investigator's responsibility to ensure that a Continuing Review Report (available in ORSP) of the status of the project is submitted to the HSRRC two months before the expiration date, and that approval of the study is kept current.

Adverse Reactions: If any adverse reactions occur as a result of this study, you are required to notify the Chair of the HSRRC immediately. If the problem is serious, approval may be withdrawn pending an investigation by the Committee.

Completion of Study: Please notify the Chair of the Human Subjects Research Review Committee (campus mail code ORSP) as soon as your research has been completed. Study records, including protocols and signed consent forms for each participant, must be kept by the investigator in a secure location for three years following completion of the study.

If you have questions or concerns, please contact the HSRRC in the Office of Research and Sponsored Projects (ORSP)

Cc: Christine Cress 